\section{LA HISTORIETA ESPAÑOLA DE 1900 A 1951}

\author{
Antonio Martín \\ Editor e historiador de la historieta
}

\begin{abstract}
The present piece of research starts after the birth of the Spanish comic by the second half of $19^{\text {th }}$ century as a new way of expression that appears linked to the satirical and humour press, created and thought especially for adult readers. From the reality of this new media the basis were set to approach the Spanish comic produced during the 1900 to 1950. During this particular period, we are facing its first development, the consolidation, and the conversion of the new comic into a mass phenomenon. At the same time, a further analyze of the industrial structure, capable to support the publishing process of the comic, is carried out too; this is put in the context of the whole Spanish society depending, not only on the economy, but also on the political and social movements that shook the country during these fifty years, causing an accelerated flow of events that became a reality during the political regimes that have built the structure of the Spanish country: Alphonse $13^{\text {th }}$ 's constitutional monarchy, Primo de Rivera's military dictatorship, parlamentary republic, civil war and finally the General Franco's personal dictatorship.
\end{abstract}

KEY WORDS: The Gato Negro; TBO; Pulgarcito; genre comics; Republican comics; cartoon stories in the press; evolution of the Spanish comics; Civil war comics; propaganda; comics in the lead years of the franquismo; censorship; political authorizations; cartoon stories' notebooks; Postwar Commercial Publishers; the invasion of the cartoon stories' notebooks; Popular Education Undersecretaryship; "desfalangización" (against Falangist Movement); women comics; Tourism and Information Ministry (Ministerio de Información y Turismo).

\section{LA HISTORIETA ESPAÑOLA, NOTAS DE SITUACIÓN A INICIOS DEL SIGLO XX}

En la última década del siglo XIX fueron artistas como Apeles Mestres, Mecáchis, Ramón Cilla, Ramón Fradera, Melitón González, Ángel Pons, Pedro de Rojas, Figuer, Ramón Escaler, Joaquín Xaudaró, Lago, Utrillo, Verdugo, Navarrete, etc., quienes sentaron las bases de la historieta en España. Con un ojo puesto en lo que se hacía en Francia y Alemania, caracterizaron personajes y tipos y desarrollaron la gestualidad, descubrieron y perfeccionaron la elipsis narrativa, la concatenación de las viñetas, hasta crear un sistema de signos convencionales propios, y establecer que la secuencia narrativa era fundamental hasta en la historieta más intrascendente. En resumen, dieron forma a la historieta española y la llevaron hasta los lectores adultos. Gracias a ellos el

\section{THE SPANISH CARTOON FROM 1900 TO 1951}

RESUMEN: El presente trabajo de investigación se inicia tras el nacimiento de la historieta española en la segunda mitad del XIX, nuevo medio de expresión que surge ligado a la prensa satírica y de humor, creada y realizada expresamente para un público lector adulto. Es ya desde la realidad del nuevo medio como se establecen las bases para el acercamiento a la historieta española durante los años 1900 a 1951, en los que tiene lugar su primer desarrollo, afianzamiento y conversión en un fenómeno de masas. Asimismo se analizan los inicios del tejido industrial que soporta la estructura editorial de la historieta, que se contextualiza respecto del conjunto de la sociedad española, en total dependencia no solo de la economía, sino también de los movimientos políticos y sociales que durante el medio siglo de estudio sacudieron España, en un flujo acelerado de acontecimientos que se concreta en los regímenes políticos que vertebraron el país: monarquía constitucional de Alfonso XIII, dictadura militar de Primo de Rivera, república parlamentaria, guerra civil y, finalmente, la dictadura personal del general Franco.

PALABRAS CLAVE: El Gato Negro; TBO; Pulgarcito; tebeos de género; los tebeos de la República; historietas en la prensa; evolución tebeos españoles; los tebeos de la guerra civil; propaganda; tebeos en los años de plomo del franquismo; censura; política autorizaciones; cuadernos de historietas; editores comerciales posguerra; invasión de los cuadernos de historietas; Subsecretaría de Educación Popular; "desfalangización"; tebeos femeninos; Ministerio de Información y Turismo.

nuevo medio logró ocupar un espacio propio, lateral en cierta medida, pero claramente distinguible del chiste y de la ilustración. Es cierto que muy pocos autores de las primeras generaciones de la historieta española lograron vivir de su trabajo. Dibujantes e ilustradores de toda condición trabajaron tanto en la prensa como en el libro, algunos cultivaron el humor gráfico y la mayoría tuvo otros trabajos, alejados de la profesión de dibujante, de los que vivir, pero muchos de ellos serían consecuentes y dibujarían historietas a lo largo de toda su vida.

Desde ahí, cada autor por separado y todos mirando la obra de todos, establecieron las estructuras básicas de la historieta $y$, al experimentar con la historieta sin palabras, llegaron a comprender la importancia que el guión tiene en la construcción del relato en viñetas. 
Las historietas se estructuraron como narraciones secuenciales en las que el dibujo hacía progresar una acción mediante la selección de momentos significativos, recurriendo a la elipsis para eludir los momentos que el lector había de cubrir mediante la lectura activa y participativa. Los dibujos venían reforzados por breves textos que se colocaban al pie de las viñetas. Estos textos no debían ser descriptivos ni explicativos, su función era expresar verbalmente lo que los personajes pensaban y hablaban, siendo los diálogos la fórmula más habitual. Al producirse la estrecha relación entre la imagen y el texto ambos lenguajes se integraban perfectamente en un único discurso narrativo.

Ahora bien, esta fórmula convencional con la que se representaba en un mismo plano la acción y la palabra funcionaba cuando el dibujante era un buen narrador o contaba con un buen guión. Pero en muchas historietas fallaban en los textos, que eran descriptivos, con lo que se producía una repetición escrita de los que los dibujos ya mostraban. Y ello se agravaba en la historieta dirigida expresamente a los niños, no ya solo en la española sino en toda la europea, que soportó desde su inicio un exceso de textos que acababan disociando la imagen de la palabra.

Los dibujantes norteamericanos dieron el paso definitivo para la integración de los textos en el interior de la viñeta mediante la convención del bocadillo o balloon. Se trata de un recurso propuesto por los realizadores y aceptado por los lectores, según el cual los textos de los diálogos se encierran en un espacio con forma de globo o nubecilla que apunta a la boca del personaje que habla. La solución era de una total eficacia y progresivamente se fue incorporando a la historieta europea, si bien el proceso de aceptación fue largo, especialmente en la prensa infantil de inicios del siglo XX.

Así entramos en los primeros años del siglo XX, momento en que el medio se disgregó en función de los lectores. La historieta para adultos continuó su camino ascendente, aunque sin apenas eco en el conjunto de la edición española. Mientras que las revistas infantiles, que hasta entonces habían rechazado las historietas, se convirtieron en el soporte preferente de las mismas.

Entre las revistas españolas que publicaron los primeros cómics americanos hay que destacar especialmente la revista Monos que comenzó a publicarse en Madrid en 1904, con la pretensión declarada de ser el semanario "que más millares de ejemplares vende y el ilustrado por los más ingeniosos caricaturistas del mundo", y la revista Los Sucesos, que también se editó en Madrid desde 1904 y que, de acuerdo con su título, pretendía ser un semanario sensacionalista que alternaba en sus páginas el último crimen sangriento con el descarrilamiento de un tren 0 un brote bélico en los Balcanes, dedicando semanalmente un espacio fijo a publicar una o más series de cómics, según las circunstancias y las épocas.

La revista Monos en su primera etapa era y parecía enteramente una revista de cómics, tantos fue los que publicó en sus primeros cincuenta números. Entre ellos, la serie Foxy Grandpa, de Charles Edward "Bunny" Schultze, que la revista rebautizó como Las travesuras de Bebé y atribuyó a un tal Márquez con el subtítulo Primera novela gráfica que se publica en España. También publicó la serie The Upside Downs of Little Lady Lovekins and Old Man Muffaroo, de Gustav Verbeek, con el título español de Aventuras de Mufaro y Lorekins.

Junto a los cómics norteamericanos, la revista publicó numerosas historietas de Méndez Álvarez, autor español que en los siguientes treinta años fue casi omnipresente en una mayoría de revistas españolas con sus historietas y chistes, Arveras, Ramírez, Robert y Karikato, cuya historieta "Un viaje al infierno" llevaba gigantescos bloques de texto al pie de las viñetas que desvirtuaban por completo la obra.

La revista Los Sucesos publicó semanalmente, durante sus casi siete años de vida, una página de la serie Buster Brown, de Outcault, rebautizada como Juanito y su perro, a la que se añadieron más tarde y con menor regularidad las series The Katzenjammer Kids, de Dirks y And Her name was Maud!, de Frederick Burr Opper. La buena acogida que la serie de Outcault tuvo en la revista puede valorarse por el hecho de que en 1916 se continuó publicando calcada 0 dibujada por un autor español, quizá por carecer de los materiales originales. El que Buster Brown se publicase siempre con los diálogos encerrados en bocadillos hubo de influir en los dibujantes españoles, por ejemplo en los experimentos que entre 1903 y 1909 realizó Atiza para integrar el bocadillo en sus historietas. También Robledano resolvió totalmente con bocadillos su serie de "continuará" El suero maravilloso, publicada en 1910-1911 en la revista Infancia.

La importancia que la empresa editora de Los Sucesos concedió a la serie se reflejó en que publicó aparte varios cuadernitos de historietas de Buster/Juanito, en formato cuadrado, impresos 
a todo color. Tenían la peculiaridad de que, para dar en cada cuaderno una única historieta del personaje la desmontaban viñeta a viñeta y se imprimía en una larga tira de papel plegada en acordeón, con una viñeta en cada una de las páginas resultantes del plegado, y con los diálogos resueltos en bocadillos. Esta publicación, que podemos considerar el primer tebeo español, se vendía al precio de 10 céntimos y se publicaron al menos once números.

El mejor ejemplo de la influencia de estos primeros cómics norteamericanos sobre los autores españoles lo encontramos en la que hasta ahora es la primera historieta española localizada totalmente "hablada". Se trata de la serie titulada "Tolin y Picks", que protagonizaban dos personajes fijos, un niño y su perro, y se publicó semanalmente en historietas autoconclusivas de una página, con los bocadillos de diálogo perfectamente integrados dentro de las viñetas. La serie arrancó en fecha tan temprana como enero de 1906 -apenas un año y medio después que Los Sucesos lanzara Buster Brown- en la revista El Omnibus Suplemento Ilustrado, a partir de su no 69, y durante el año 1906. El autor firmaba con el acróstico QM el, que muy probablemente correspondía al dibujante Robert, quien años más tarde publicó una serie similar, también con bocadillos y también protagonizada por un niño y su perro, que en este caso se llamaban "Tito y Tiquet", en el tebeo Totó de El Gato Negro.

Para cerrar este apartado, hay que destacar la publicación a partir de 1907 de la serie Little Nemo in Slumberland, de Winsor M cCay, en varias revistas españolas, especialmente en La Semana llustrada que se publicaba en Madrid. Así y con el título castellanizado de Los Sueños de Manolín la serie se publicó durante varios años en la última página de la revista, unas veces a todo color -la revista recalcaba: "Impreso en máquina rotativa especial para colores", consciente de la novedad que estaba ofreciendo- y otras a dos tintas. Siempre con la mención explícita de: "Originales propiedad del New York Herald"1.

\section{DEL SEMANARIO FESTIVO A LA REVISTA INFANTIL DE CÓMICS, 1915-1921}

La progresiva, aunque lenta, implantación de la historieta que se inició a partir de 1915 se debió a su conversión en negocio. En aquellos momentos el país vivía un cambio sociológico que se acentuó cuando España se declaró neutral en la guerra de 1914-1918, lo que permitió al mundo de los negocios beneficiarse con la venta de materias primas y suministros a los dos bandos. Ello favoreció el auge de la imprenta y de la prensa, tanto por la mayor circulación de dinero como por la guerra de propaganda que ambos bandos combatientes libraban y que tuvo uno de sus principales escenarios en España. Teniendo todo ello en cuenta, no parece coincidencia el que en este periodo se produzca el nacimiento de los primeros tebeos, todavía sin este nombre, como soportes editoriales a través de los que se comercializaría mayoritariamente la historieta durante varias décadas.

En estas circunstancias fueron muchos los pequeños editores que buscaron una oportunidad de hacer negocio, los impresores que tenían libre parte del tiempo de trabajo de sus máquinas, los especuladores a la caza de oportunidades y los simples aventureros que decidieron probar suerte. Sin ideas claras, sin experiencia, sin proyectos definidos, con escasos recursos económicos y muy escasas posibilidades de financiación, los nuevos editores buscaron, a través de un proceso de tanteo, repetición y acumulación, un nuevo modelo de prensa entre la revista de humor y la revista infantil, utilizando como gancho comercial la historieta.

La prensa de humor estaba formada a principios de siglo por una serie de revistas gráficas dirigidas a un público general, con textos breves, caricaturas de los personajes y figuras de actualidad, chistes más o menos cotidianos y algunas historietas costumbristas, a veces cercanas al sainete, con interesantes logros en el retrato de la vida cotidiana y unas escasas pinceladas exóticas. Por su parte, la prensa infantil del XIX había permanecido de espaldas a la historieta, por su propia condición de publicaciones instructivas.

En estas circunstancias fue fundamental la concentración industrial producida en Barcelona, sus muchas imprentas y la existencia de un amplio mercado potencial de lectores. Hay que sumar el avance de la imagen, el lento pero constante aumento de los niveles de alfabetización, el crecimiento de las ciudades y las nuevas propuestas que comenzaban a plantearse a favor de la lectura voluntaria y recreativa. Todo ello, sumado a las nuevas tecnologías aplicadas a la imprenta, que hacían posible una prensa más barata, llevó a la aparición, después de diversos intentos fallidos, de un nuevo tipo de publicaciones ilustradas en el que la historieta se desarrolló de forma muy primaria, con planteamientos expresivos lineales, guiones pobres y excesivamente inmediatos². 
Los beneficiarios inmediatos de este proceso fueron los nuevos pequeños editores de las dos primeras décadas del siglo, que hoy conocemos: Navarrete, Baguñá, Buigas, Heras, Ediciones Populares, Bauzá, El Gato Negro, Barbany, Vincit, Granada, Editorial Aurora, Magín Piñol, Marco, más los muchos que por la falta de documentación han quedado en el olvido.

Dichos editores se lanzaron a la edición de publicaciones populares baratas, a veces de calidad muy baja, impresas en mal papel y con contenidos mediocres, dirigidas a la población urbana más popular. Entre la abundante producción hay que destacar varias especies de impresos. Las novelas por entregas que, desde la herencia del folletín decimonónico, se convirtieron en aventuras publicadas en cuadernillos de pocas páginas, cubierta colorida, dirigidas poco a poco desde los adultos al público juvenil e infantil. También los recortables. Los juguetes y juegos de papel y cartulina. Los cuentos infantiles de todo modelo y condición, siempre muy baratos. Muy importantes fueron también las ediciones que podríamos llamar de carácter "divulgativo", por llegar más allá del público infantil hasta los adultos escasamente alfabetizados.

Muy pronto estos editores extendieron su negocio a la publicación de un nuevo tipo de prensa infantil con historietas, que simultanearon con sus restantes ediciones en un totum revolutum. Así, la historieta penetraría en la sociedad española hasta ocupar un espacio propio.

La creación del modelo editorial del tebeo y sobre todo su estandarización como soporte preferente de la historieta española fue fruto de un proceso de muchos años, con varios momentos en los que los tebeos avanzaron a impulsos crecientes hacia el establecimiento de una cultura de masas basada en la historieta. Los primeros títulos no aparecieron claramente definidos como revistas de historietas. Eran revistas con historietas, pero aún se publicaron como extensiones derivadas de las revistas de humor fin de siglo.

Con la aparición de Dominguín, publicada en Barcelona en 1915 con el subtítulo Semanario cómico, con cuatro páginas de historietas a tamaño gigante en la línea de los suplementos dominicales en color de la prensa americana, podemos hablar con certeza de la primera revista española considerable como tebeo, por más que el subtítulo sea similar al de otras revistas de humor adultas y no parezca dirigirse a los niños (imagen 1 ).
Dos meses después apareció Charlot, editado por Navarrete, 1916, con el subtítulo de Semanario festivo, y en cuyas páginas el principal protagonista era el personaje procedente del cine cómico estadounidense, sin que tampoco el editor pensara en los niños como público preferente. En 1917 apareció el semanario cómico Max Linder, con historietas protagonizadas por el popular actor del cine francés. En marzo de 1917 apareció Charlotín, como prolongación de Charlot, con el subtítulo Semanario festivo peliculero infantil.

Y, por fin, en marzo de 1917, apareció el primer número de TBO (imagen 2), cuyo editor, el impresor Arturo Suárez, lo subtituló Semanario festivo infantil, dando así el paso definitivo desde la revista de humor a la revista para niños con historietas. En un plazo de dos años y siempre en Barcelona se configuró formalmente la existencia de revistas de contenidos variados con historietas y dirigidas a los niños, todo ello con el precio mínimo posible en aquellos momentos, 5 céntimos de peseta. Título a título surgía el modelo editorial de los tebeos.

Es así como, de la deriva cultural de las revistas de humor y de la introducción de la historieta en la prensa infantil, se llegó al nuevo modelo de los tebeos. Un modelo de prensa que, si inicialmente era indefinido -y al que llamamos tebeo por comodidad semántica y como generalización del título TBO-, con el paso de los años, durante la década de 1920 y a inicios de los treinta, acabó por instalarse de pleno derecho en el mercado de la prensa española con una presencia importante.

Por la suma de los títulos publicados y el análisis de sus características más comunes, podemos resumir que el modelo más habitual de los primeros tebeos de los años veinte tenía formato vertical, con ocho páginas de $35 \times 25 \mathrm{~cm}$, que se obtenían al plegar en cruz un pliego de papel, tamaño 70 × $50 \mathrm{~cm}$. Para imprimir se utilizaban máquinas planas de pequeño formato, que a veces permitían imprimir los tebeos de dos en dos.

Una cara del pliego solía estar impresa en negro y la otra a dos tintas, si bien progresivamente se pasó a imprimir la portada a tres tintas para obtener el todo color. La impresión se realizaba en tipografía, por lo que las historietas, chistes, ilustraciones, etc. se reproducían mediante fotograbados. Generalmente estos tebeos no se guillotinaban ni grapaban. 


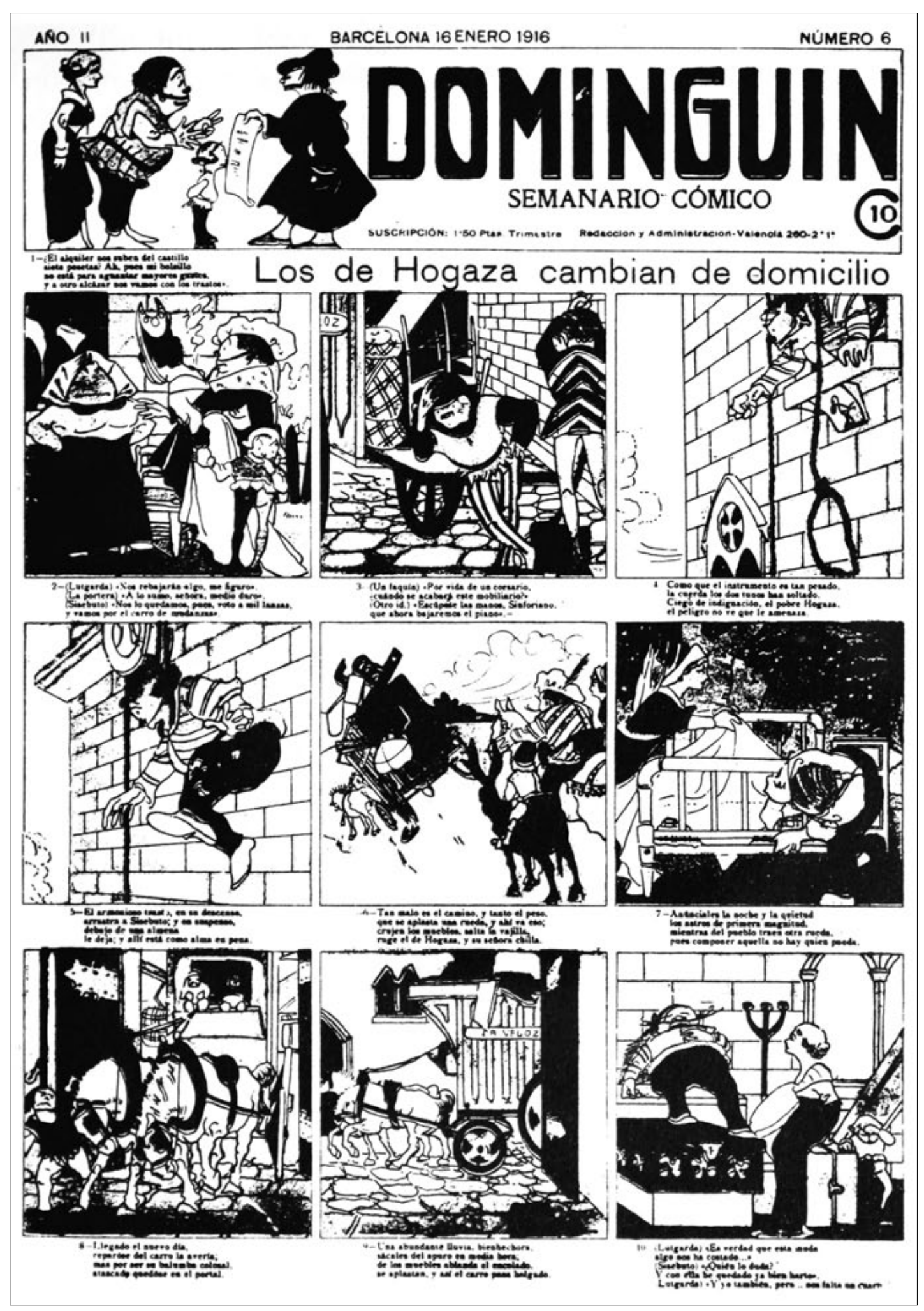


Fue relativamente frecuente el que algunos editores, como El Gato Negro, dando un pliegue más al papel, presentasen tebeos a la mitad de tamaño y con doble número de páginas. A la inversa fue más raro, pero también algunos editores publicaron tebeos que superaban las medidas estándar.

En portada del tebeo aparecía impreso el logotipo del título y generalmente también la dirección postal de la redacción y la administración editoriales, así como el año de publicación y el número de orden correlativo; más raramente se publicaba el pie editorial y la fecha de edición. Este modelo de publicación fue el más común durante la mayor parte de los años veinte, aunque debe tomarse como un esquema tipo, sobre el que los editores realizaban todas las variables que pudieran financiar, en tamaño, número de hojas, color, etc.

Fue así, a través de un público lector infantil, popular e indiscriminado, como el medio se implantó definitivamente. Si bien ello ofreció la contrapartida de que durante décadas la mayor parte de la historieta española fuese excesivamente infantil y adoleciera de una temática trivial, que inicialmente cargó sobre los lectores y que a la larga limitaría a los propios autores.

En paralelo se desarrolló durante este periodo una historieta adulta, publicada en la prensa adulta, en la que los autores innovadores experimentaron con los límites expresivos del medio llevándolos siempre más allá, en la búsqueda de un lenguaje que integrase con mayor eficacia la palabra escrita y la imagen dibujada en un único lenguaje más y más perfecto ${ }^{3}$.

\section{CONTENIDOS Y MODELOS DE LOS PRIMEROS TEBEOS POPULARES}

Los primeros tebeos circulaban en una economía de mercado, que lógicamente había de llevar a la competencia entre títulos. La imitación, la copia y el plagio fueron muy frecuentes en estas décadas. Ello vino propiciado por la pequeñez del mercado editorial, la relativa escasez de dibujantes, la casi inexistencia de guionistas y la falta de mercados estatales.

En los tebeos de estos años las temáticas más importantes fueron las derivadas de la vieja novela folletinesca, que se "modernizó" siguiendo el modelo de las novelas de aventuras exóticas para niños que los editores del momento publicaban por entregas. En paralelo, las primeras historietas publicadas en aquellos tebeos partían de guiones basados en los temas y personajes más frecuentes de las novelitas de aventuras seriadas, 0 bien se estructuraban sobre guiones procedentes del folclore popular y tomaban por personajes a gigantes, hadas, gnomos, brujas, reyes y príncipes, caballeros valerosos, etc. Estas historietas, con pretensiones de dibujo "realista", eran muy primitivas y a veces ni siquiera llegaban a ser historietas sino series de ilustraciones con grandes textos descriptivos situados al pie de las viñetas.

A las primitivas historietas "realistas" les daban el contrapunto las historietas cómicas, que muchas veces no eran sino simples gags estirados hasta dar la medida-unidad de una página. Este tipo de historieta partía del humor popular más chocarrero y se basaba generalmente en personajes comunes, extraídos de la vida diaria y convertidos en arquetipos. Hacia mediados de los años veinte se incorporaron diversos animales antropomórficos, siguiendo la influencia del cómic inglés de Amalgamated Press. Y también una caterva de seres fantásticos como extensión del folclore más extremo, en su mayoría creados por dibujantes españoles.

Añadamos a ello que varios dibujantes y editores -no importa de quien fuera la idea, ya que la decisión última fue claramente editorial-, tomaron como personajes a los protagonistas del cine de humor, primero francés y después norteamericano. Se trataba de un movimiento inicialmente espontáneo, derivado del éxito que dicho cine había alcanzado en los primeros barracones y salas en las que se proyectó. Polidor, Salustiano, Max Linder y otros personajes del cine francés, pasaron así a las historietas. Casi inmediatamente lo hicieron Charlot, Buster Keaton, Harold Lloyd, Fatty..., que habían sido popularizados por el cine norteamericano, del que pasaron a los cómics de las revistas infantiles británicas y desde ellas fueron publicados, copiados, plagiados 0 calcados en muchos tebeos españoles ${ }^{4}$.

Y es que este periodo de la historieta española se encuentra atravesado por una corriente de cómics ligados al cine. Baste con recordar algunos títulos de tebeos, como Charlot, 1916; Max Linder, 1917; Suplemento del semanario Charlot, 1917; Charlotin, 1917; Aventuras Cómicas de los Reyes de la Risa, Fatti, Charlot y otros, Madrid (s.a.); Fatty, 1919; El y Ella, 1921; Aleluyas de Charlot, 1921; Chiribito, 1922; Aventuras de Charlot, el rey de la risa, 1923; Mary Osborne y su negrito, 
1923; Chiquilín, 1924; y ya doblada la mitad de la década: Chiquitin, Periquito, Rin Tin Tin, Charlot el rey de la risa, Tom Mix, La Pandilla, Nuevo Tom Mix, Alegría Infantil-Shirley Temple, etc. Después, las películas por episodios enlazaron con la tradición editorial española del folletín y así se generaron sinergias en el sector editorial, tanto con nuevas y abundantes colecciones de novelistas por entregas para niños como en la temática de nuevas series de historietas, cultivadas por todas las editoriales de tebeos que tomaron temas y arquetipos tanto de la novela por entregas como del cine de aventuras, especialmente de los seriales norteamericanos. Sin que debamos descuidar la influencia que el cine por episodios pudo tener en la tradición del "continuará" narrativo en la historieta.

Alternativamente al modelo editorial del tebeo con contenidos y temas variados, los editores españoles crearon una variante de tebeos que solo publicaban historietas, sin más añadidos ni otros materiales. Se trataba de un nuevo formato con las características de un cuaderno o cuadernillo formado inicialmente por un pliego de 12016 páginas incluyendo las cubiertas, que solían imprimirse en el mismo papel del pliego, cada número era auto conclusivo y contenía una única historieta. Los temas se basaron inicialmente en el folclore tradicional, en personajes tópicos de la novela por entregas, en acontecimientos históricos, en personajes tomados de los sucesos contemporáneos y más tarde en la temática de aventuras.

Las primeras colecciones basadas en este nuevo modelo editorial fueron publicadas por Editorial Heras con la colección Cuentos y Aventuras de Periquín, 1918, cuadernos de historietas en formato vertical, con 16 páginas impresas en color y al precio de 10 céntimos. En 1919, Joaquín Buigas, nuevo propietario de TBO, comenzó a editar la colección gráfica $T B O$, cuadernos de historietas en formato grande apaisado, con 16 páginas impresas en bicolor más cubierta a todo color y al precio de treinta céntimos, con espléndidas cubiertas ilustradas por Opisso aunque las páginas interiores fuesen obra de diversos dibujantes.

A estos dos títulos, que marcaban un nuevo camino para el tebeo español, se sumaron las colecciones La Novela en láminas de Periquín, 1920. Historias y Cuentos TBO, 1920; Aleluyas de Pulgarcito, 1921; El Cuento Infantil Semanal, 1923; El Cuento en imágenes, 1923; La Novela Gráfica Infantil, 1924, estas cuatro últimas publicadas por El Gato Negro; Mary Osborne y su negrito, publicada en formato de cuaderno apaisado pequeño en 1923 por Navarrete; La Novela Gráfica Infantil publicada en 1924 por El Gato Negro; Cuentos de Pierrot, 1927, etc.

Estas colecciones se encontraban formadas por series de cuadernos de historietas, en cada uno de los cuales se desarrollaba una única historia larga, generalmente de aventuras y con dibujo realista, bien que las historietas continuaron siendo primitivas con extensos textos descriptivos al pie de las viñetas. Este conjunto de publicaciones marcó la contraposición a los tebeos de contenido variado y así, desde los años veinte, comenzaron a prefigurarse sucesivos formatos y modelos alternativos de nuevas publicaciones de historietas de distinta extensión.

No obstante y pese a la novedad que estos tebeos presentaban, con su contenido único de historieta, dejaron de publicarse sin que en base a la documentación existente podamos encontrar una explicación suficiente y válida, más allá de refugiarnos cómodamente en las leyes del mercado, según las cuales parece que se impuso el modelo del tebeo de contenidos variados.

\section{LA PRENSA DE MADRID Y LA HISTORIETA}

En los mismos años, en Madrid se publicaron las revistas infantiles El pequeño Séneca y Los Muchachos, ambas en 1915; ABC Infantil y Pulgarcito, ambas en 1916; La moda infantil, 1917; Recreo escolar, 1920, todas las cuales estaban muy lejos de ser tebeos. Hasta 1924 y 1925, en plena dictadura del general Primo de Rivera, no aparecieron en Madrid los primeros verdaderos tebeos, en los que la historieta jugaba un papel importante. Fueron títulos como Caperucita, 1924, realizado por dibujantes españoles; Pinocho, Chiribitas, los dos publicados por la editorial Calleja en 1925, y en los que junto a escritores y dibujantes españoles de primera línea tuvieron especial importancia los cómics de prensa norteamericanos 5 .

Pinocho, para los niños (imagen 3), y Chiribitas, para adultos, publicaron, junto a las historietas de los dibujantes K-Hito, Salvador Bartolozzi, Francisco López Rubio, Echea, o 

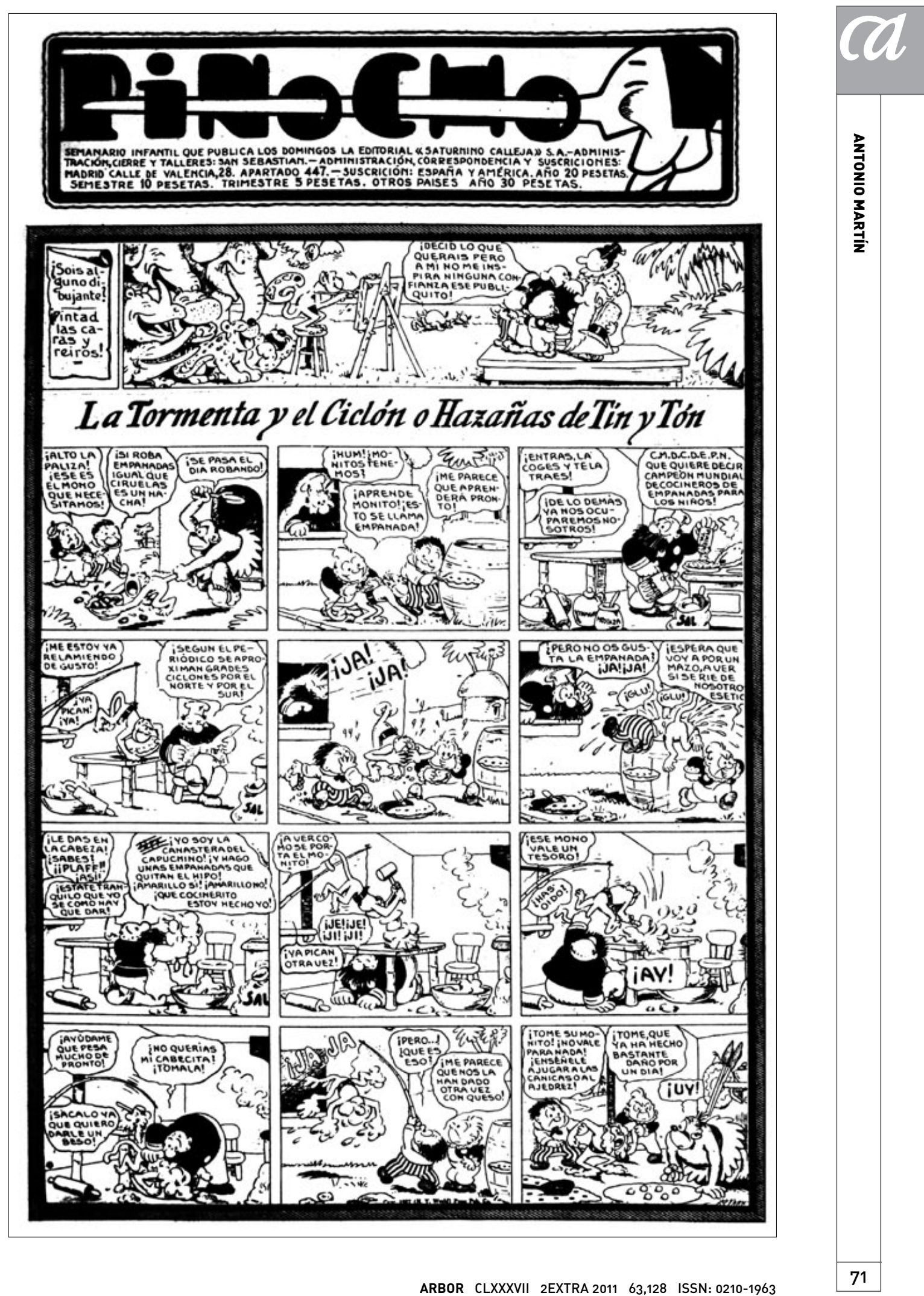
Barradas, las series de cómics americanos The Gumps, Winnie Winkle, Felix the cat, Orphan Annie, The katzenjammmer kids, Polly and her Pals, Bringing up father, Tillie the toiler, Barney Google and Spark Plug, Moon Mullins, Toots and Casper, etc. Se trataba de cómics de humor producidos por King Features Syndicate y por Chicago Tribune-New York News Syndicate, que llegaban a España en la que podríamos llamar enfáticamente la "segunda oleada" del cómic USA.

La valoración más importante de la historieta editada en M adrid durante este periodo hay que hacerla a través de las revistas de humor de adultos que se publicaron en los años de la dictadura del general Primo de Rivera, 1923-1930. De entre la mucha prensa de humor que apareció en Madrid durante la década de 1920, hay que destacar tres títulos de especial importancia. Son las revistas Buen Humor (imagen 4) que aparece en 1921, Muchas Gracias, 1924, y Gutiérrez, 1927 (imagen 5), en las que se reunieron los escritores y dibujantes más modernos, que mejor conectaban con los vientos de cambio artístico quea soplan desde Europa. En torno a estas revistas, y por extensión desde ellas a muchos otros títulos, se agruparon los nuevos dibujantes españoles

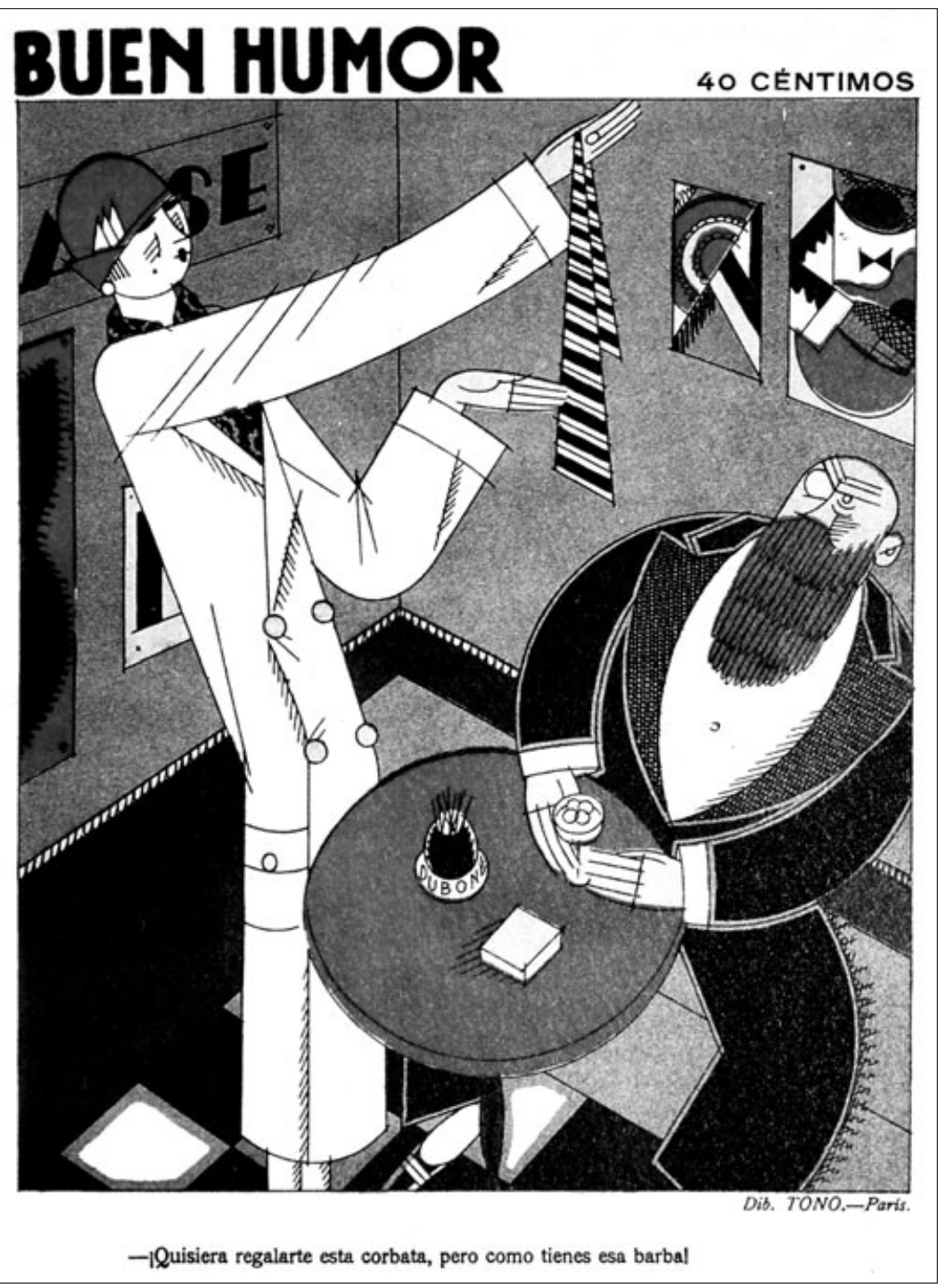

Imagen 4 
de la ilustración, la pintura, el humor gráfico, el cartel, el diseño de libros...

En el núcleo formado por estas tres revistas encontramos a Bosch, Bagaría, Federico Ribas, Joaquín Xaudaró, Garrido, Sirio, Menda, Salvador Bartolozzi, Francisco Lopez Rubio, Echea, K-Hito, Robledano, Penagos, Pérez Muñoz, Márquez, Bellón, Linage, Demetrio, Díaz-Antón, Serny Miguel Mihura, Tono, Bluff, Moreno, De Diego, Alfaraz, Jubera, Galindo, Roberto, etc., etc., autores de una versatilidad artística que los hacía capaces de dibujarlo todo y de trabajar para distintos medios según diversas técnicas. $Y$ si bien todos ellos fueron importantes y dejaron una fuerte impronta en el dibujo y el arte, para la historia del cómic español hay que destacar los nombres de las figuras decisivas, aquellos dibujantes con una obra mayor en la prensa de adultos y cuyos planteamientos estéticos y la renovación del grafismo y del concepto del humor que llevaron a cabo supuso, al mismo tiempo, una ruptura radical con la historieta española de épocas anteriores. Estos dibujantes son K-Hito (Ricardo García) y Miguel Mihura, principalmente, y junto a ellos Tono (Antonio Lara), Francisco López Rubio y Bluff (Carlos Gómez Carrera).

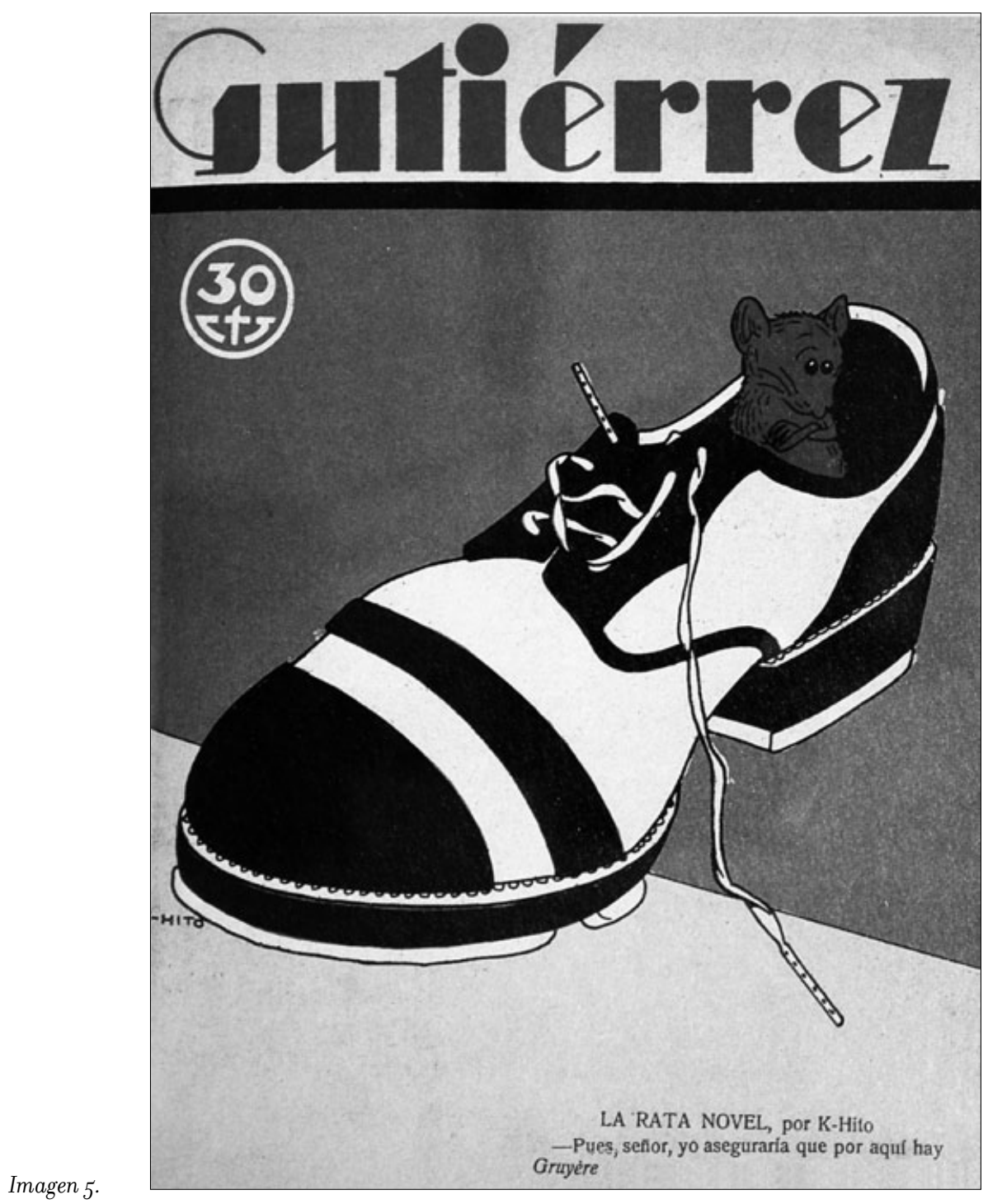


Hay que señalar a K-Hito como el gran creador, que marca un tiempo y un espacio con su innovador tratamiento de la composición y de la figura y sobre todo con su desarrollo de la gramática narrativa de la historieta. Entre sus obras mayores en la historieta es obligatorio señalar sus series de personaje fijo "De cómo pasan el rato Currinche y Don Turulato", en el tebeo Pinocho, "Dorotea o la suerte de la fea", en la revista Por esos mundos, "Gutiérrez", en la revista del mismo nombre, "M acaco y Macaquete" en el tebeo Macaco, "Desventuras del Rata primero", en la revista Nuevo Mundo, "Desventuras de Paco el Feo", en el diario El Debate, etc., con el interés añadido de que K-Hito utiliza ya el bocadillo de forma consciente y con excelentes resultados expresivos en historietas de una rara modernidad. Lo que le convierte no solo en maestro del humor gráfico sino también en un adelantado de la historieta española, con obras de una rara perfección escasamente lograda en el resto de Europa en los mismos años.

El éxito de K-Hito repercutió sobre los dibujantes contemporáneos, que llevaron más lejos su estilo haciendo posible no solo el cambio estético sino también la evolución del lenguaje narrativo de la historieta española. Ello se reflejó especialmente en la obra de Miguel Mihura, que prolongó y desarrolló los logros alcanzados por K- Hito, de manera que allí donde las historietas de este eran absolutamente lógicas y coherentes, dentro de la deformación propia del tratamiento humorístico, Mihura fue aún más lejos: simplificó el dibujo, esquematizó la figura humana y llevó el humor al absurdo, en una serie de historietas antológicas, que carecen de personaje fijo y ganan en variedad por eso mismo. Por su parte, Francisco López Rubio aprovechó los avances expresivos de K-Hito y Mihura. Bluff, Tono, Alfaraz, y algunos otros desarrollaron las enseñanzas de K-Hito y confirmaron el giro expresivo del humor gráfico y de la historieta para adultos de los años veinte, prefigurando así los grandes cambios de la década siguiente.

El seguimiento de este hilo conductor muestra cómo la historieta adulta española realizada hasta la guerra civil ofreció las obras más importantes. Mientras que las historietas publicadas en los tebeos y en la prensa infantil acumularon un enorme retraso expresivo, por su rechazo del bocadillo, y estético en general, salvo historietas concretas publicadas en tebeos de Madrid.

\section{LA PRENSA INFANTIL IDEOLÓGICA DE LOS AÑOS VEINTE}

No fue casual que la historieta publicada en los tebeos y en las revistas dirigidas a un público infantil entre 1915 y 1930 fuese primitiva y en muchas ocasiones ni siquiera mereciera el nombre de historieta por el exceso de texto y a la subordinación de las viñetas a funciones ilustrativas. No hay que atribuirlo a la incapacidad de los editores. Fue algo buscado.

Solo cabe aventurar las razones que llevaron a esta realidad. De un lado, sin duda, la de que el tebeo "durase" más por ser mayor el tiempo de lectura que exigían los textos. Cabe también pensar en el prestigio achacado al texto escrito en una sociedad que aún no había salido del analfabetismo. Tampoco puede descartarse la posible presión sobre los editores de los educadores, y al fondo la Iglesia, que no veían con buenos ojos la existencia de una prensa puramente recreativa dirigida a los niños y aún menos basada en la imagen. De ello quedan abundantes referencias en las acciones de los grupos católicos, que en estos años entraron en la vida pública española y muy especialmente en el campo de la prensa, impulsados por los papas León XIII y Pío X6.

El siguiente paso fue iniciar la edición de revistas para niños desde el ámbito eclesiástico para oponerlas a los tebeos comerciales. Estas revistas estaban inspiradas en la doctrina emanada de los papas y en la política más conservadora de la dictadura. Sobre los antecedentes de El Amigo de la Juventud, 1912, editado por los Hermanos Maristas, primero en Burgos y a partir de 1913 en Barcelona, o Los Niños, 1914, editada por Ángel Bueno en Madrid, apareció en 1924 la revista Titirimundi, creada en Madrid por el claretiano J osé Dueso y sus Legionarios de la Buena Prensa. Siguieron la revista catalana Alegría, 1925; Macaco y Gente Menuda en su nueva etapa como suplemento de la revista Blanco y Negro, 1928. Y en 1929 comenzó a editarse en Madrid el tebeo Jeromín, obra del sacerdote Federico Gonzalez Plaza.

De estos títulos, el más importante fue Alegría, por su perfecta sincronía con los planteamientos ideológicos de la dictadura de Primo de Rivera y porque al editarse en Cataluña se pretendía que fuese una alternativa española a $E n$ Patufet (imagen 6). La revista fue obra de la maestra Magdalena Rosell Matlléu, quien se movía en la órbita monárquica y anticatalanista. En 1924, Rosell asistió a una reunión convocada por el delegado gubernativo de Terrassa, 

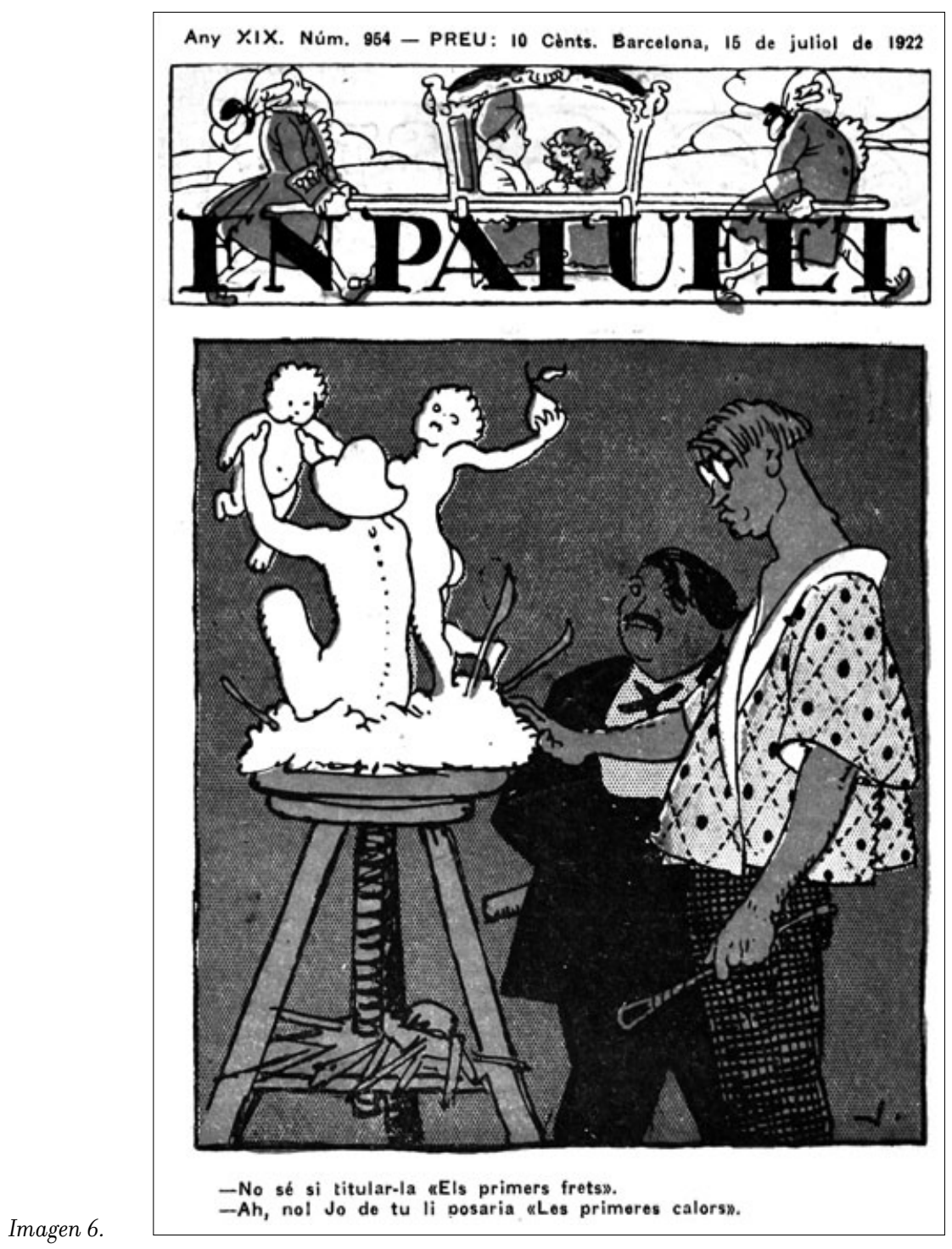

teniente coronel Jorge Villamide. En esta reunión, Rosell planteó la utilidad de crear un "periódico infantil, ameno, que interesase al niño de todas las edades, labor que debía desarrollar el Estado [...] [para hablar al niño] en tono elevado, incluso en los temas infantiles, y esta misión por lo difícil, solo debe confiarse a personas aptas [...]"7.

La revista atravesó varias etapas, tuvo diferentes formatos y distintos colaboradores y más tarde trasladó su redacción a Barcelona. A nuestros efectos, su etapa más importante es la inicial por ajustarse más estrechamente a los principios patrióticos invocados por el general Primo de Rivera, y por ofrecer, junto con unos contenidos religiosos, espacios recreativos y de historietas, haciendo bueno el lema de la dictadura: "Patria, Religión y Monarquía".

Alegría desarrolló su misión de apostolado hasta el año 1933, último del que hemos podido manejar ejemplares, con la revista editada en Tortosa bajo la égida de la Editorial Católica. Su ejemplo marcaría el camino a seguir en la ideologización de los niños durante la guerra civil, por la alianza entre la cruz y la espada. Entre sus colaboradores estaban los dibujantes Urda, Farell, Rapsomanikis, Boix, Martínez Surroca, y el pintor uruguayo Rafael Barradas, que 
realizó ilustraciones, cubiertas e historietas. También incluyó en sus páginas cómics ingleses de humor. Entre los colaboradores literarios contó con José María Huertas Ventosa, años más tarde director de los tebeos Pocholo y Mickey, Luis G. Manegat y el canónigo José M ontagut Roca.

No hay que olvidar que una de las medidas de la dictadura de Primo de Rivera fue la instauración de la censura. Pero no la censura ocasional, que siempre había existido durante la Restauración por medio de las leyes de Policía de Imprenta, ya fuera a manos de los gobiernos conservadores o liberales, sino una censura institucional, permanente, con un cuerpo de funcionarios, con una estructura capilar que llegaba hasta el último punto de España y sometía a control cualquier impreso, incluso las letras de las canciones o los argumentos y diálogos teatrales. Una censura que, como tantas otras instituciones de la dictadura, funcionó bajo el mando militar.

\section{JOAQuíN BUIGAS, EDITOR DE HISTORIETAS EN LOS AÑOS VEINTE}

La actividad de los editores de tebeos comerciales se centró en la producción de impresos de carácter popular y barato sobre los que estructuraban una economía basada en la acumulación de muchos pequeños beneficios. Dada la escasa financiación de estos editores, estas medidas eran obligadas para poder permanecer en el mercado. Al estudiar el funcionamiento de la Casa Editorial TBO, nombre que dio a su empresa Joaquín Buigas, falla la documentación, parcial y escasamente respaldada por datos verificados. Por todo ello, el análisis se ha de basar en el estudio directo de los ejemplares editados. A partir de ellos podemos hacer el seguimiento de los diferentes domicilios sociales del TBO. Sabemos que J oaquín Buigas no tuvo taller de imprenta propio y que trabajó con diferentes impresores, siendo el principal José Baguñá -que editaba En Patufet y publicaciones derivadas-. El cuerpo de redacción de los primeros años lo formaban el periodista Joaquín Arqués, con cierta experiencia editorial y que había asesorado a Arturo Suárez en la inicial creación de $T B O$, el italiano Tomassetti y el propio Buigas como inspirador de la revista y principal guionista de la misma. Y según se menciona en el propio tebeo, el director artístico fue durante varios años el dibujante Opisso, creador del logotipo clásico que TBO llevó en portada a partir del no 10.

Del estudio de los ejemplares de TBO desde su aparición hasta finales de los años treinta y aceptando que la revista gustase a los lectores infantiles de aquel tiempo por su novedad respecto a los anteriores modelos, debemos concluir que las historietas publicadas fueron globalmente mediocres. Tanto por el dibujo como por su rígido lenguaje expresivo. Y estamos hablando de las historietas de Donaz, Urda, Nit, M éndez Álvarez, Opisso, Yorick, Tinez (Juan Martínez), Rapsomanikis y más tarde Mestre, Serra Massana, un primerizo Benejam, etc. Con las colaboraciones de dos dibujantes franceses muy populares en aquellos años: Maurice Cuvillier y Louis Forton, creador de la serie "Les Pieds Nickéles".

Hemos visto algunos guiones escritos por J oaquín Buigas así como sus anotaciones en los originales indicando al dibujante qué debía cambiar. En todos los casos fue él quien personalmente marcó la línea a seguir. Hay pues que pensar que los resultados objetivos no son fruto de la impericia de los dibujantes sino que responden a los criterios de su director.

Inicialmente Buigas diversificó su oferta: $T B O$, colección gráfica $T B O, B B$, Historias y Cuentos TBO, etc., con aciertos importantes como publicar la primera revista de historietas dirigida específicamente a las niñas -adelantándose en más de veinte años al boom del tebeo femenino-. Pero, al desaparecer estos títulos y concentrar su esfuerzo en $T B O$, incurrió en una especialización tan absoluta que generó fragilidad empresarial.

Esto permite valorar el férreo control que Joaquín Buigas ejerció sobre los contenidos de TBO. Sobre todo cuando, con el paso de los años, la revista se singularizó por la extensión de su título para designar todos los tebeos, momento en que Buigas congeló el modelo editorial sin permitir prácticamente que evolucionase.

\section{De Juan Bruguera TeiXidor a la editorial El Gato Negro}

Ignoramos el año exacto en que Juan Bruguera Teixidor creó El Gato Negro. Utilizó este pie editorial tiempo antes del lanzamiento de la revista Pulgarcito, 1921, sin poder 
concretar más. Lo poco que sabemos de las primeras actividades editoriales de Juan Bruguera es que, tras una primera etapa incierta correspondiente a su juventud - en la que se le relaciona con los jóvenes bárbaros de Lerroux y con la Semana Trágica de Barcelona-, se inició editorialmente a comienzos de la década de 1910 ligado a dos revistas sicalípticas de Barcelona, El Don Juan y El pobrecito Valvuena. Más tarde se estableció como editor de novelas de folletín con su propio nombre y después continuó en sociedad con pequeños editores y a veces con impresores.

Finalmente, a finales de la década de 1910, creó su propia empresa, El Gato Negro, con varios domicilios en Barcelona, hasta que en los primeros años veinte se radicó definitivamente en Vallcarca, entonces prácticamente en las afueras de Barcelona. Durante sus primeros años de editor, su escasa economía obligó a Juan Bruguera a trabajar en el límite de lo posible, comprando para cada título la cantidad mínima de papel en función de la edición prevista y llevándolo personalmente en un carretón a la imprenta para recogerlo una vez impreso y, ayudado por su mujer, plegarlo y encuadernarlo manualmente para formar los ejemplares de colecciones de novelas por entregas, manteniendo una economía casi de subsistencia.

Fue ya con el nombre de El Gato Negro cuando J uan Bruguera, sin abandonar la edición de novelas por entregas, de folletos variados, de todo tipo de cuentos infantiles, recortables y otros impresos, inició en 1921, con Pulgarcito (imagen 7), la publicación de revistas infantiles. El subtítulo de este primer tebeo: Periódico infantil de cuentos, historietas, aventuras, entretenimientos, etc., definía sus planteamientos editoriales, en los que la historieta solo ocupaba un papel secundario. Entre sus colaboradores estaban los dibujantes Donaz, Urda, Vinaixa, Pasarell, Clapera, Robert, otros de los que no consta el nombre y más tarde M oreno, Niel (M elchor Niubó), Salvador M estres, Emilio Boix, etc. $Y$, entre los escritores, Tomassetti, que pasó de $T B O$ a El Gato Negro aportando conocimientos y muchos datos útiles, Donaz, que escribió los guiones de sus historietas y cientos de episodios de novelas por entregas, Emili Graell Castells, Agustín Piracés, Antonio Ollé y Bertran, etc. ${ }^{8}$.

Juan Bruguera encontró en la revista infantil de contenidos variados el modelo editorial que le facilitaba la presencia semanal en los puntos de venta. Esto suponía una ventaja, ya que las colecciones de novelas podían tener 8 , 20, 30, 48 entregas y, al finalizar, había que lanzar una nueva colección, acreditar su título y afianzarla en el mercado. En cambio un tebeo tenía una duración ilimitada, tan larga como el favor del público decidiese, y podía ser un magnífico soporte para narraciones y hasta novelas por entregas. En cambio, la historieta se abrió paso muy lentamente y aún en los primeros años treinta no tuvo otra función que la de simple material complementario entre los múltiples contenidos.

Tras lanzar Pulgarcito, Juan Bruguera aumentó de forma constante y rápida su fondo editorial de tebeos y publicó una serie de títulos que eran simples prolongaciones de otros ya existentes: Aleluyas de Pulgarcito, El Cuento Infantil Semanal, de 1921; Crispín, 1922; La Alegría Infantil, 1923; La Novela Gráfica Infantil y AEI, de 1924, y en el mismo año el tebeo catalán Sigronet, Totó, 1925; La Aventura infantil y Charlot, de 1928; Picolín y Miau, de 1929, etc. Una de las cualidades comerciales de Bruguera fue su sentido práctico, por lo que cuando un tebeo no alcanzaba los beneficios mínimos para mantener su continuidad lo suprimía y sustituía por otro.

La concurrencia de varios editores con productos similares acabó a mediados de la década con la desaparición de alguno de ellos, como Heras, Magín Piñol, Aurora y otros. Hay casos realmente interesantes, como el de Magín Piñol, quien habiendo comenzado en 1922 a editar tebeos, novelas por entregas y otros productos populares, en 1925 abandonó la edición, pese a que sus tebeos tenían mejores dibujantes y una calidad técnica más alta que los de sus competidores. Juan Bruguera aprovechó la ocasión, compró sus marcas y continuó editando sus tebeos, Colorín, Pierrot y iHay que ver!, pero con una calidad más baja.

Al cerrarse los años veinte, cercanos ya los tiempos de la República, los planteamientos comerciales de Juan Bruguera, su continua dedicación así como la constante reinversión de los beneficios, hicieron crecer la empresa: construcción de nuevos edificios -levantados por el propio Bruguera y familiares-, compra de maquinaria de imprenta, contratación de más personal y el lanzamiento de más productos, probando nuevos formatos, aumentando las tiradas y desarrollando una creciente red de corresponsales en provincias para potenciar las ventas 9 . 


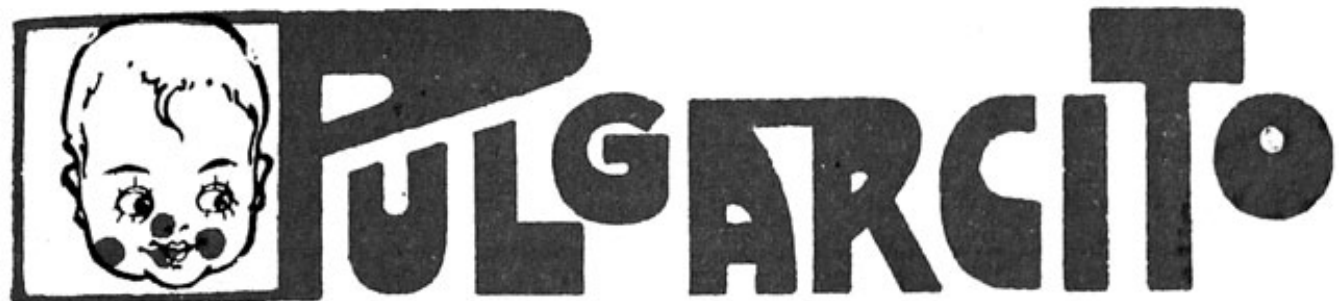

PERIODICO INFANTIL de Cuentos, Historietas, Aventuras, Entretenimientos, etc., etc.,

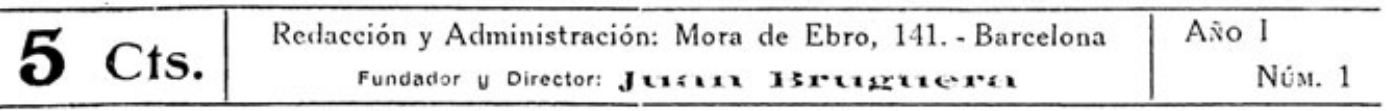

EI PATAGUAS

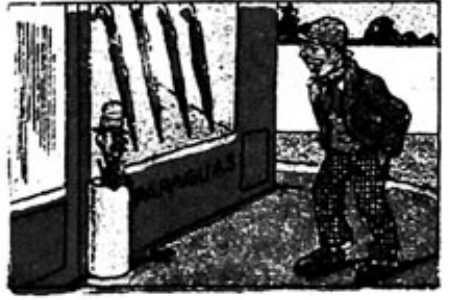

El dueño de *Et Sol*, estabecimiento dedicado exclusivamente a vender paraguas, tuvo la humorada de poner a la puerta de su tienda un paraguas-anuncio que era la admiración de todos cuantos lo veian. Su originalidad era tal, que Perico Picaporte,muy amigo de lo ajeno, al verlo no pudo disimular su alegria y se dijo

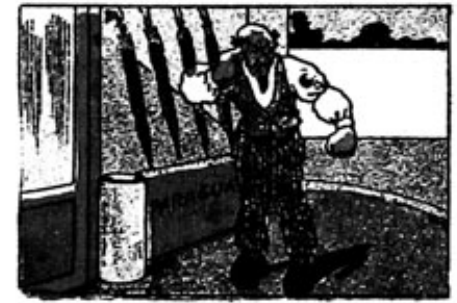

de meditar profundamente, dedujo que no podía habérselo llevado sino un discipulo de $\mathrm{Caco}$, al que cra preciso dar su merecido.

El paragüero que no era tanto, como lo demuestra el buen acierto que tuvo en la elección del titulo de su tienda, halló pronto uin medio para poder lograr su objeto.

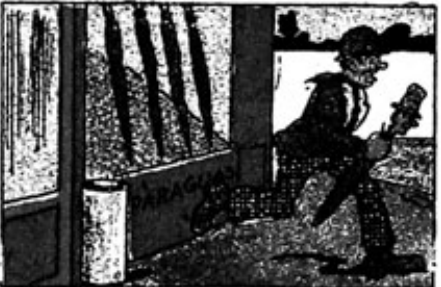

in menti: semejante artefacto Ilama poderosamente mi atención $y$ hace clespertar mis deseos de poseerlo.* Advertimos que estos deseos despertaban en Picaporte antes que él, pues se dió el caso de que, hasta durmiendo, hizo pasar a su bolsillo un magnifico reloj que yacía en el de su compañero de hospedaje.

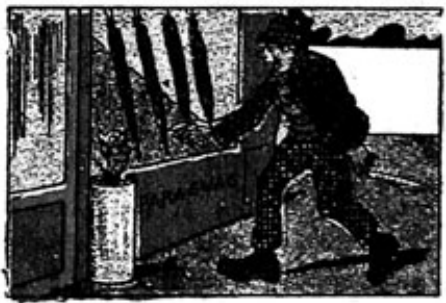

Inmediatamente, puso un nuevo paraguas en lugar del desaparecido. Perico Picaporte, al verlo, se dispuso a llevárselo: No se lo pensó mucho, y alargó su pecadora mano. Pero esta vez, fué él el cogido: Un magnifico foxterrier saltó de pronto e hizo presa en su mano derecha. El grito que lanzó Picaporte fué tan estriden-

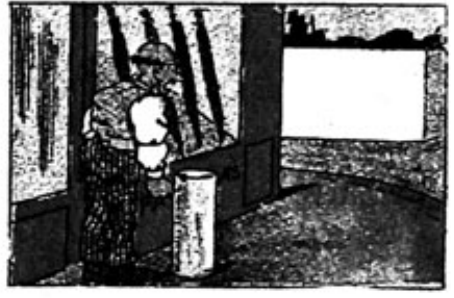

Asi, pues, Perico miró en torno suyo y viendo que el gracios, paragüero estaba distraído, $s$ : apoderó del curioso objeto, seliendo de estampia, y.dispuest, a no aparecer por alli, al meno: con el paraguas.

Renunciamos a describirla sorpresa del paragüero, al ver qu: su anuncio no estaba alli. Lueg,

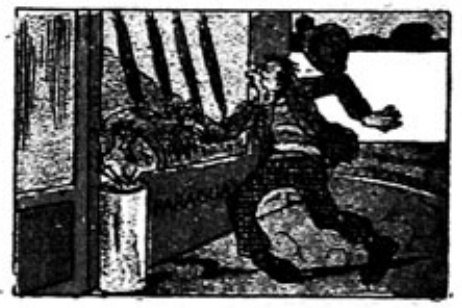

te, que más bien que un sonido de Picaporte, semejó el estampido de un cañón. El perro no soltó hasta dejar una buena señal; tanto es así, que Perico quedó lo suficiente escarmentado, y no pensó apoderarse, en lo sucesivo, de los bienes ajenos. La astucia del paragü•ro surtió, pues, efecto.

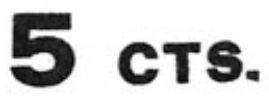




\section{LOS TEBEOS DE GÉNERO}

Los primeros tebeos españoles se dirigían a "todos los públicos" sin distinción de sexo ni edad. Inicialmente las niñas leían los tebeos de humor y los de sus hermanos hasta que surgió un nuevo tipo de tebeos para niñas, que se centraban en una temática "sentimental". La codicia de los editores, siempre ansiosos por captar nuevo público, dio nacimiento a los tebeos para niñas.

El primer título "femenino" fue $B B, 1920$, que Joaquín Buigas lanzó como un suplemento de TBO. Se trataba del modelo tradicional de los tebeos de los años veinte: un pliego de papel plegado en cruz, que daba ocho páginas, cuatro de las cuales se imprimían en negro y las otras cuatro en bicolor. La novedad, inspirada en similares publicaciones francesas, radicaba en que por primera vez se ofrecía una publicación de historietas pensadas y dibujadas en función de las niñas, acompañadas de cuentos, manualidades, pasatiempos y juegos. Los autores eran Opisso, Urda, Yorick, Rapsomanikis, etc., y la "feminidad" radicaba en que los protagonistas de las historietas eran niñas o mujeres y en las labores y patrones de costura que ofrecía.

Buigas tan solo pretendía explorar y explotar el nicho sociológico de las posibles lectoras. La aparición de $B B$ hay que valorarla en el contexto de los primeros años de siglo, cuando se quería potenciar un público consumidor femenino sin ninguna pretensión de cambio en su condición. Buigas era consciente de la novedad que tal publicación suponía, ya que intentó reforzar su lanzamiento con la creación del personaje "la niña BB", paralelo al "niño TBO", ambos dibujados por Opisso, llegando a crear recortables de $B B$, con su ropa, guantes, sombrero, etc.

$B B$ se editó hasta 1925. Los sucesivos intentos que otros editores realizaron en la misma línea, antes de 1936, fueron: $L a$ Nuri, 1925, en catalán y dirigido por la gran ilustradora Lola Anglada; La Chiquilla, 1927; Mari-Luz, 1934 y varios suplementos para niñas en la prensa. Ninguno de estos títulos aportaba nada nuevo a las lectoras, pero asentaron una prensa específica para las niñas. Fueron: Miniatura "Sección especial para las niñas" en la revista El Hogar y la Moda, 1934; Pocholina "Página femenina" en el tebeo Pocholo, 1934; Marujita "Sección para las niñas" en el tebeo Mickey, 1935, que no era sino una extensión de la colección de cuentos Marujita, que Molino había comenzado a publicar en
1934, en libritos de pequeño tamaño, con interiores ilustrados e impresos en negro y cubiertas en color, encuadernados con grapa.

La guerra civil hizo que los primeros tebeos femeninos quedasen en simples ejercicios editoriales sin continuidad, ya que no parecían haber arraigado en el mercado. No es posible saber lo que habría ocurrido si no se hubiese producido el golpe de Estado de julio de 1936, pero es un hecho que la idea estaba en el aire y que los años treinta eran más adecuados para que fructificara al calor de los derechos que la mujer iba conquistando bajo el régimen republicano.

\section{LA EDICIÓN DE TEBEOS A FINALES DE LOS AÑOS VEINTE}

Los años finales de la década, mientras la dictadura de Primo de Rivera se agota y los problemas económicos, políticos y sociales se incrementan, se cerraron con una abundante producción de tebeos, editados por El Gato Negro, Casa Editorial TBO, Luis Montiel, La Casa de Pichi, Lotario Vecchi, Federico González Plaza primer editor de Jeromín, Ramón Vives, Diario M ercantil Valenciano, Marco, Baguñá, etc., que en conjunto publicaban medio centenar de cabeceras, en los que ya comenzaban a ser mayoría las páginas dedicadas a la historieta.

El estudio de los tebeos permite analizar cómo los editores populares de Barcelona y Madrid, si bien se iniciaron en la publicación de historietas con un absoluto desconocimiento del medio, al borde de los años treinta habían dado un gran paso, tanto por asumir su función de intermediarios entre lectores y autores, como por el conocimiento de que esta función repercutía en una nueva forma del negocio editorial, que no podía plantearse ya como una simple aventura comercial de toma el dinero y corre. Los editores más representativos ${ }^{10}$ se plantearon que para permanecer era necesario reconvertir sus empresas desde el negocio casi amateur a formas industriales.

Para finales de la década hay que destacar varios aspectos: el casi monopolio del mercado popular que habían conseguido los editores de Barcelona con sus tebeos de carácter más popular, sobre todo El Gato Negro que, con menor calidad, ponía sin embargo muchos más títulos en el mercado. La debilidad estructural que mostraba la empresa 
de TBO ante la dura competencia y la imitación mejorada de su modelo editorial con tebeos como Pocholo. El afianzamiento de Madrid como capital editorial con títulos de la calidad de Titirimundi, Chiquilín, Pinocho, Pifa, Macaco, El Perro, el ratón y el gato. Y al mismo tiempo la apertura de una línea de tebeos populares madrileños, con títulos como Jeromín, Pichi y Macaquete. La aparición de los primeros tebeos valencianos como Boby y Los Chicos, suplemento semanal del Diario Mercantil Valenciano. La comprensión por parte de La Iglesia de la necesidad de dar sus batallas de apostolado con revistas más modernas, con su mejor ejemplo en el tebeo Jeromín. La entrada en el mercado de editores italianos afincados en España como fueron Lotario Vecchi y más tarde Enrique Guerri.

Hay que señalar también la entrada ocasional de los grandes grupos de prensa en la edición de tebeos. Los ejemplos para el periodo estudiado pueden ser el pool de empresas de Luis Montiel, que editó los tebeos Macaco y Macaquete. 0 el de Prensa Española, de Luca de Tena, cuando editó en diferentes momentos el suplemento Gente Menuda (imagen 8). 0 la empresa CIAP al editar la revista infantil de lujo $E I$

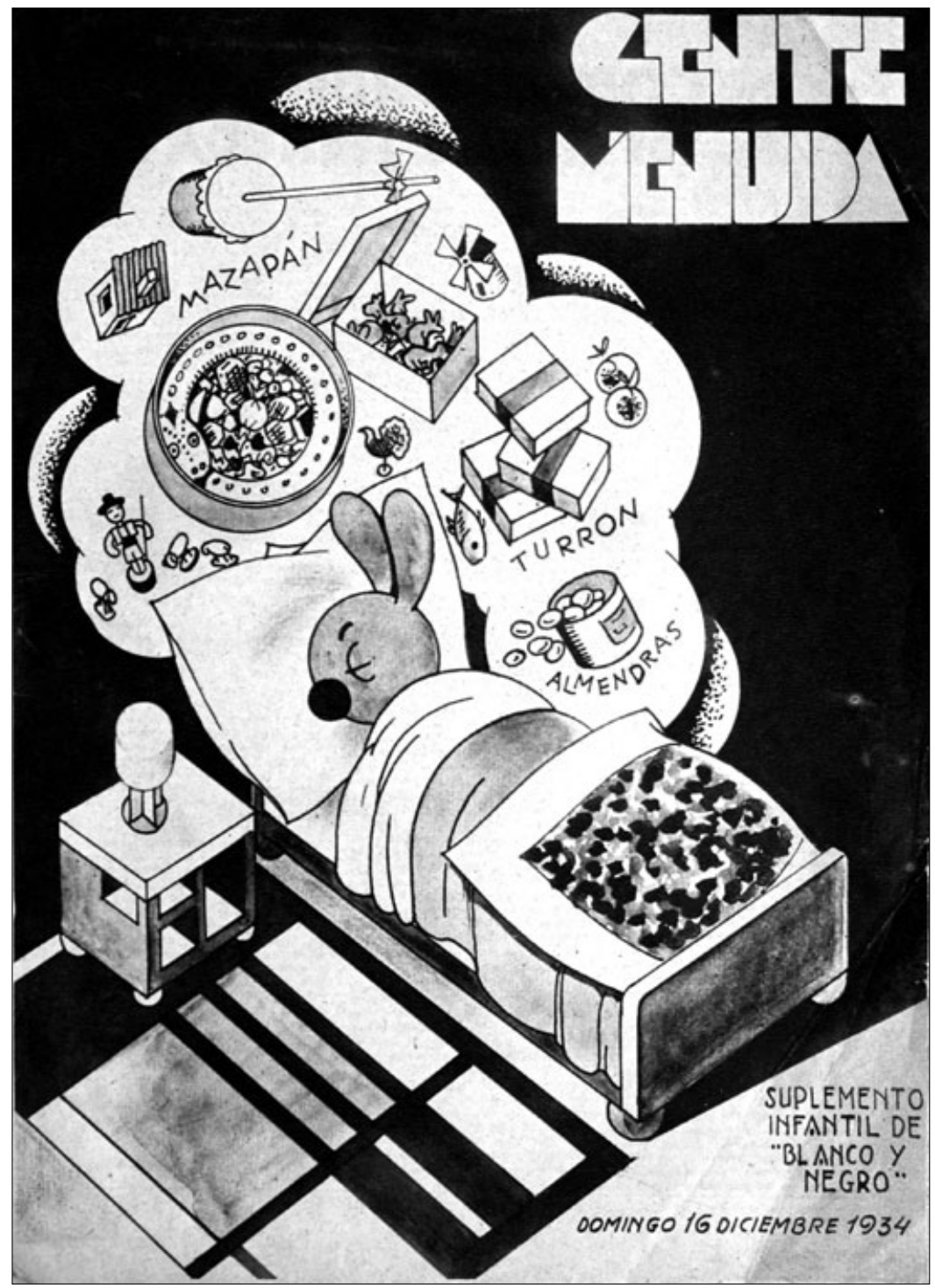

Imagen 8. 
perro, el ratón y el gato. Ante la fuerte competencia y las contracciones del mercado, estas empresas dejaron caer sin ningún problema los tebeos, que tan solo constituían un parte ínfima de su negocio editorial, y pasaron a otra cosa sin ningún interés por permanecer en el mercado y si ningún problema por los dibujantes que dejaban sin trabajo.

Podemos concluir que el conjunto de miles de páginas de historietas publicadas en los tebeos y revistas españoles para niños de 1910 a 1930 no ofrece calidad, son malas historietas, muy primitivas, mal narradas y con solo casos excepcionales publicados en Madrid. Por el contrario, el cómic aparecido en la prensa general, no infantil, especialmente en las revistas de humor, pero también en la prensa diaria y en las revistas semanales de todo tipo, dio un giro completo a los planteamientos de la historieta español para adultos -si cabe utilizar esta categorización por grupos de edad-, llevándolo más lejos, tanto temáticamente como en su lenguaje y desarrollo expresivo, respecto a los grandes clásicos españoles de 1880 a 1915.

\section{1, LOS TEBEOS dE LA REPÚBLICA, NUEVAS HISTORIETAS}

Los años treinta supusieron un tiempo de crisis, crisis de crecimiento. Fue entonces cuando por vez primera la cultura llegó hasta las masas. Por supuesto, se trataba de una cultura eminentemente urbana, que penetraba con dificultades en el mundo campesino. La II República, proclamada el 14 de abril de 1931, supuso un tiempo de mayores libertades, que se reflejó en el campo editorial en el aumento de títulos, en la rápida renovación de los géneros, en la variedad temática y en la apertura intelectual y moral. Y aún más, en la apetencia del público por leer y abrirse a los nuevos temas y géneros que llegaban sobre todo desde Estados Unidos. En aquellos años el cine se hizo más moderno y más glamouroso, es el momento en que el star system de Hollywood causa furor en España y ello se reflejó en la prensa, en las novelas, en los tebeos ${ }^{11}$.

En nuestro campo de trabajo, los años de la República supusieron un tiempo de transición, ya que si bien muchos de los editores de los años veinte mantuvieron los viejos modelos editoriales, caso de TBO, En Patufet, Pulgarcito y la mayoría de tebeos de El Gato Negro, Jeromín, etc., otros empresarios lograron que sus tebeos despegasen gracias a la modernización de sus páginas de historietas, caso de Pichien Madrid y de Pocholo en Barcelona. Pero, los resultados mejores se concretaron en los títulos publicados a partir de 1934, que rompieron definitivamente la fórmula tradicional de la historieta europea a partir de la nueva línea de cómics de aventuras que se había iniciado en Estados Unidos en 1929 con las series Tarzan y Buck Rogers. Sin olvidar las historietas que comenzaron a crear los autores jóvenes españoles, integrando el bocadillo en la viñeta y agilizando la dinámica narrativa, además de abrirse a temáticas más modernas.

Es así como, además de mantenerse la mayoría de editores de la década anterior, en los años republicanos hubo empresas editoriales que se dedicaron a los tebeos, por ejemplo la Editorial Guerri, especializada en la novela por entregas, que publicó en Valencia el tebeo KKO, 1932 (imagen 9), después titulado KKO Perragorda, dirigido por el dibujante Arturo Moreno (véase nota 11). En Barcelona Lotario Vecchi, editor de novelas por entregas, se inició como editor de tebeos, para algo más tarde cambiar el nombre de su empresa por el de Hispano Americana de Ediciones con la publicación de Yumbo, 1934, su primer gran título. En paralelo, la empresa de Pablo Molino, editor desde 1933 de novelas populares más cercanas al modelo norteamericano del pulp que al español de la novela por entregas, lanzó en 1934 su tebeo Mickey (imagen 10), que supuso, junto con Yumbo, el inicio de la gran oleada de los cómics de prensa estadounidenses. Por su parte, Germán Plaza pasó en estos años de vendedor callejero de libros a editor con pequeños folletos, algún almanaque de tebeos y las colecciones de libros Teatro Selecto y Vidas Extraordinarias que publicó con el pie Editorial Cisne. También hay que contar los tebeos barceloneses Cholito, clara imitación de Pocholo, y Boliche, donde un joven Jesús Blasco creó la primera versión de su personaje Cuto, la revista para niñas María Luz. Y varios suplementos infantiles de diarios y revistas como El Rincón de los Niños, del Diario de Madrid, En Xaneta del diario El Matí, Mapa Mundi suplemento de El Día Gráfico, etc.

Al hablar de la publicación de historietas en la prensa española de los años treinta, hay que señalar que muchos diarios y revistas semanales abrieron sus páginas a la historieta. Una historieta que no se dirigía a los niños y que tocaba todos los géneros: humor, satírico, política, erotismo, aventuras, costumbrismo, etc. Baste recordar las historietas publicadas en los diarios El Sol y La Voz, donde junto a López Rey y K-Hito publicó Martínez de León; La Vanguardia, que publicó las tiras 

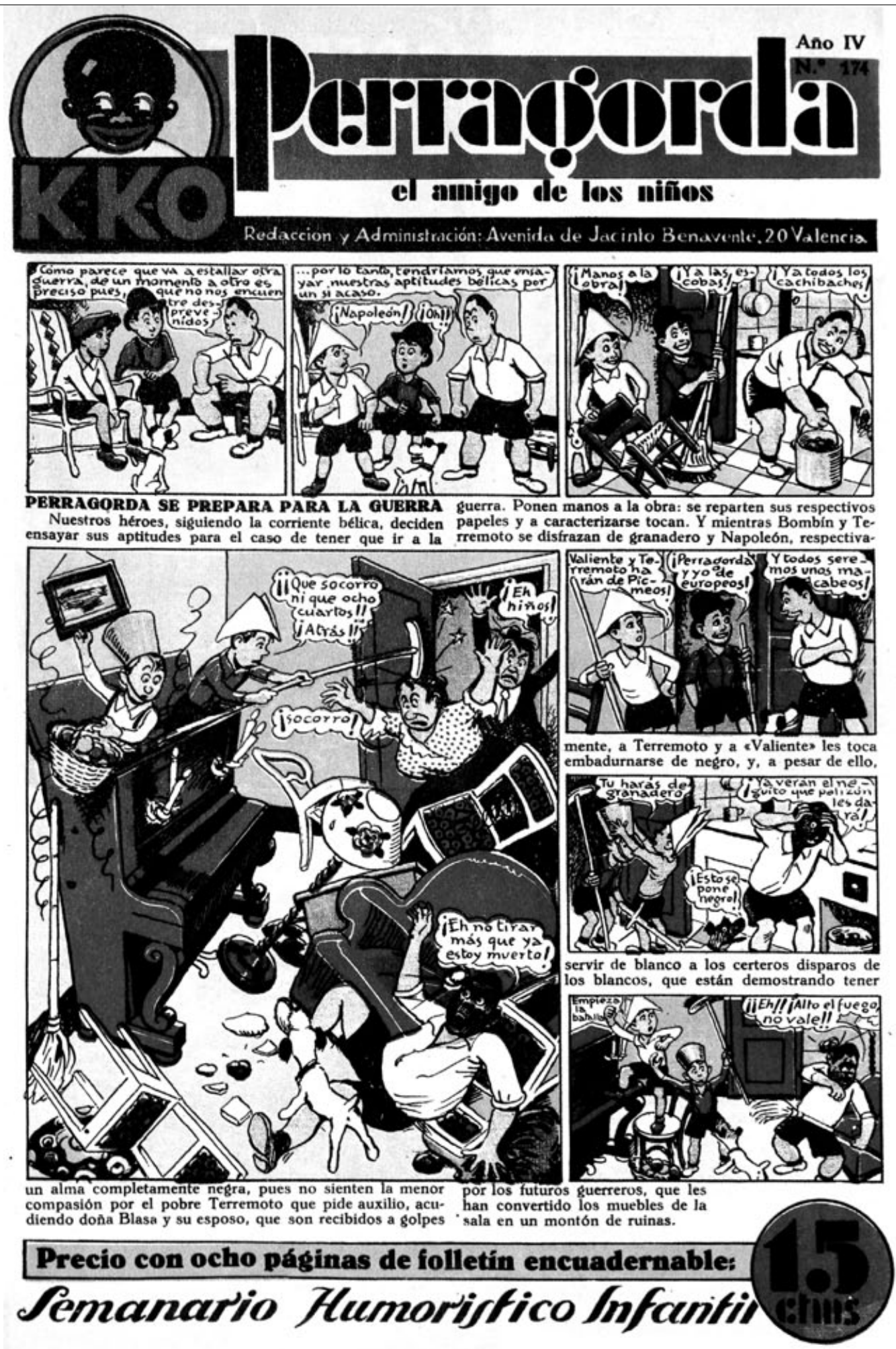

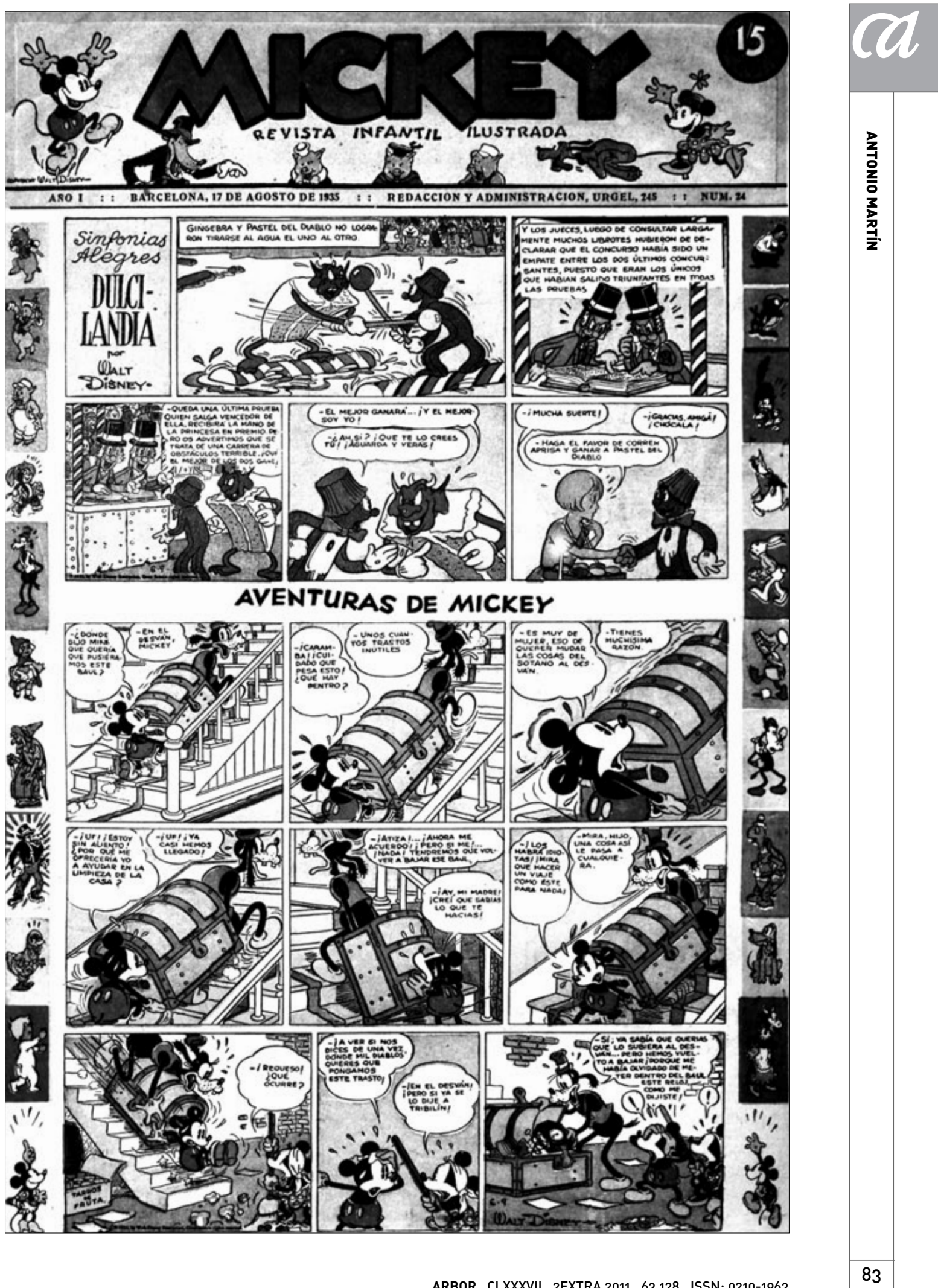
de Mickey; El Debate, con las tiras de Felix the Cat; Libertad, Ya, con las tiras de Mihura, López Rubio y Alfaraz; Luz, donde colaboraron Tono, Climent y Echea; El Día Gráfico con Popeye, Crisol, La Voz Gallega y La Correspondencia de Valencia; Ahora donde publicó Bartolozzi, y un larguísimo etcétera.

En Madrid fue fundamental la revista Gutiérrez que pasó del humor por el humor a la sátira política, y Gracia y Justicia, de extrema derecha y antigubernamental, que hizo un uso eficaz de la historieta satírica. $Y$ en Valencia es obligatorio señalar la revista La Traca, de humor rabiosamente antirreligioso y al mismo tiempo casi pornográfico, que renació con la República, desapareció con el gobierno de derechas de 1934 y volvió con el Frente Popular. Estas, junto con otras muchas revistas de aquellos años, fueron una de las plataformas en las que las izquierdas y las derechas dirimieron sus diferencias antes de llegar a la violencia de julio de 1936.

Igualmente destacaron en Madrid las revistas Estampa, con la serie "Las aventuras de Pipo y Pipa" de Salvador Bartolozzi, Mundo Gráfico, con la serie "La vuelta al mundo de Colás y Barullo" de Emilio Ferrer, Crónica, con las series "Lolín y Bobito" de Demetrio y más tarde "Canito y su gata Peladilla" de Pitti Bartolozzi, todas dirigidas a los niños. Y en Barcelona hay que señalar por la atención que prestaron a la historieta Algo, El Hogary la Moda y Lecturas. Algo se presentaba como una revista de curiosidades en línea con los magazines de divulgación creados en otros países, en sus páginas dedicó constantemente espacio a la historieta y publicó numerosas páginas auto conclusivas y algunas series, como "Alejandro y Napoleón, Sociedad General de Grandes Aventuras", de Serra Massana. Su Iogro más importante fue la publicación de "Los Aventureros del Espacio", de Hal Colson, posiblemente la primera serie de cómic de auténtica ciencia ficción publicada en España. Lecturas, además de publicar los chistes e historietas de Arturo M oreno, Kim (M untañola), Guasp, Cabrero Arnal, Opisso, D'Oc, Niu, Xirinius (Jaime Juez), Urda, Martí Bas, etc., convocó dos concursos de historieta con la intención de descubrir nuevos dibujantes. Por su parte, la revista El Hogar y la Moda, publicó varias series de autores españoles, "El retorno del Marqués de Bolamayor", de Castanys, "Aventuras de un faraón en el siglo XX", de Arturo Moreno. A partir de enero de 1931 comenzó a publicar la serie "Zig et Puce", creada en 1926 por Alain Saint-Ogan, dibujante francés que llevó la historieta a su máxima altura en la composición por página, en el ritmo de lectura, en las elipsis narrativas y, sobre todo, en el uso total del bocadillo, con una obra que fue un modelo para el primer Hergé.

\section{LA EVOLUCIÓN DE LOS TEBEOS ESPAÑOLES}

Al iniciarse los años treinta la historieta aún arrastraba las carencias expresivas de la etapa anterior, habituales en los tebeos infantiles, si bien al avanzar los años pasaría por grandes cambios. El ejemplo más importante de estos cambios, y quizá el más perfecto, es Pocholo, que Ramón Vives comenzó a editar en Barcelona en 1930, primero en la línea marcada por TBO, en secciones, páginas, color, tratamiento expresivo. Después, número a número, este tebeo definió su propia línea editorial, siempre basada en la publicación de autores españoles: Longoria, Nit, Becquer, Opisso, Cabrero Arnal, Salvador Mestres, Arturo Moreno, Xirinius, con la apertura de sus páginas a dibujantes jóvenes y la incorporación del bocadillo a sus historietas. La evolución de Pocholo se aceleró a partir de 1935 alcanzando niveles de calidad muy altos e incorporando a autores como J aime Tomás, Celemín, Escobar, Benejam, Antoni Clavé, Riera Rojas... hasta llegar a la generación más joven con Jesús Blasco.

Pocholo se convirtió rápidamente en uno de los tebeos más populares y dejó atrás a los clásicos TBO y Pulgarcito, siendo el título decisivo para conocer y comprender la historieta española de los años treinta. La función de su editor, Ramón Vives, fue decisiva, ya que mostró amplitud de miras y dejó atrás los viejos modelos para aceptar nuevas ideas. Pero lo más decisivo fue la existencia de la figura de un director de la revista, que hasta estos momentos apenas si se había dado en la edición de tebeos donde el propietario y editor se desdoblaba también en director.

En el caso de Pocholo hubo dos, el primer director fue el periodista Diego Jiménez de Letang, a quien sustituyó más tarde el escritor y también periodista José María Huertas Ventosa. Ambos se plantearon con ambición el proyecto editorial. Hay que recordar las historietas largas seriadas, como "Guerra en el País de los Insectos" de Cabrero Arnal, "Vida, dimes y diretes del Mago de los Penetes" que dibujó Jaime Tomás con guión de Huertas Ventosa, "Punto Negro en el País del Juego" de Arturo Moreno, que junto 
con otros personajes fijos, un humor moderno y secciones activas formaron un conjunto que conectó con los lectores y dio una amplia difusión a Pocholo.

El caso contrario nos lo ofrece $T B O$, ya que Joaquín Buigas se aferró a la fórmula que en la década anterior le había dado éxito y ofreció una resistencia total a las innovaciones, por lo que las historietas publicadas en estos años continuaron llevando al pie de las viñetas densos textos explicativos, con páginas recargadas y una diagramación nada atractiva. La entrada de nuevos dibujantes, Salvador M estres, Benejam, Utrillo, Soriano Izquierdo, Cabrero Arnal, Ramón Sabatés, no pudo salvar la brecha que se abría entre la revista y el público. Pese a los alardes auto promocionales de Buigas, afirmando en la prensa de la época, incluso mediante publicidad de pago, que TBO alcanzaba tiradas semanales de 150.000 ejemplares en 1933, ello no es creíble.

Algunos editores intentaron resistir la competencia buscando soluciones que adaptasen sus tebeos a los nuevos tiempos. Marco había logrado poner en marcha durante los años veinte un amplio abanico de títulos: Chiquitín, 1925; La Risa infantil, 1925; Periquito, 1927; Rin Tin Tin, 192812. El modelo editorial de estos tebeos era el tradicional del pliego plegado en cruz dando cuatro páginas. La mayoría de los contenidos eran historietas inglesas y francesas calcadas 0 imitadas mal que bien por anónimos dibujantes, con algunas historietas propias, en todos los casos mal dibujadas y abundantes pies de texto bajo las viñetas. La necesidad hizo que Marco diese trabajo a muchos dibujantes noveles, de los que nos quedan los nombres de Yrandi, Samibel, Nyébit, Regúlez, Boix, Farell, Robert, Tínez, etc.

Entre las soluciones que Marco buscó para poder competir en el mercado de los años treinta, la primera fue la renovación de los contenidos, lo cual supuso un proceso de varios años, sobre todo porque implicaba la mejora del grafismo, dejar de calcar las historietas inglesas y comenzar a crear materiales propios, así como modernizar el lenguaje expresivo. Para lo primero, contó con la colaboración de José Canellas Casals, que no siendo profesional de la historieta ni buen escritor resultó ser un colaborador irrepetible por sus vuel os literarios en los que se mezclaban elementos tradicionales del folletín con la más disparatada imaginación. Canellas partió de la recomendación del propio Marco para que diera a su guiones y novelas "[...] mucho movimiento, mucha acción y misterio ]...]"13. Complementariamente, se buscaron nuevos dibujantes y se reciclaron algunos de los ya existentes dándoles trabajos más creativos, como Emilio Boix, Albert Mestre, Francisco Darnís y Marc Farell quien también firmó con el seudónimo Kif.

\section{El Gato Negro en la CRISIS de los años treinta}

Los años treinta fueron decisivos para El Gato Negro, cuya segura pero conservadora política editorial dejó a la empresa a la zaga de los editores más modernos. Bruguera era sin duda el editor que mayor número de publicaciones ponía mensualmente en el mercado: novelas por entregas, cuadernillos de chistes y pasatiempos y canciones, folletos de todo tipo y hasta cromos y recortables, además de tebeos, pero todo ello mantenía aún el estilo y las formas de los años veinte. La empresa había crecido en ediciones, edificios, maquinaria, almacenes, personal y facturación, pero su posición en el mercado se veía comprometida ante el rápido crecimiento de varios competidores. El mayor volumen de la empresa aumentaba el riesgo al no existir un tejido industrial suficiente como base del negocio del tebeo.

Juan Bruguera Teixidor incorporó a la empresa a finales de los años veinte a su hijo mayor Pantaleón y más tarde haría lo mismo con su hijo Francisco. Progresivamente fueron teniendo participación directa en las decisiones, bien que sujetos a la autoridad última de Juan Bruguera. Ello se reflejó en una serie de tanteos formales: cambios de formatos editoriales, nuevas secciones, mayor uso del color, nuevas temáticas y la concesión progresiva de una mayor importancia a la historieta, aunque aún se resistían al uso del bocadillo en el interior de la viñeta. Se agilizó la diagramación de los tebeos y también se renovaron los colaboradores $y$, aunque El Gato Negro nunca prescindió de dibujantes como Urda, Vinaixa, Pasarell, Donaz, sí concedió cada vez mayores oportunidades a Arturo Moreno, Salvador Mestres, Emilio Boix y especialmente a Niel (M elchor Niubó). Enfermo desde hacía años, Juan Bruguera murió tempranamente en 1933, cuando El Gato Negro estaba publicando los tebeos Pulgarcito, Charlot, La aventura infantil, Pierrot, iMiau!, Picolín, La alegría infantil, Boy, Bobin. A partir de su muerte, los hermanos Bruguera tomaron totalmente en sus manos la editorial, Pantaleón en las tareas administrativas y Francisco en la parte editorial y más creativa. 
Los cambios introducidos por los hermanos Bruguera se reflejaron de forma más evidente en la renovación de las temáticas, en el lanzamiento de títulos más modernos, en la renovación en función de las caídas de ventas y en la búsqueda de personajes actuales. Es así como se convirtió a varios actores del cine -Stan Laurel y Oliver Hardy, Clark Gable, Shirley Temple - en protagonistas de múltiples historietas, con su propio nombre o no, habitualmente dibujados por Salvador Mestres. Se experimentó con los formatos y, por fin, se incorporó el bocadillo en las historietas, si bien no en todas.

La lectura de sus tebeos de este periodo, Aventuras, Aventuras y emociones, Cine Color, La Alegría Infantil Shirley Temple, Detective, iJa... Ja!, AEl en su nueva época, La Pandilla y siempre con Pulgarcito como buque insignia, produce una sensación contradictoria. Y es que los nuevos títulos muestran que, si bien los hermanos Bruguera lavaron la cara de los tebeos aparecidos hasta 1933 y lanzaron nuevos, en realidad la filosofía editorial no varió, ya que los nuevos títulos respondían a planteamientos que no se correspondían en profundidad con los cambios que estaba experimentando el mercado, y las historietas, aún las habladas mediante bocadillos, seguían construidas sobre modelos de guión arcaicos.

Cuando se cierra este periodo, en julio de 1936, El Gato Negro continuaba siendo una empresa familiar, cuyas estructuras no se habían modernizado. Es cierto que la facturación crecía, las ventas iban bien, el negocio funcionaba y había equilibro entre inversiones y beneficios. Además, contaban con un fondo editorial con centenares de entradas correspondientes a productos de todo tipo, siempre populares, a veces populacheros, que parecían ajustarse a los gustos de un público fiel. Pero todo ello no era bastante, era preciso pasar de la empresa familiar a la industrial.

\section{LA 'REVOLUCIÓN' QUE TRAJO EL CÓMIC AMERICANO}

En los años treinta se produjo la tercera y más importante entrada de cómic norteamericano. En realidad fue una auténtica invasión de la cultura norteamericana a todos los niveles. La agencia Opera Mundi contrató los derechos de los cómics de Disney para Europa. Al mismo tiempo adquirió los derechos de los nuevos cómics de aventuras que habían comenzado a producirse en Estados Unidos desde 1929. Fueron estos materiales los que provocaron una auténtica revolución en el mercado español, al igual que ocurrió en Italia y Francia.

La entrada masiva del cómic estadounidense influye poderosamente sobre los gustos de los lectores infantiles y sobre los dibujantes más jóvenes a partir de 1934. Este cómic no solo sería un poderoso competidor que rompió el equilibrio del mercado sino que, además, actuó como revulsivo sobre los dibujantes españoles, mientras que las empresas editoriales comprendieron cómo la edición de tebeos podía convertirse en un negocio millonario.

El primer paso lo dio Lotario Vecchi, que se había establecido en Barcelona en 1910 procedente de Roma y durante veinte años había publicado novelas de folletín con el nombre de Casa Editorial Vecchi, iniciando su actividad con el novelón María, el hada del bosque. Durante esos años pasó por diversos altibajos pero siempre siguiendo una línea ascendente, hasta el punto de tener imprenta propia en Barcelona y crear nuevas casas editoriales en Italia, Francia, Alemania, Portugal y Brasil, siempre dedicado a la publicación de novelas del más rancio estilo folletinesco. Siguiendo una política habitual en muchas editoriales, se rodeó de familiares en los puestos directivos de la empresa, como su hermano Arturo Vecchi o su primo Otelo Parenti.

Para ampliar su negocio Vecchi lanzó sus primeros tebeos, Mundo Infantil en Portugal y Nuevo Tom Mix en España, que funcionaron mediocremente. Aprendiendo de sus errores se interesó por el modelo de las revistas inglesas para niños de Amalgamated Press, contrató en exclusiva los derechos de sus cómics y lanzó en el mercado italiano la revista Jumbo en 1932, obteniendo un gran éxito que le llevó a publicar Rin Tin Tin, 1933; Tigre Tino, 1933; L'Audace, 1934, etc.

Lotario Vecchi inició en noviembre de 1934 la publicación de la revista Yumbo en España, que aún partía de los cómics ingleses. Pero consciente del éxito que La Casa Editrice Nerbini estaba teniendo en Italia con las revistas L'Avventuroso y II Giornale de Cino e Franco, Vecchi decidió copiarlas, para lo que compró los derechos de los nuevos cómics de King Features Syndicate y lanzó las revistas Aventurero, mayo de 1935 (imagen 11) y La Revista de Tim Tyler, abril de 1936.

Podemos valorar la importancia que tuvieron en el mercado español los nuevos tebeos de Vecchi -que en 1935 había 
cambiado el nombre de su empresa por el de Hispano Americana de Ediciones, S.A. - con solo enumerar algunos de los cómics que publicaban: Flash Gordon de Alex Raymond, Tarzan de Hal Foster, Brick Bradford de Clarence Gray, Mandrake the Magician de Lee Falk y Phil Davis, Tim Tyler's Luck de
Lyman Young, Radio Patrol de Charlie Schmidt, Red Barry de Will Gould, Buck Rogers de Phil Nowlan y Dick Calkins, Popeye de Segar, etc. Con el interés añadido de que los episodios semanales se publicaban en los tebeos españoles pocos meses después de su primera aparición en Estados Unidos.

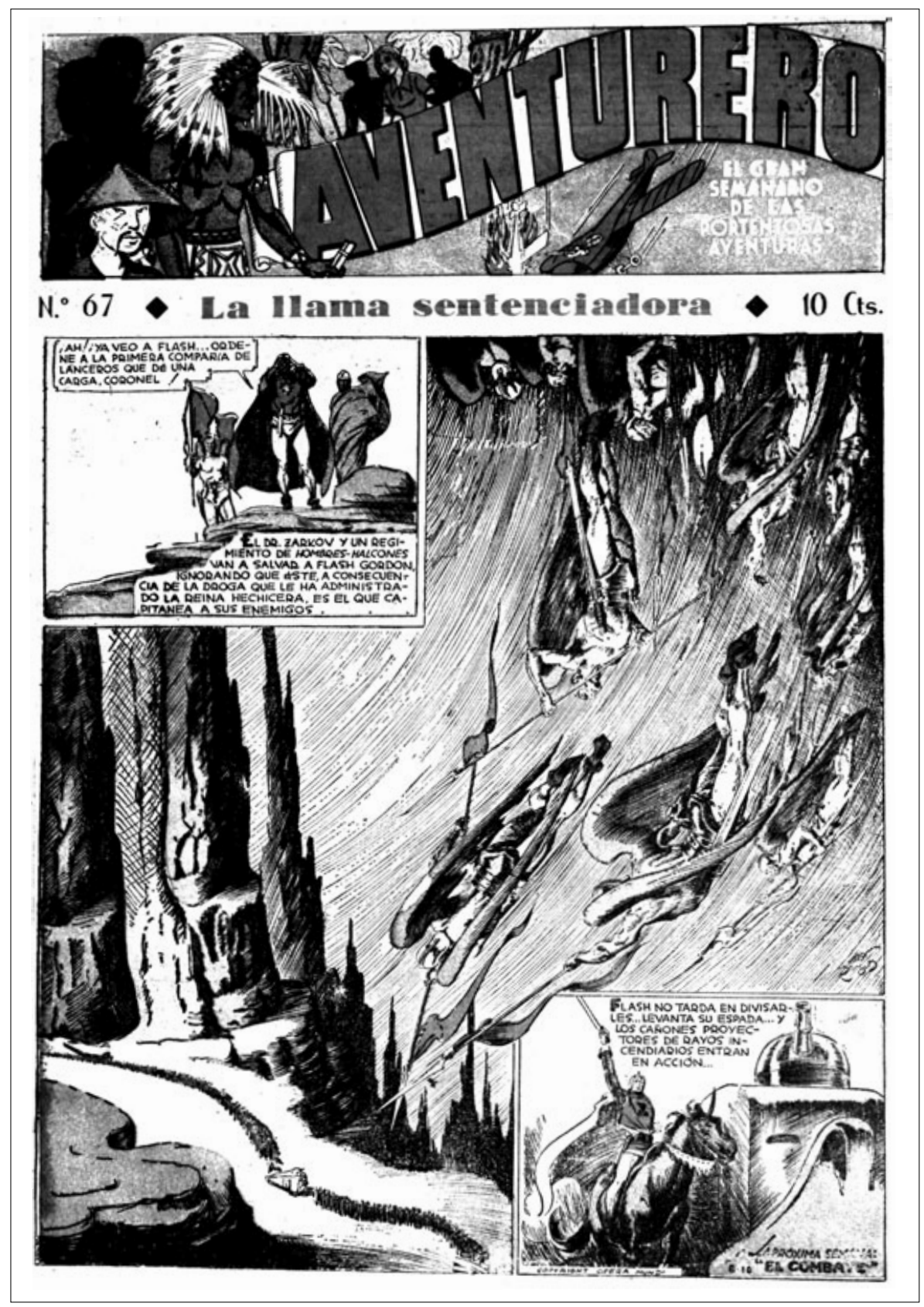

Imagen 11. 
La sacudida que estos cómics supusieron para los lectores españoles, ofreciéndoles nuevas historias, nuevas formas de dibujar, un lenguaje expresivo totalmente basado en la interrelación del texto y la imagen por medio del bocadiIlo, escenarios exóticos, vino acentuada por la edición de Mickey, marzo de 1935, por la Editorial Molino. Este tebeo estaba dirigido por Huertas Ventosa, que dejó Pocholo y trasladó su forma de trabajar, estimulando la participación de los lectores para así lograr la fidelización de los mismos.

Mickey aportó nuevos incentivos a los lectores españoles, pues además de publicar los cómics de Mickey, Donald, Pluto y restantes personajes de Disney, también publicó Jungle Jim de Alex Raymond, Terry and the Pirates de Milton Caniff, Ace Drumond de Rickenbacker y Clayton Knight, Pete the Tramp de Clarence D. Russell, etc. Con el añadido de las historietas de los dibujantes españoles Arturo Moreno, Riera Rojas, Emilio Freixas, Longoria, Mondragón y, más tarde, Jaime Tomás, Cabrero Arnal, Jesús Blasco y Xirinius.

El desafío comercial que planteaban los novísimos tebeos de Hispano Americana y de M olino repercutió sobre la historieta española y su modernización. El Gato Negro prescindió de sus dibujantes más antiguos, aumentó los formatos y el uso del color y añadió exotismo y acción a sus historietas. Por su parte, Marco luchó por no quedar fuera de juego, para ello introdujo nuevas historietas de aventuras fantástiscas, totalmente "habladas" mediante bocadiIlos, que realizaron Mestre, Darnís y Farrel sobre guiones de Canellas Casals, con argumentos delirantes, artefactos de ciencia ficción diabólicos, poderosos guerreros, bellas mujeres más desvestidas que muchas de las heroínas de Flash Gordon. Y aún dio Marco un paso más al crear el tebeo Cine Aventuras-Betty Boop, en 1936, que dedicó a publicar cómics norteamericanos, como Betty Boop (imagen 12), de los estudios Fleischer, The Pussycat Princess de Ruth Carroll, Polly and Her Pals de Cliff Sterrett, Skippy de Percy Brosby, Johnny Round-the-World de William LaVarre, etc.

\section{LAS HISTORIETAS DE MADRID EN TIEMPOS REPUBLICANOS}

M adrid, otrora capital editorial del reino, también en la edición de revistas para niños, fue perdiendo tal condición a lo largo de los años veinte de manera que al proclamarse la
República solo se publicaban los tebeos Jeromín, aparecido en 1929, y Pichi, aparecido en 1930, que continuaron durante los años republicanos. También en 1930 se publicó Macaquete, dirigido por K-Hito y editado por Luis Montiel, pero su vida fue breve. Y en 1930 se inició la publicación de la gran revista El perro, el ratón y el gato, dirigida por Antonio Robles y editada por CIAP, que desapareció al quebrar la empresa en 1931. De entre los varios suplementos de la prensa adulta, hay que destacar por su interés Gente Menu$d a$, que en 1932 volvió a publicarse como suplemento de la revista Blanco y Negro. En 1934 comenzó a publicarse la revista Iván de España, de marcada tendencia derechista. Y en 1935 el Diario de Madrid lanzó su suplemento infantil EI rincón de los niños. Igualmente importantes fueron las historietas dirigidas expresamente a los niños que publicaban las revistas Estampa, Mundo Gráfico y Crónica.

Mucho más importante que historieta para niños fue la edición de historietas en la prensa de adultos, en mayor cantidad cuando no era meramente informativa sino que tenía una tendencia política, pues entonces la historieta, gracias a su capacidad como medio, se prestaba a ser utilizada como soporte para la crónica, la información, la burla, sin olvidar los casos en los que se combinaban la sátira $y$ el humor verde.

Hemos citado los diarios de Madrid El Sol, La Voz, El Debate, Libertad, Ya, Luz, El Día Gráfico, Crisol, Ahora y las revistas Gutiérrez y Gracia y Justicia. Pero son muchos más los títulos de revistas que se multiplicaron gracias a la situación política, alternando sus golpes satíricos a izquierda y derecha, como ejemplos podemos recordar Cascarrabias, Fray Lazo, La chunga, El gorro frigio, Bartolo, iEl Straperlo!, Manos limpias, etc. En esta prensa, en la que menudearon los ataques contra políticos de todas las ideologías, encontramos obras de los dibujantes Galindo, Alfaraz, Bluff, Mihura, Jubera, Orbegozo, Soravilla, Kin (J oaquín de Alba), Demetrio, Morán, Alfaraz, Fersal, Méndez Álvarez, Moisés, K-Hito, Carnicero, Estebita, Bigre (Opisso), M atamala, Blas, Bellón, Cuesta, Jubera, Karikato, Tovar, Barciales, Antequera Azpiri, Nelo, etc.

La aceptación que la historieta alcanzó como medio de comunicación durante los años republicanos se hace más evidente en su creciente uso en la prensa de adultos. La urgencia de la prensa diaria y semanal impuso la rapidez del trazo, el esquematismo gráfico, el predominio de lo 

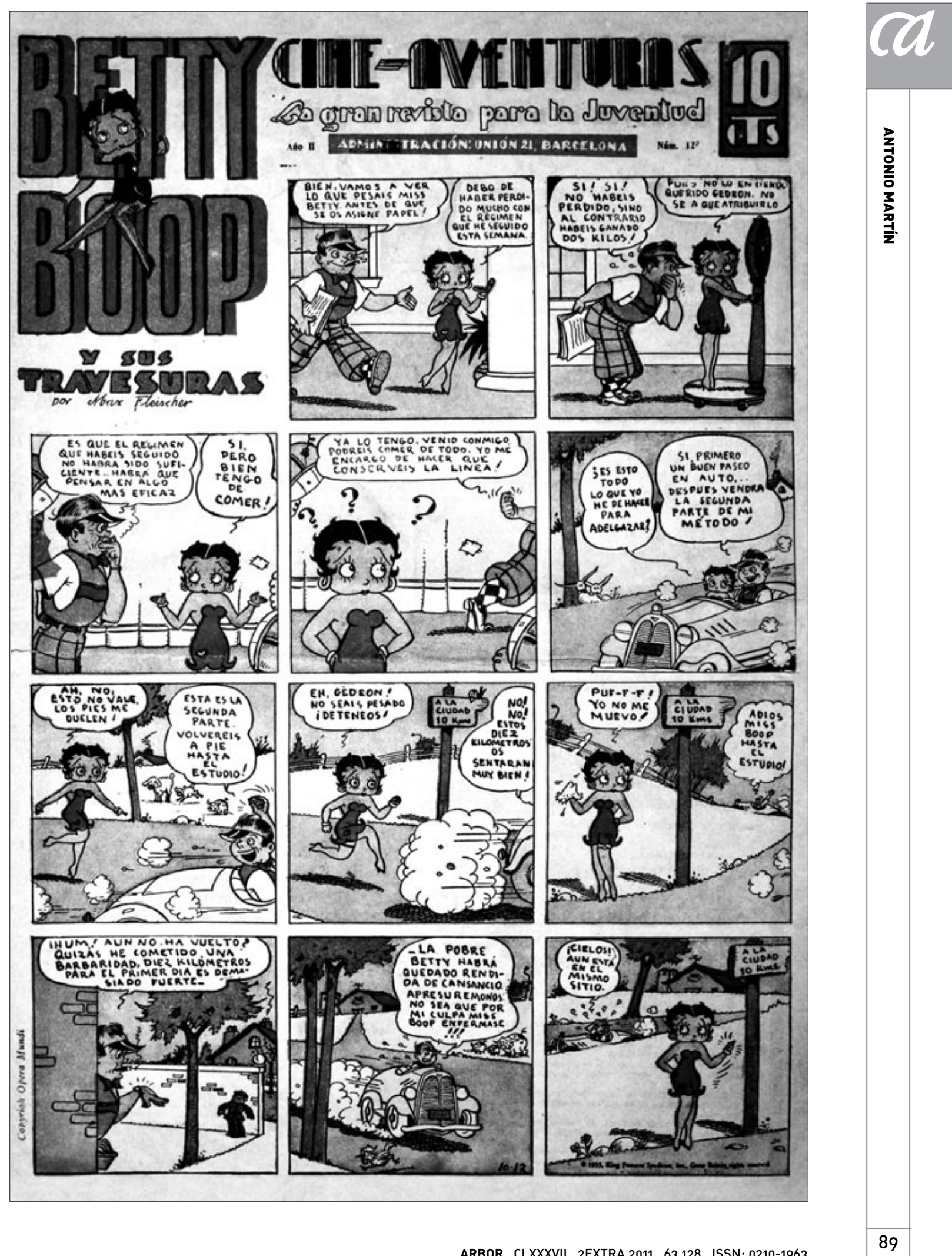

ARBOR CLXXXVII 2EXTRA 2011 63,128 ISSN: 0210-1963 
gestual y el uso frecuente del bocadillo. Las revistas editadas en Madrid, que como capital se convirtió en el epicentro político de un Estado asediado desde la derecha y la izquierda, requerían cada vez más ilustradores, lo que ofreció trabajo abundante a los nuevos dibujantes que, unidos a los profesionales de la década anterior, dieron lugar a uno de los momentos más brillantes alcanzados en España por la prensa gráfica, por más que en tal abundancia se produjera también mucho material oportunista de escaso valor iconográfico.

En cuanto a los tebeos madrileños que se editaron durante los años treinta, el más importante fue Jeromín, creado en 1929 por el sacerdote Federico González Plaza, con la pretensión de lograr un tebeo de inspiración católica que le permitiese llegar hasta los niños. El resultado fue un producto barato, que seguía el modelo habitual del pliego plegado en cruz para obtener cuatro hojas, con una cara impresa en negro y la otra a dos tintas con la cubierta en color, y con un contenido de chistes, ilustraciones e historietas de diverso formato, aún primitivas con los textos al pie de las viñetas. Y todo ello al mismo precio que el más barato de los tebeos, 10 céntimos. Los principales colaboradores del tebeo fueron Manuel G. Bengoa como autor literario y los dibujantes Cristino Soravilla y Teodoro Delgado que buscaron realizar historietas sencillas, construidas en torno a gags humorísticos. El tebeo fue tomando forma y atrayendo nuevos colaboradores, popularizándose en los ambientes escolares y entre las familias católicas.

En 1931, Jeromín pasó a depender de la Editorial Católica, importante grupo de presión de la derecha española. Pronto las mejoras introducidas en Jeromín dieron fruto y en 1932 declaraba una tirada de 100.000 ejemplares, cifra quizá exagerada pero posible desde el momento en que la impresión en rotativa exigía unas tiradas mínimas. En momentos en que los católicos españoles militaban activamente en partidos políticos, como la CEDA, cabe creer que muchos padres de familia eligirían como lectura para sus hijos este tebeo, editado con exigencia moral y educativa. Así, en su no 142 se afirmaba: "J eromín tiene un plan pedagógico completo, cosa de que carecen los demás. Por ello, no solo tiene la preferencia de los niños sino también la de los padres y maestros". Que su éxito era real lo demuestra el que llegase hasta julio de 1936.

El suplemento infantil más importante de prensa en estos años fue Gente Menuda, que reapareció en 1932 como encarte de la revista Blanco y Negro de Prensa Española, grupo editor del diario $A B C$. Con una larga historia, en este nuevo lanzamiento era, más que un suplemento, una auténtica revista y como tal se presentaba, como una publicación con cubierta propia, grapada para poder extraerla de la revista madre y conservarla aparte, con fecha de aparición en cubierta, correspondencia con los lectores y una multiplicidad de secciones.

Del conjunto gráfico de Gente Menuda destacaron Tauler, F. Ramírez, Orbegozo, Alfaraz, Areuger, Pitti Bartolozzi, Tilu, Galindo, Teodoro Delgado, etc. El dibujante fundamental fue Francisco López Rubio, que en sus historietas dio vida a una serie de personajes antológicos que han quedado en el imaginario popular de varias generaciones: el conejo Roenueces, el Mago Pirulo, Don Oppas, el Profesor Bismuto, etc. Pero la importancia mayor de López Rubio se centra en haber trasladado las enseñanzas de K-Hito y de la revista de humor Gutiérrez a los tebeos: predominio de la línea, preferencia por el trazo curvo, simplificación de la figura y los decorados y todo ello puesto al servicio de un humor del absurdo, resuelto en gags sumamente eficaces, en historietas auto conclusivas de una página; por otra parte López Rubio fue uno de los dibujantes que más y mejor jugaron con las convenciones gráficas de la historieta.

\section{LOS TEBEOS DE LA GUERRA CIVIL}

La guerra civil ha quedado inscrita en la memoria colectiva de la sociedad española tanto por su crueldad como por haber cambiado radical e irreversiblemente la Historia de España. A las pocas semanas quedó claro que la sublevación militar había fracasado en su objetivo inmediato: conquistar la capital de España, Madrid, y los mecanismos del Estado. Así, la sublevación llevó a la guerra civil. La radicalización política dio lugar a un amplio despliegue propagandístico que se canalizó en una auténtica guerra de papel, paralela a los hechos de armas. Del lado de los militares sublevados, esta guerra de papel se cifró especialmente en la multiplicación de revistas, diarios, libros, folletos y también en la edición de tebeos para niños. Las fuerzas más politizadas que apoyaban a los militares sublevados eran la Comunión Tradicionalista -nuevo nombre de la vieja rama del carlismo-, con su brazo armado el Requeté. Y la Falange Española de las JONS, de José Antonio Primo de Rivera, que en los años previos a la guerra había 
actuado como fuerza de choque de la extrema derecha española.

En la España leal la guerra de propaganda se cifró muy especialmente en los carteles, los periódicos y revistas, hojas volanderas y panfletos, romanceros de guerra y un gran despliegue de ilustraciones. En cuanto a la edición de historietas, esta continuó en 1936 como si no ocurriera nada, ya que se continuaron publicando los mismos tebeos que antes del golpe militar. En cambio, en las revistas y diarios de la guerra, dirigidos por los partidos políticos y los sindicatos a los adultos, sí que se publicaron abundantes historietas claramente militantes. En el bando de los sublevados desaparecieron los tebeos, ya que las ciudades españolas que habían sido tradicionalmente centros editoriales - Madrid y Barcelona - permanecieron fieles al Gobierno de la España republicana y los tebeos editados dejaron de circular por el territorio bajo mando de los generales rebeldes. Pero, según estos se afianzaban en Navarra, Aragón, Castilla la Vieja, Sevilla, etc., se inició en ellas la edición de toda clase de publicaciones dirigidas a los niños.

Falangistas y carlistas se plantearon desde el mismo año 1936 la captación de los niños, a los que se propusieron catequizar políticamente para encuadrarlos en las organizaciones infantiles paramilitares que ambos grupos crearon para este fin. Flechas por los falangistas y Pelayos por los carlistas. Los primeros tebeos de la guerra civil editados con una intencionalidad ideológica fueron Flechas, publicado por Falange en Zaragoza en noviembre de 1936 (imagen 13) y Pelayos, de los carlistas, editado en San Sebastián en diciembre de 1936 (imagen 14). Ambos estuvieron politizados desde su primer número y en todos sus contenidos, conviritendo los tebeos en un terrible instrumento en la propaganda de guerra, tanto más mortífero por dirigirse a los niños y realizar en ellos un auténtico "lavado de cerebro" al servicio de la beligerancia. Todo lo cual se acentuó en los años siguientes hasta alcanzar niveles panfletarios absolutos.

Por el contrario, en el primer año de la guerra y más allá de las convulsiones militares, políticas y sociales, los tebeos dirigidos a los niños de la España republicana mantuvieron su función recreativa. Empresarialmente, las editoriales fueron colectivizadas por comités de obreros de CNT o UGT, pero sin que ello tuviese consecuencias sobre sus contenidos, salvo casos aislados que en los primeros meses de la guerra civil se concretaron en algunas cubiertas e historietas bufas alusivas a la guerra, sin auténtica trascendencia. La edición de estos tebeos se concentró en Barcelona, con un título o dos en Valencia, mientras que en Madrid no se publicó ningún tebeo, fuera de las páginas de historietas que ya aparecían antes de la guerra en algunas de sus revistas informativas ilustradas. El mismo año 1936 y pocas semanas después de iniciarse la guerra civil, la Editorial Molino suspendió la edición de Mickey y sus propietarios se trasladaron a Argentina.

\section{LoS dibujantes de Franco en 1937}

El segundo año de la guerra fue el más importante en muchos sentidos. Por parte de los carlistas y de los falangistas aumentó la actividad propagandística, reflejada en una fuerte ideologización de toda su prensa. Ante la dispersión editorial, con varios tebeos falangistas que durante 1936 y parte de 1937 se editaron en Sevilla, Cádiz y Palma de Mallorca, Juan Manuel Hedilla, jefe nacional de Falange, decidió que solo se editase un único tebeo, que fue Flecha y apareció en enero de 1937, con mayor tirada y alcance. La edición de tebeos, totalmente monopolizada por Falange de la JONS y la Comunión Tradicionalista, se concentró en San Sebastián donde existían los talleres de impresión offsset más importantes de España. Los responsables de Pelayos, M osén Rosell y el Canónigo Vilaseca, sacerdotes huidos de Barcelona, ante la falta de colaboradores tuvieron que improvisar nuevos dibujantes, ya que la mayoría permaneció en la España republicana.

Los dibujantes de Franco durante la guerra civil tenían muy diversas procedencias. Estaban los artistas que unieron su suerte a la de los militares sublevados. También estaban los simples profesionales del dibujo que no militaban en ningún partido. Desde 1937 y para todo el tiempo de la guerra hay que destacar los nombres de Dorda, Miguel, Serra Massana, Tri-Tri, Rapsomanikis, Avelino Aróztegui, Máximo Ramos, Bora, Alcaide, Consuelo Gil, también dibujante y mucho más escritora, Teodoro Delgado, Ojeda, Mercedes Llimona, Carmen Parra, María Claret, AS (Valentín Castanys), Carmen Sert, el italiano Athos Cozzi, Salvador Ojeda, Chuchi (Jesús Fragoso del Toro), Santi, Usabiaga, etc., y entre los guionistas Alcapone (Álvaro de Laiglesia) y Benjamín (J osé Canellas Casals). Todos ellos colaboraron indistintamente en Pelayos 
y en Flecha, por más que algunos lo hiciesen solo en uno de los dos tebeos por militancia. Algunos eran dibujantes improvisados y apenas si tenían experiencia profesional; otros, como Rapsomanikis, Castanys, Serra Massana, Teodoro Delgado, eran profesionales reconocidos.

En la prensa de adultos destacó la revista de humor $L a$ Ametralladora, escrita, dibujada y realizada por Lilo (Miguel
Mihura), dibujante de Gutiérrez, seguidor de K-Hito y gran escritor teatral, Tono (Antonio Lara), Castillo, Teodoro Delgado, Arre- $M$ ete, etc. Mientras que en el conjunto de la prensa franquista, sobre todo en las revistas Fotos, $Y$, Vértice, etc., estaban, además de los ya citados, Carlos Sáenz de Tejada, Máximo Ramos, M. A. López Robert, Usa, Sánchez-Vázquez, José Caballero, Serny (Ricardo Summers), Julián Nadal, ATC, J osechu, etc.

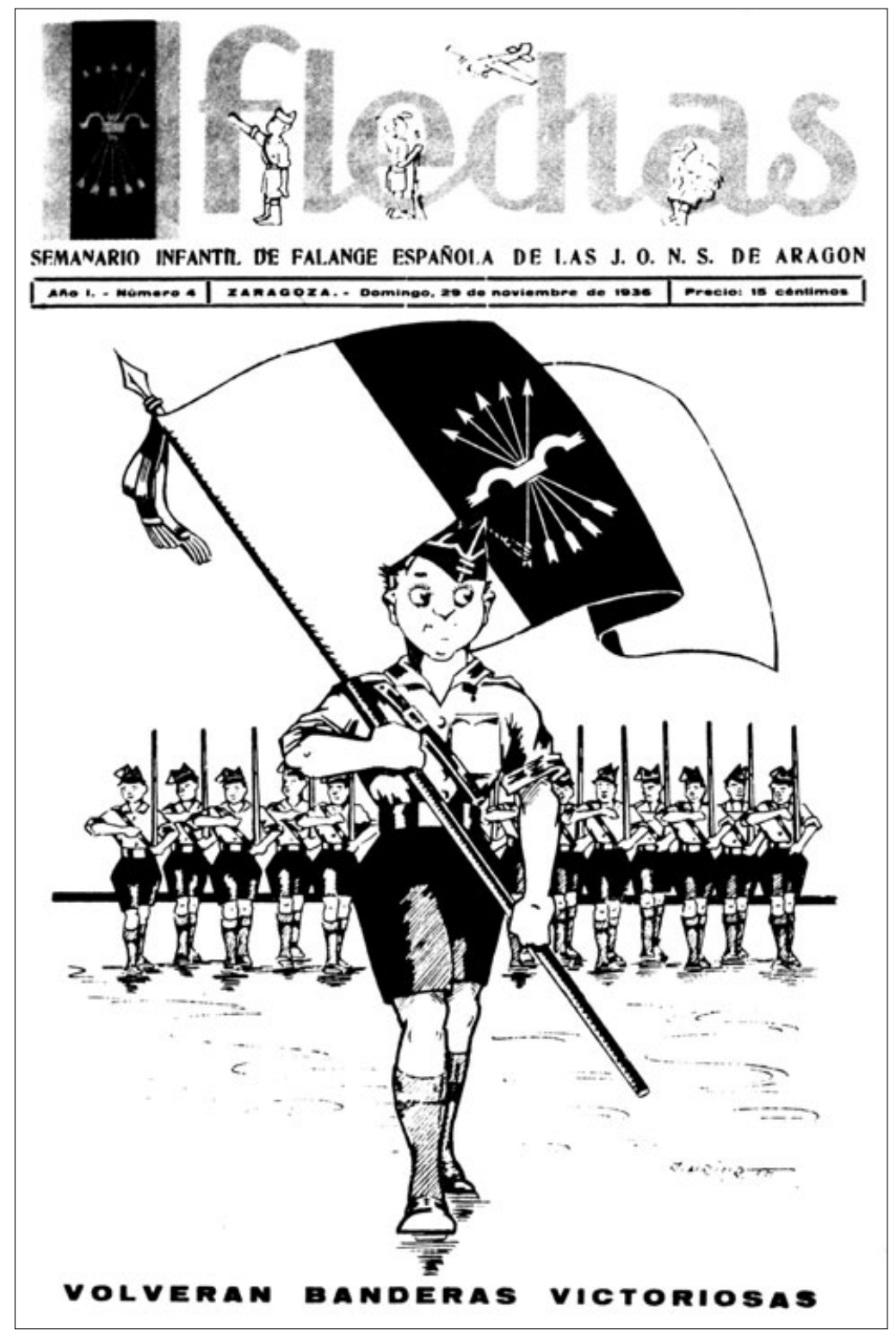

Imagen 13. 
El conjunto de los dibujantes de Franco contribuyó eficazmente a la propaganda de guerra, tanto desde el cartel como desde el tebeo, para crear el arquetipo negativo del "rojo", una imagen simbólica en la que se concentraban todos los males de la República: democracia, libre pensamiento, ateísmo, masonería, marxismo, etc. Carlistas y falangistas acuñaron una serie de tópicos que, repetidos semana tras semana, ofrecieron a los niños de la zona rebelde una imagen panfletaria de los combatientes republicanos, que en las páginas de Pelayos y de Flecha eran todos ladrones, asesinos y monstruos deformes.

Esta imagen representaba al enemigo por excelencia, el rojo, en una radical metáfora visual y literaria, milicianos mal encarados, con rasgos fisionómicos bestiales, a veces tuertos o con cicatrices, mal vestidos, tocados con los

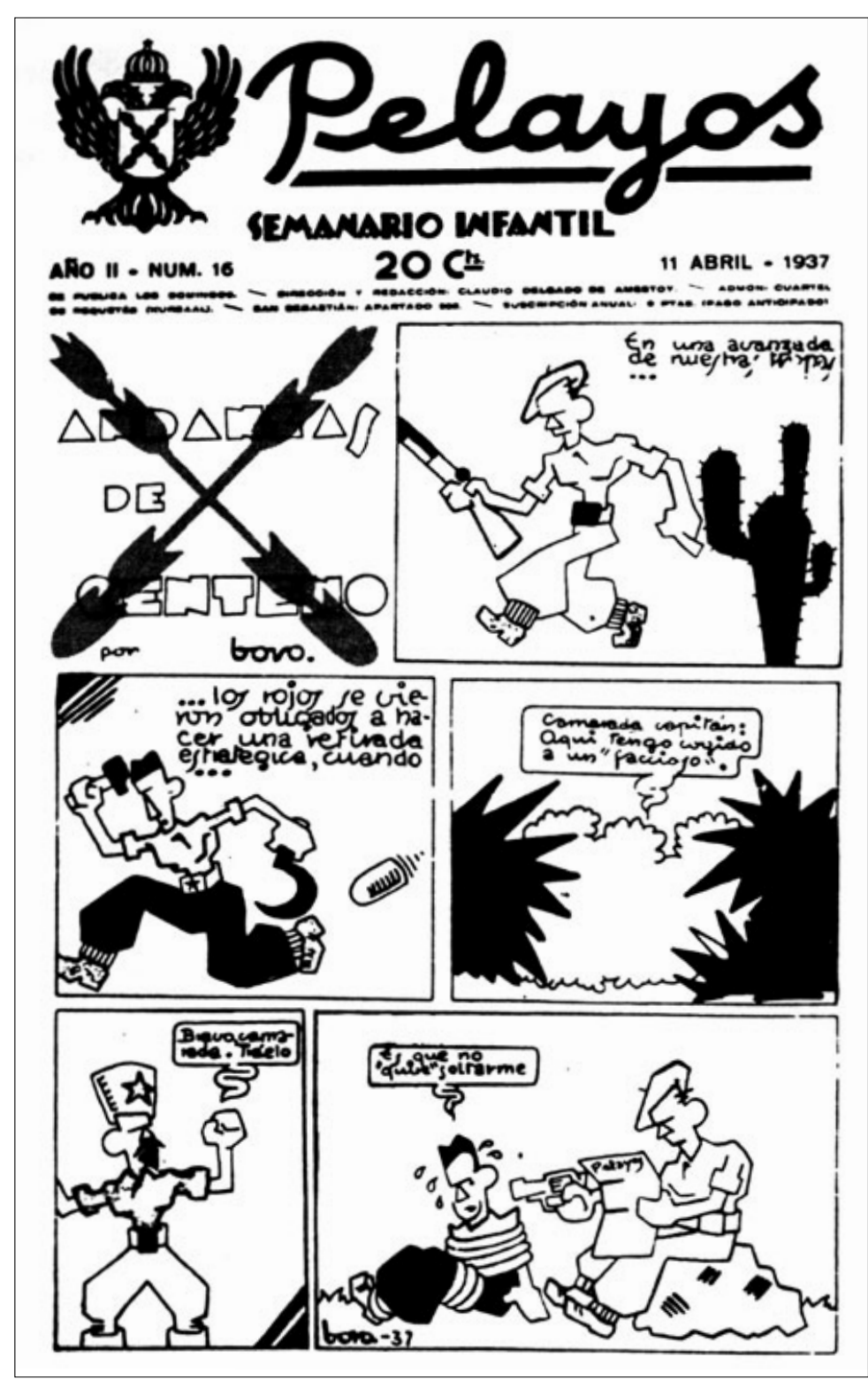

Imagen 14. 
pañuelos rojinegros de los anarquistas o con gorros estrafalarios decorados con la estrella roja y siempre sucios, barbudos y desaseados. Los rojos aparecían sedientos de sangre, babeantes, dispuestos a robar y asesinar, armados con toda clase de instrumentos mortales. Eran la representación suprema del Mal, frente a la cual carlistas y falangistas se erigían en paladines del Bien, vencedores en todas las batallas. Desde estos planteamientos, lo menos importante era el argumento o la credibilidad de lo narrado, pues todo se subordinaba al logro del efecto propagandístico.

El 19 de abril de 1937 Franco promulgó el Decreto de Unificación de todas las fuerzas políticas de la España nacional en un partido único bajo su mando: Falange Española Tradicionalista y de las JONS. Ello repercutió en todos los niveles de la vida tanto cotidiana como política y militar. En los tebeos para niños tuvo un reflejo sesgado, pues elevaron aún más el maniqueísmo y la beligerancia de sus contenidos, especialmente Pelayos. Toda la prensa, incluidos los dos tebeos, funcionaron a partir de entonces como una enorme caja de resonancia de las virtudes personales y militares, de Franco, convertido en Generalísimo de todos los ejércitos, jefe del Estado de la Nueva España, jefe del Partido Único y cabeza visible de todo poder.

\section{LOS TEBEOS REPUBLICANOS EN 1937}

En la España republicana se mantuvo la edición de tebeos como un entretenimiento para los niños. En ningún momento intentaron utilizar las publicaciones que tenían a su disposición para hacer propaganda, ello aparte de que varios comités que controlaban las editoriales de tebeos estaban infiltrados por gente afín a los patronos. Algunos de estos tebeos, debido a los problemas de materias primas, tuvieron que reducir páginas, utilizar papeles de peor calidad, suprimir color, disminuir tamaños, etc., problema que se acrecentó al año siguiente. En 1937 la Editorial Marco dejó de publicar sus tebeos. En ese mismo año aparecieron nuevos títulos, algunos en catalán y uno de ellos bilingüe: Estel, Mirbal, Pervenir y Porvenir, este úlñtimo con ediciones, en castellano y en catalán. Además comenzó a publicarse La Vanguardia de los Niños, suplemento del diario La Vanguardia, y YO, distribuido por la Sociedad General Española de Librería.
En los tebeos de Hispano Americana de Ediciones, Buigas y El Gato Negro, la guerra no repercutió en sus contenidos, fuera de algunas historietas burlescas, realizadas por Niel para Pulgarcito, en las que Stan Laurel y Oliver Hardy se veían convertidos en milicianos que luchaban con los moros de Franco. Entre los tebeos de tipo popular, solo Pocholo, publicado por "CAM Empresa Colectivizada CNT", sacó una serie de corte propagandístico, titulada "El pueblo en armas. Escenas de la revolución y la lucha antifascista", dibujada por Sacha.

El aspecto más interesante de la propaganda política en la historieta radicó en los materiales que se publicaron en las revistas de humor para adultos: L'Esquella de la Torratxa, Barcelona, La Traca, Valencia, No veas, Madrid. Y en la utilización específica del medio en la prensa de trincheras para los soldados, con pretensiones tanto educativas como satíricas del enemigo. En esta prensa para adultos se puede hablar concretamente de historieta política. L'Esquella de la Torratxa destacó por sus textos, pero más y mejor por sus ilustraciones, chistes gráficos, historietas y hasta recortables. En su primera etapa, 1936, los dibujantes que formaron la primera línea en esta guerra fueron Altimira, J osé Escobar, que ya se había hecho un nombre como historietista en Pulgarcito y en Pocholo, Goñi, Martí Bas, etc. Pero fue en La Traca donde se alcanzó el máximo nivel político gracias al trabajo combinado de Palmer (Enrique Pertegás), Juan Pérez del Muro, Bluff (Gómez Carreras), Carnicero, etc., quienes dirigían constantes y agudos ataques a Franco, Mola, Queipo de Llano, Hitler, Mussolini, el Comité de No Intervención, etc. La revista No Veas, dirigida por el extraordinario dibujante, ilustrador y cartelista Bardasano, fue la que ofreció menos historietas.

Durante la guerra civil y en el territorio de la República tan solo se publicaron dos tebeos beligerantes dirigidos a los niños. El Pionero, editado en 1937 por el Partido Comunista del País Vasco en el que colaboraron, entre otros, Ugarte y José Arrué, llegándose a dibujar un Popeye apócrifo que luchaba por la causa de la República. Este tebeo, bastante correcto teniendo en cuenta las circunstancias, dejó de publicarse al caer Bilbao en poder del ejército franquista y las fuerzas italianas. Por otra parte y en la primavera de 1937, la organización Juventud Comunista Ibérica, que dependía del POUM (Partido Obrero de Unificación Marxista) publicó la revista infantil Pionero Rojo, con algunas historietas anónimas cercanas al "realismo socialista" y con ilustraciones, chistes y textos acordes con su subtítulo de 
Semanario de los niños obreros y campesinos. Ambos títulos fueron significativamente rechazados desde la propia izquierda por los pedagogos, debido a que sus contenidos se consideraron inadecuados para los niños.

Como resumen de esta rápida revisión de las historietas republicanas de 1937, destracaremos los dibujantes J osé Escobar, Martí Bas, Bofarull, Ernest Guasp, Goñi, J osé Renau, Bardasano, Nyerra (Enric Clusellas), Subirats, Bluff (Gómez Carreras), Salvador Bartolozzi, Sancha, Castelao, Yes, Kalders, Alloza, Fontseré, Ley (Soriano Izquierdo), Desiderio Babiano, Altimira. Lola Anglada, Juez, Puyol, Pitti Bartolozzi, Tísner (Avel.lí Artís Gener), Narro, Tona, Antoni Clavé, Porta, Martínez de León, Castillo Canedo, Rivero Gil, Becquer, Sim, Bagaría, Echea, Emilio Boix, Sacha, Cabrero Arnal, Niel, Batlle, Moreno, y un larguísimo etcétera. No todos realizaron historietas, pero todos pusieron su dibujo al servicio de la República en guerra.

\section{LoS Últimos teBEOS DE LA GUERRA DE PAPEL, 1938}

En 1938 se habían liquidado prácticamente los intentos de publicar cómic político en el bando republicano. En Barcelona, ciudad frecuentemente bombardeada, solo algunos editores continuaron publicando sus tebeos, cada vez en peor papel, con tiradas más cortas y con una difusión limitada a su propio ámbito geográfico. Aquel año los recursos disminuyeron drásticamente, sobre todo en una industria que no era estratégicamente útil para la guerra, y los editores encontraron dificultades para conseguir papel. El mercado se contrajo hasta el punto que hay que preguntarse qué lógica podía mover a seguir editando para un territorio tan pequeño.

Por el contrario, en la España de Franco la vida diaria era más fácil, tanto por el control que los sublevados habían logrado de las mayores regiones cerealísticas como por las posibilidades de un abastecimiento exterior a través de Alemania e Italia. En febrero de 1938 apareció Chicos, un nuevo tebeo fruto de la iniciativa personal del empresario Juan Baygual y de su directora Consuelo Gil Roësset (imagen 15). Las publicaciones gozaron de todo tipo de facilidades materiales y progresivamente mejoraron técnicamente. En paralelo aumentó el control del Estado sobre la edición, facilitado por la Ley de Prensa de abril 1938 que Serrano Suñer, ministro del Interior, había promulgado para someter la prensa de los distintos partidos y ponerla al servicio del
Estado. En el otoño de 1938, una Orden del Servicio Nacional de Prensa forzó a las revistas Pelayos y Flecha a unificarse y a depender directamente de la Delegación Nacional de Prensa y Propaganda de FET y de las JONS. En diciembre de 1938 apareció la nueva revista Flechas y Pelayos, dirigida por Fray Justo Pérez de Urbel, monje benedictino, que por entonces era asesor religioso de la Sección Femenina de FET y de las JONS. Con los mismos criterios, en noviembre de 1938 la Delegación Nacional se había incautado de Chicos, su propietario recibió una parca indemnización y se confirmó a Consuelo Gil en la dirección del tebeo.

Hasta finales de 1938 los hermanos Bruguera, a cuyas manos había vuelto el año anterior el control de El Gato Negro, probaron toda clase de formatos, utilizaron papel de ínfima calidad, redujeron los tamaños y el número de páginas y, sobre todo, imprimieron casi únicamente materiales de archivo. Todo ello y el hecho de que, desde abril de 1938, lo posibles compradores habían quedado reducidos al territorio de Gerona, Barcelona y Tarragona, obliga a preguntarse por qué y para quién editaban o si lo hacían únicamente para mantener la empresa en marcha y permanecer en el mercado, pese a las dificultades. Los tebeos de Hispano Americana de Ediciones redujeron su gran tamaño y también utilizaron papel de bajísima calidad, pero continuaron editando cómics americanos pese a que la situación de guerra debería hacer imposible la compra de los materiales extranjeros. A finales de diciembre de 1938, un mes antes de que la ciudad cayera, se editaron en Barcelona los últimos números de Pulgarcito, En Patufet, Yumbo, Aventurero y la Revista de Tim Tyler. Serían los últimos tebeos republicanos ${ }^{14}$.

\section{TebeOS EN LOS AÑOS DE PLOMO DEL FRANQUISMO, 1939-1946}

Cuando hacemos historia y no recuerdo sentimental, hemos de hablar de la larga década en que la guerra se prolongó en el destierro, la cárcel y la muerte violenta en una permanente represión. Nunca se repetirá bastante cómo los años cuarenta estuvieron bajo el signo de la crueldad. Se padecía hambre y frío, faltaban electricidad, transportes, medicinas, dinero. Y el trabajo era incierto. Pero lo peor, lo que rompía las voluntades era el miedo permanente y la alternativa " 0 nosotros o la guerra civil". Los editores que llegaron a Madrid y a Barcelona incrustados en los ejércitos de Franco 


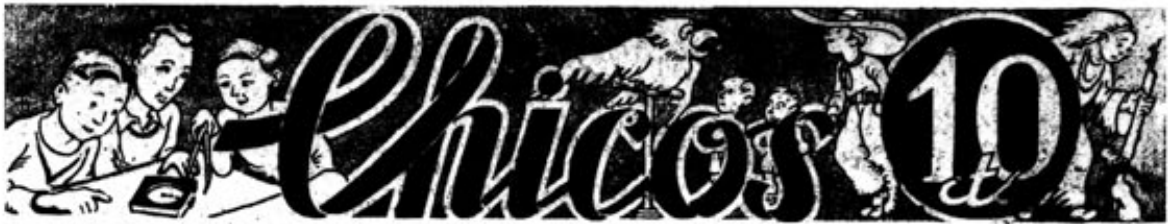

An० I - No I

II AAO TRIUNFAL

23 d6 F Finoro do tose

REDACCION 'Y ADMINIBTAACION: BAN FRANCIBCO, 10, 4. - SAN SEBABTÍAN
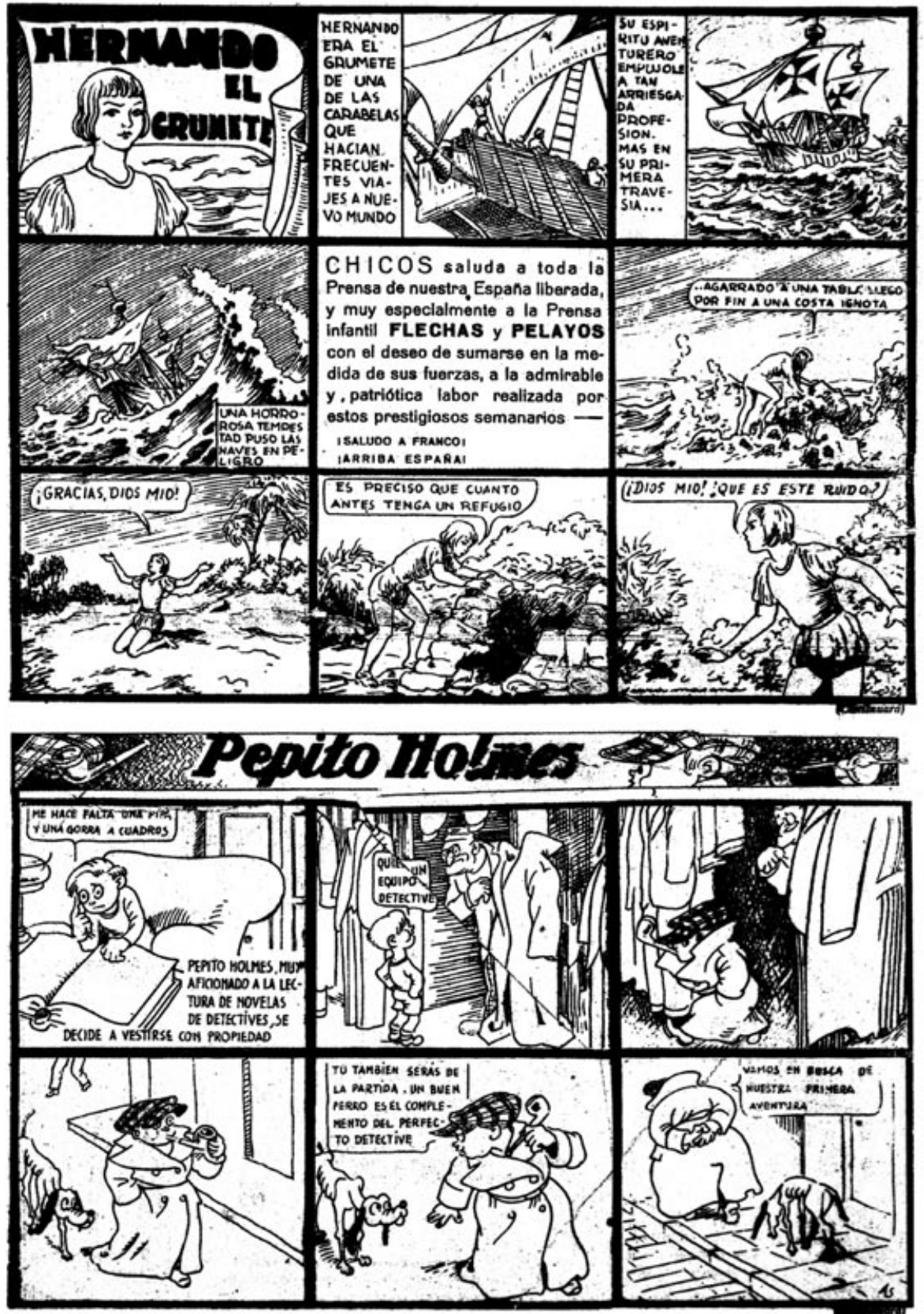

Imagen 15 
reclamaron y consiguieron una parte del botín, como vencedores. Algunos ya eran parte del sistema durante la guerra como directores de los tebeos propiedad de la Delegación de Prensa y Propaganda de FET y de las JONS y se limitaron a seguir publicando los que ya editaban en San Sebastián. Es el caso de Fray Justo Pérez de Urbel con Flechas y Pelayos y de Consuelo Gil Roësset con Chicos. Otros fueron dibujantes que colaboraron en la guerra de papel de la propaganda, por lo que su fidelidad fue recompensada. Los vencedores obtuvieron todo lo que pidieron y todas las ayudas legales y materiales que el nuevo régimen podía otorgarles.

Aparte, como una nueva clase de apestados, quedaron los editores que no estuvieron en las filas de los vencedores y siguieron editando en Barcelona. Lo que importaba al régimen es que continuaron editando sus tebeos durante la guerra. Y por ello fueron automáticamente metidos en el saco de los perdedores. Del que solo podían salir los que conseguían avales políticos y los que testificaban su fidelidad al nuevo régimen y a Franco. Entre los editores "republicanos", "no afectos al régimen", "catalanistas" o tan solo políticamente "tibios", estaban los hermanos Bruguera, Tomás Marco, José Baguñá, Germán Plaza, Joaquín Buigas, Enrique Guerri. Pero, más que rojos o republicanos, eran empresarios que querían continuar con su negocio, y por ello, recién acabada la guerra, ya estaban planeando cómo rehacer sus empresas y seguir editando.

La Ley de Prensa de 1938 suponía el control total de la prensa, que quedaba sujeta al Estado como un servicio público, incluso en el caso de la prensa propiedad de empresas privadas. La ley establecía la censura previa de todas las publicaciones impresas antes de su difusión. Los directores serían nombrados por el Ministerio de Gobernación y tenían que jurar los principios fundamentales del Movimiento (nombre con el que se había bautizado el conglomerado político surgido de la guerra civil) y ser militantes de Falange Española Tradicionalista y de las JONS.

El control de la prensa por el Estado significaba también el control de las publicaciones infantiles, lo que se confirmó cuando en diciembre de 1940 se promulgó el Decreto por el que la infancia y la juventud españolas pasaban a ser competencia de FET y de las J ONS. De esta forma la realidad editorial se configuró conforme a la superestructura ideológica de los vencedores y fue la vicesecretaría de Educación Popular de FET y de las JONS, y en ella la Delegación
Nacional de Prensa y Propaganda, la que regulaba la aparición de toda la prensa española. También los tebeos.

De acuerdo con la legislación de prensa, se establecieron dos categorías fundamentales para las publicaciones que no fuesen libros. De un lado quedaban las publicaciones periódicas, que se autorizaban como revistas, con título propio, periodicidad fija, fecha de salida, numeración correlativa, y la posibilidad de recibir del Estado cupos de papel "protegido" a precios más baratos que los de mercado. Los permisos de edición de nuevas publicaciones periódicas solo se concedieron a los organismos oficiales y a las empresas que se habían hecho merecedoras de ellos por los servicios prestados durante la guerra. Entre estos se encontraban los tebeos Flechas y Pelayos y Chicos, y los nuevos tebeos que tanto Fray Justo Pérez de Urbel como Consuelo Gil inventaron tras acabar la guerra. También las publicaciones de la Iglesia. Y las de las personas cercanas al régimen, como Teodoro Delgado con la revista- tebeo Leyendas Infantiles (imagen 16). Y en la prensa adulta el caso de Miguel Mihura, con La Codorniz.

Los títulos que no entraban en la categoría de publicaciones periódicas se podrían autorizar como publicaciones unitarias o folletos, pero para ello tenían que renovar el permiso de edición número a número, cada vez con un título diferente, no tenían periodicidad fija ni numeración y debían comprar el papel a los precios de mercado. Entre 1939 y 1951 solo se autorizaron con la categoría de prensa periódica las siguientes revistas infantiles y tebeos: Flechas y Pelayos, Maravillas y Biblioteca Maravillas y más tarde Clarín, todas bajo la férula de Fray Justo Pérez de Urbel, Chicos, Mis Chicas, Chiquitito y El Gran Chicos controlados por Consuelo Gil Roësset, Pepe y Mari dirigido por Maruchi de la Mora de la Sección Femenina, Bazar de la Sección Femenina de FET y de las JONS, iZás! y Trampolín de Acción Católica, Leyendas Infantiles de Teodoro Delgado, Junior Films de Baguña Hnos., editado gracias a la relación de Jaime Baguña con Chamartin Films, y algún título más de carácter religioso o político, además de varios suplementos infantiles de la Prensa del Movimiento como Peques, Pituso, Chaveas, Chaval, El Peque, Hoja del recreo, Centurias, etc.

Los procesos de autorización fueron muy poco trasparentes. Una de las múltiples causas era que el interdicto impuesto en beneficio de la exclusividad de la prensa infantil cercana al régimen, pasaba por la decisión última de Fray J usto Pérez de Urbel, quien hizo lo posible para que 


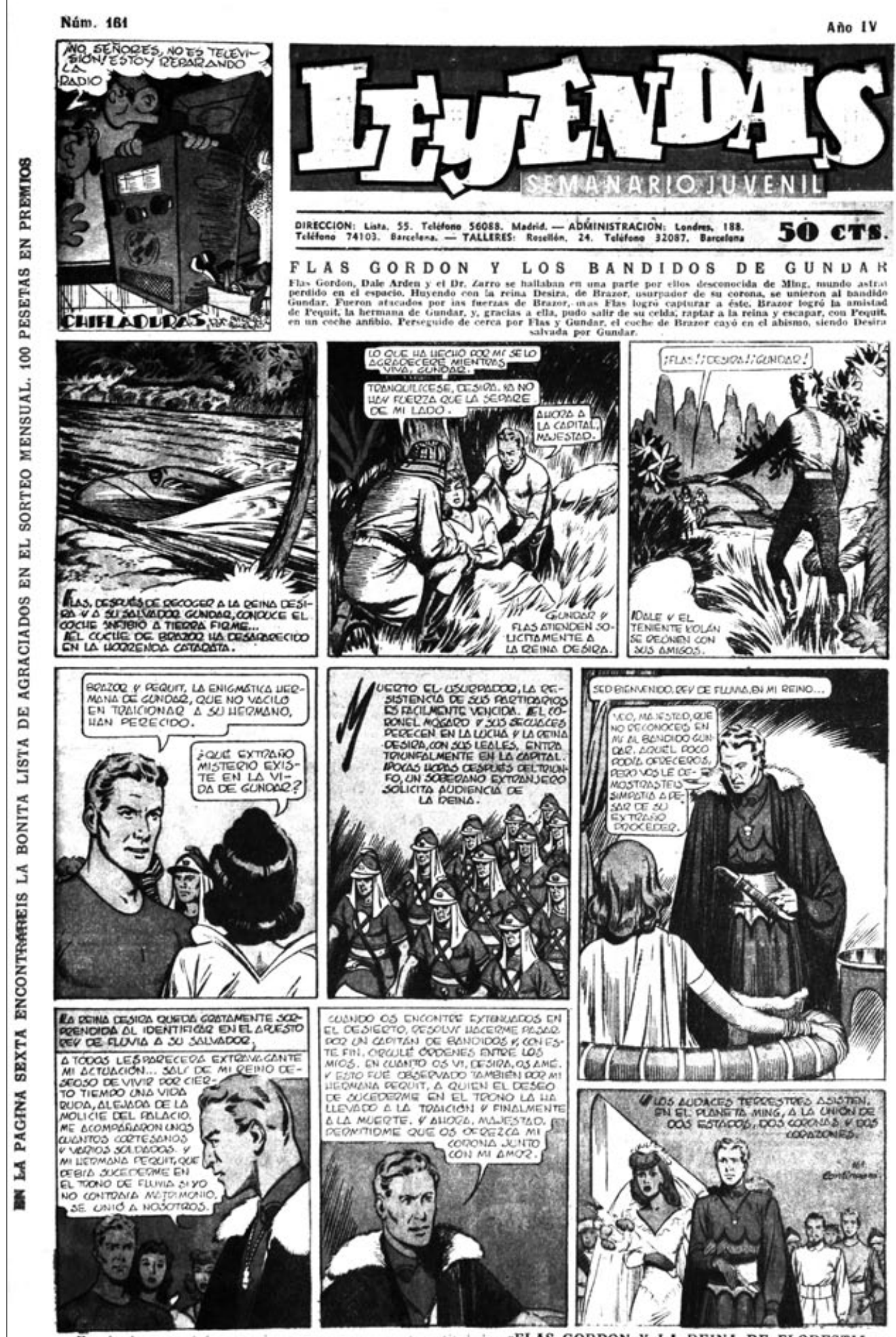

En el némero próximo comienza una nueva aventusa tituiadas tFLAS GORDON Y LA REINA DE FLORESTIAs 
en la etapa 1939-1945 se restringiese la autorización de nuevos títulos de revistas de historietas y así reducir la competencia con Flechas y Pelayos.

\section{LOS EDITORES COMERCIALES ANTE LAS NUEVAS REGLAS DEL JUEGO}

Los primeros pasos seguros los dieron los empresarios que mejor se adaptaron a los nuevos tiempos, los que supieron burlar los límites marcados por el régimen, los que contaban con mayores recursos económicos y los que supieron cómo estructurar sus empresas para obtener los mayores beneficios: Editorial Marco, J oaquín Buigas, Hispano Americana de Ediciones, Editorial Bruguera y Editorial Valenciana. Estas empresas estuvieron en la base de la industria de la historieta española y generaron un frágil tejido industrial que soportó durante años la edición de tebeos, con diversos resultados. Otras editoriales, que publicaron tebeos durante estos primeros años, como Ameller, Rialto, Publicaciones Cinema-Editorial Grafidea, hicieron aportaciones interesantes y alguna prolongó su actividad durante décadas, en una larga decadencia. Y en menor grado las editoriales Marisal, SGEL, Germán Plaza y Proa, algunos de las cuales crecerían posteriormente, y algunos editores mínimos, oportunistas, como Esteller, Iberia, España, Aguilar, etc.

De forma similar a lo ocurrido en los años veinte, aunque ahora por razones bien diversas, fueron muchos los impresores y los pequeños empresarios que quisieron invertir en el negocio de los tebeos. Los años cuarenta fue un tiempo confuso en el que, junto a los empresarios de siempre, surgieron numerosos editores casuales que pensaban hacer negocio con una inversión mínima, mal pagando a un dibujante, editores que no preveían la carga de la distribución y aún menos lo que suponía el publicar con continuidad. Es así como en los años cuarenta y cincuenta se contabilizaron docenas de editores sin continuidad, que contribuyeron a la fragilidad del tejido industrial de la edición de historietas en España.

Los editores hicieron pruebas con diversos formatos para tantear el mercado. A los graves problemas económicos se sumó el desconcierto que provocaba la política oficial de autorizaciones de nuevas publicaciones. Al no poder editar con periodicidad y tener que solicitar el permiso de edición número por número, tuvieron que buscar soluciones alternativas. Se trataba de encontrar el cómo, respetando la letra de la ley, se podían editar unos tebeos que los lectores pudiesen identificar e individualizar del resto de publicaciones existentes en el quiosco. De esta forma, en los primerísimos años cuarenta, se "redescubrió" el modelo editorial del cuaderno de historietas, cuyos precedentes estaban en los cuadernos publicados en los años veinte por Heras, Buigas, El Gato Negro y otros editores. En términos editoriales el cuaderno de historietas, de contenido monográfico, se ajustaba perfectamente al concepto de folleto previsto por la Ley de Prensa, ya que fuera cual fuera su contenido y tanto si formaba parte de una colección o no, se podía destacar de forma llamativa el título del episodio que se publicaba en cada cuaderno. El nombre o título de colección quedaba relegado a un segundo término, en letras más pequeñas, los cuadernos no se numeraban o se hacía con una tipografía pequeña en la contracubierta.

Pura picaresca que contentaba a los funcionarios, permitía al editor publicar y facilitaba a los niños la identificación de su tebeo. La solución era absolutamente inestable y siempre sujeta a las decisiones de las delegaciones provinciales de la Vicesecretaría de Falange. Adoptado como la solución menos mala, el modelo del cuaderno de historietas, constituyó en términos comerciales y durante casi dos décadas la principal fuente de ingresos de los editores españoles de tebeos. Dos empresas radicalmente contrapuestas fueron las primeras que en el mismo año 1939 comenzaron a editar cuadernos de historietas: la Editorial Española de mosén Rosell y El Gato Negro de los hermanos Bruguera. Inmediatamente, en 1940, media docena de editores más se lanzaron a publicar este modelo de tebeo que para 1946 se convertiría en una auténtica avalancha de títulos, en manos de las treinta editoriales que para entonces ya funcionaban a pleno rendimiento.

La Editorial Española, creada en San Sebastián cuando la guerra daba sus últimos coletazos, sirvió de puente entre los años de la guerra civil y los de la posguerra. El permiso para crear esta editorial, en 1939, fue una especie de pago a mosén Rosell, hombre fuerte de la revista Pelayos, en compensación por la incautación de esta. La producción de la Editorial Española, en la que Rosell se asoció con el impresor barcelonés Mariano Blasi, se centró en una serie de cuadernos apaisados, precisamente para evitar todo problema con la administración del Estado, además de postales y de 
varios cuadernos coloreables, dibujados por Castanys bajo el título común de Álbum infantil para colorear motivos bélicos, alusivos a la guerra recién acabada. El mismo año la editorial ya estaba instalada en Barcelona y a resultas de la entrada de Aguilar, gerente de la distribuidora cinematográfica Nueva Universal, cambió su nombre por el de Publicaciones Cinema. Con este nombre comenzó a editar tebeos monográficos como La epopeya de Sagunto, El vampiro polar y la colección de cuadernos apaisados Bravo Español.

\section{De El Gato Negro a la Editorial Bruguera}

Con unos meses de diferencia, también en 1939, El Gato Negro retomó la edición. Pantaleón y Francisco Bruguera habían seguido editando hasta los últimos momentos de la guerra y, tras finalizar esta, el mismo año 1939, publicaron diversos tebeos en números únicos, realizados siempre a partir de viejos materiales. El primer tebeo localizado, aunque pueden aparecer otros, es Historietas para niños y niñas, un cuaderno de formato cuadrado, con cubierta impresa a dos tintas con un dibujo de Salvador Mestres, 16 páginas interiores impresas en negro con historietas dibujadas en su totalidad por Urda, procedentes del Pulgarcito de anteguerra y, como colofón en contracubierta el dibujo de la cara de un niño sonriente impresa a dos tintas, donde figuraba como único pie editorial: A.G. "El Gato Negro". Durán y Borrell, 16. Barcelona. El precio de 25 céntimos iba sellado con tampón en la cubierta. Un paso siguiente es el número único, en formato vertical, Número Almanaque Infantil año 1940, en cuya cubierta impresa a tres tintas se veía un tranvía cargado de niños dibujado por Ormes (Salvador Mestres), con 16 páginas más cubiertas y precio de cubierta de 40 céntimos. En contracubierta llevaba el viejo logotipo: el gato negro con chaqué y sombrero de copa en la mano izquierda mientras que en la derecha sujeta una pluma de ave y el texto: "Editorial El Gato Negro. Barcelona. Fundador Juan Bruguera".

El baile de referencias en los pies editoriales señala que no sabían muy bien qué editar y cómo. Lo confirma el tercer ejemplar que documentamos. Se trata de un tebeo vertical de contenidos variados, Aventuras de Pulgarcito, con cubierta de fea cartulina gris con el dibujo de un niño vestido de cowboy que monta un caballo, lo firma Ormes, el precio 50 céntimos, 16 páginas de viejos materiales reciclados y en contracubierta un anuncio de la colección
Tesoro de Cuentos Infantiles a toda página. Y lo importante es que no lleva ningún pie editorial. Este fue el momento, entre los meses finales de 1939 y los primeros de 1940, en el que los hermanos Bruguera, movidos sin duda por el cúmulo de circunstancias sobrevenidas desde que Barcelona se había convertido en ciudad conquistada y convencidos de que a la larga la marca El Gato Negro había de producirles más problemas que beneficios, decidieron cambiar el nombre por el de Editorial Bruguera.

El cambio de marca se documenta con la que fue la primera colección de cuadernos de historietas. En 1939 Francisco Bruguera retomó el título de los años de guerra Miniaturas y creó la colección Miniaturas de cuadernos de historietas, tamaño $7 \times 6 \mathrm{~cm}$, con 16 páginas impresas a todo color. Para crear cada tebeo, Francisco Bruguera tomaba una historieta del archivo y convertía cada una de las viñetas en una de las minúsculas páginas del nuevo tebeo. La colección Miniaturas tuvo dos series: la de Bobito, con dibujos de Niel tomados de las historietas publicadas en el tebeo Bobín de 1930 y la de Mari-Pili y Toni, con dibujos de Salvador Mestres, tomados del tebeo La Alegría Infantil-Shirley Temple, 1930, transformando a Shirley Temple en Mari- Pili. En la cabecera de todas las cubiertas aparecía impresa una línea con la mención: Editorial "El Gato Negro" Barcelona. Cuando aún no habían publicado una docena de títulos, a principios de 1940, los hermanos Bruguera decidieron cambiar el nombre de la empresa. Fue así como se publicaron tres nuevas series de la colección Miniaturas, con las mismas características de los números anteriores, pero con las nuevas series Morrofino y Rabilinda, Orejitas y Piruja y Guau Guau y Ricitos, con dibujos de Bataller. En cubierta de cada número aparecía destacadamente Editorial Bruguera. El Gato Negro había desaparecido.

\section{EL CUADERNO DE HISTORIETAS, RECURSO Y NEGOCIO}

Los editores comerciales de Barcelona optaron por dedicarse a la publicación de cuadernos de historietas, a la espera de tiempos mejores. Los primeros fueron Editorial Grafidea, continuando las colecciones de Publicaciones Cinema, Editorial Bruguera, Hispano Americana de Ediciones, Marco y Editorial Valenciana. Con una única variación en su formato, que podía ser apaisado, el más frecuente y abundante, o vertical, podemos agrupar las múltiples colecciones que comenzaron a editarse en 1940 en dos 
categorías absolutamente convencionales, derivadas de su tamaño, que llamaremos: Cuadernos Grandes, con unas medidas aproximadas de $24 \times 34 \mathrm{~cm}$, que posteriormente se ajustaron a $21,5 \times 31,5 \mathrm{~cm}$ para aprovechar el papel y la entrada en máquina. Y Cuadernos Pequeños, con medidas de $17 \times 24,5 \mathrm{~cm}$. Estas medidas se reajustaron según las editoriales y en función del papel utilizado y las máquinas de imprimir de que disponían. Inicialmente y durante buena parte de los años cuarenta coexistieron los dos tamaños. Aceptado a nivel oficial, el modelo del cuaderno de historietas constituyó la principal fuente de ingresos de los editores españoles de tebeos.

Entre 1939 y 1943 lo común fue que los cuadernos tuviesen ocho páginas de historietas impresas en negro, más cuatro de cubiertas en papel de mayor gramaje, impresas en color con el dorso en blanco. El cuaderno se encuadernaba con una grapa a caballete, pudiendo ir guillotinado o no según los editores. El resultado de estos primeros cuadernos, en los que se intentaba meter el máximo posible de viñetas por página, fue casi siempre mediocre. El conjunto final presentaba dibujos muchas veces minúsculos y textos superabundantes. Los dibujantes habían de pelear con los excesos de texto, atender las imposiciones de los editores y a su propia concepción de la historia para lograr planificarla correctamente, dibujarla atractivamente y procurar que por los resultados les encargasen dibujar otro cuaderno.

Publicaciones Cinema editó pocos tebeos con esta marca: La epopeya de Sagunto, El vampiro polar y la colección de cuadernos apaisados Bravo Español. Suyo fue el mérito de "descubrir" al gran dibujante Lozano Olivares. Poco más tarde, al entrar nuevos socios en la empresa, adoptó el nombre de Editorial Grafidea y como tal publicó durante años muchos cuadernos de historietas. Editorial Marco se hizo presente inmediatamente en el mercado de posguerra y probó a sacar su revista de anteguerra La Risa Infantil. Pero pronto hubo de cortar la edición y centrarse en los cuadernos de historietas, de los que en los primerísimos años cuarenta publicó la gran colección Aventuras Gráficas con varias series como Los Broncos, César el Hombre Relámpago, Jaime Bazán, Lucio Crin, Javier Montana, etc., la colección Los Vampiros del aire, así como números monográficos. Después lanzó la colección Acrobática Infantil, con series de humor que se hicieron famosas en los años cuarenta, como Hipo, Monito y Fifí, Pirulo y Tontolote, Rabanito y Cebollita y también la colección Pipa, protagonizada por los detectives Cartapacio y Seguidilla. Todas dibujadas por Emilio Boix.

La editorial Hispano Americana de Ediciones estuvo dirigida después de la guerra por Lotario Vecchi y su primo Otelo Parenti, a quien nombró apoderado debido a que Vecchi viajaba a menudo para supervisar la marcha de sus restantes editoriales europeas. Hispano Americana lanzó en 1940 la colección Las Grandes Aventuras, que publicó sendas adaptaciones en historieta de Don Quijote y de la historia de Cristóbal Colón, para dar una imagen positiva de la editorial, según la cual esta ofrecería "[...] las gloriosas hazañas de los grandes conquistadores españoles, que con su bravura e inteligencia difundieron la cultura y la civilización hispana [...]". En el mismo año publicó la colección Audaz, cuya primera y más importante serie fue la de Juan Centella, castellanización de la serie Dick Fulmine de la Italia fascista, 1940, la colección Aventuras y Misterio, con series como la de Ciclón el Superhombre que no era otro que el Superman o los cuadernos de Jorge y Fernando (Tim Tyler's Luck).

La editorial basó su economía en reciclar los materiales de los cómics americanos, publicados en los años treinta, en grandes cuadernos de historietas. El formato apaisado obligó a hacer penosos remontajes con retoques del dibujo y añadidos llevados a cabo por dibujantes españoles, que también dibujaron las cubiertas. Se rompía así la puesta en página y el ritmo narrativo de los autores americanos, además muchas de las viñetas llevaban más dibujo añadido que original para encajarlas en el nuevo formato y para evitar cuanto pudiese rozar la moral, y ello incluía hasta una pareja besándose. Por otra parte, Hispano Americana de Ediciones buscó nuevos dibujantes para multiplicar sus ediciones, así dio trabajo a Sabatés, Bataller, Pedro Alférez, Torrent, F. Molina, R. Beyloc, Jiménez Arnalot, Ardel, Manuel Vázquez y a otros muchos.

Editorial Valenciana, que antes de la guerra había publicado solamente libros y folletines, se introdujo en el mercado del tebeo en los años cuarenta y a lo largo de la década logró ser una de las editoriales más importantes comercialmente. En 1940 lanzó la colección Selección Aventurera, con muchos números únicos de contenido monográfico como "El Buque maldito", "Harka", "La conquista de un reino," "El abanderado", etc. La colección Aventuras Cómicas tuvo algunos de los primeros cuadernos dirigidos al público 
femenino, todo en 1941. Su gran lanzamiento de este mismo año fue la colección de cuadernos de historietas policíacas Roberto Alcázar, que más tarde llevaría el subtítulo de Roberto Alcázar y Pedrín (imagen 17). Esta colección exige un estudio que permita comprender su enorme éxito pese a los mediocres dibujos de Eduardo Vañó y los endebles guiones de sus varios escritores. En 1943, Editorial Valenciana publicó al gunas de sus colecciones de cuadernos míticas de los años cuarenta: El Capitán Maravillas, El misterioso Doctor Satán, Los tambores de Fu-Manchú.

Por su parte, Editorial Bruguera, tras su iniciación con los pequeños cuadernitos de la colección Miniaturas, diversificó sus acciones en todos los campos de la edición popular: Cuentos en distintos formatos y precios, como la colección Infancia, novelas, tebeos encuadernados en formato libro de tapa dura con historietas con textos al pie de las viñetas, como la colección Música de Risas, coloreables como la colección Colorín pinta, recortables, como la colección Para Ti, cromos, como la colección de Cromos Cultura, libros pedagógicos como la Colección Parvulino y cuadernos de historietas, como colección Cine Cómico, Sensacionales aventuras de Bala Certera, colección Querubín, colección Alegría Infantil, todas de 1942. Y las siguientes colección Cine Aventuras y colección Gente Menuda.

\section{LOS EDITORES DEL RÉGIMEN EN LOS PRIMEROS AÑOS CUARENTA}

En 1939, finalizada la guerra civil, Fray Pérez de Urbel creó una nueva revista, Maravillas, que apareció como suplemento de Flechas y Pelayos. Su propósito era el de ser "[...] la biblioteca en la que encontraréis las grandes revelaciones, las grandes sorpresas, los grandes tesoros con que un niño español debe enriquecer su espíritu [...]", para ello dedicó la mayor parte de sus páginas a publicar relatos literarios, cuentos, reportajes y otras secciones de texto, que venían complementadas por algunas historietas.

Pese a que Flechas y Pelayos se autonombraba "Semanario Nacional" y en su cubierta campeaba el lema "Por el Imperio hacia Dios", no podemos calificarla como una

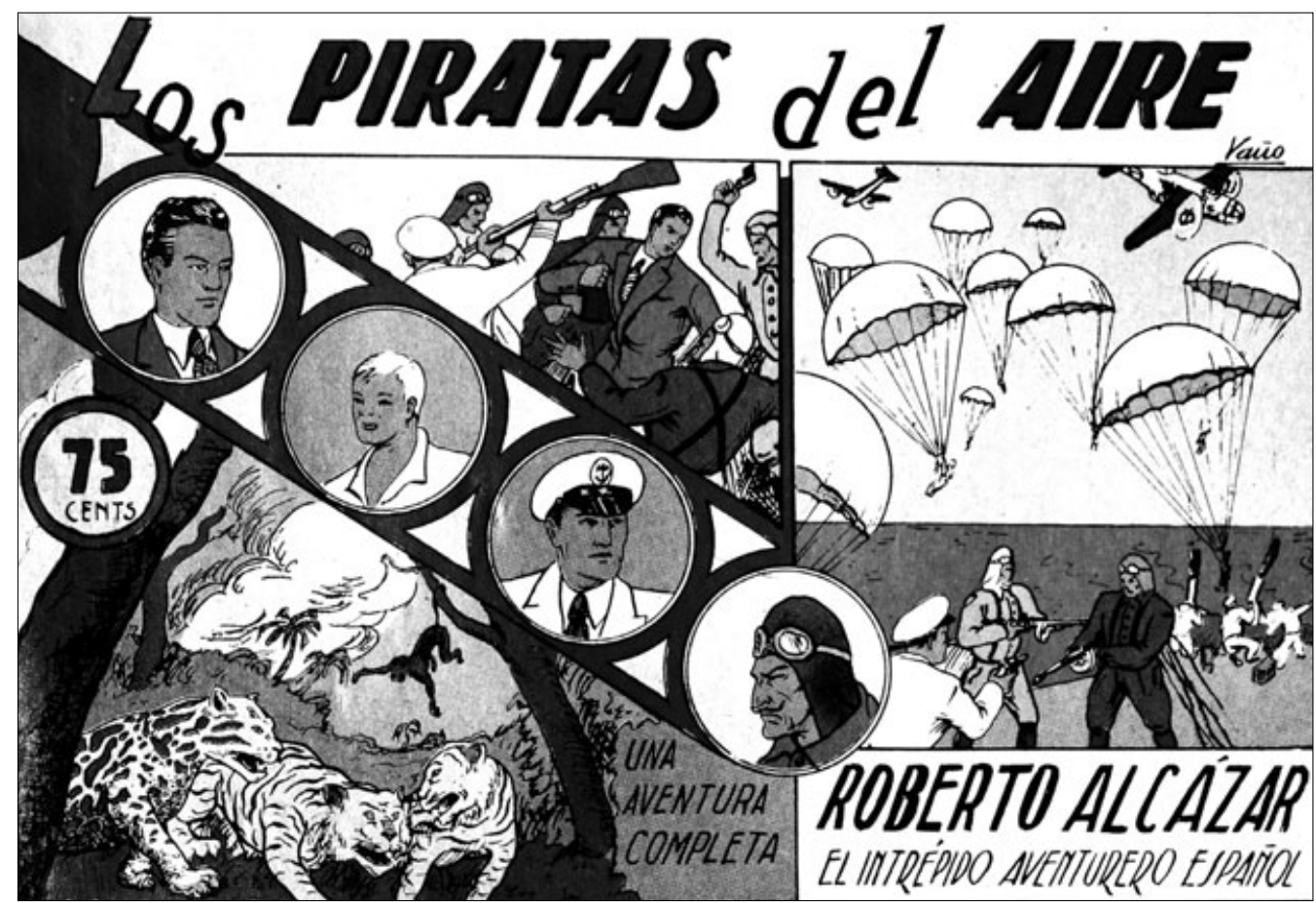

Imagen 17 . 
auténtica revista de "agit-prop" dirigida a la captación de los niños. Lo cierto es que esta revista se difundía básicamente por los canales oficiales, entre los niños convencidos del Frente de Juventudes 0 entre quienes se afiliaban al mismo para conseguir unas botas y comida gratis, mientras que en el quiosco se vendía mal. Flechas y Pelayos y Maravillas acabaron por caer en la burocratización del Movimiento, que convirtió a los militantes en funcionarios. Y estas revistas se convirtieron en un pequeño negocio editorial, cuyo posible déficit cubrían los presupuestos oficiales de manera que los beneficios se convertían en un dinero seguro para sus gestores. Nada que ver con la extrema beligerancia de Flecha 0 con la sordidez panfletaria de Pelayos durante la guerra civil.

Pérez de Urbel y su equipo hicieron evolucionar las revistas $y$, ante la fuerte competencia de los tebeos comerciales, aumentaron su carácter recreativo a costa del doctrinal. Como la revista tenía garantizada la continuidad, pudo mantener también la periodicidad y el número de páginas, salvo en momentos excepcionales. Gracias a ello ofrecía abundante trabajo, barato y muchas veces pagado sin puntualidad, que atrajo a un gran número de colaboradores, sobre todo los residentes en Madrid. Ejercieron de guionistas y colaboradores literarios de Flechas y Pelayos el propio Pérez de Urbel, Pilar Valle, Gloria Fuertes, Carmen Martel, Emilia Cotarelo y otros más que nos han quedado anónimos. Entre los dibujantes podemos citar a Avelino Aróztegui, Penagos, Soravilla, Pena (Pedro Naval), Ardel (Juan Ernesto Vinardell), María Claret, Gabi (Gabriel Arnao), José Luis M oro, Alcaide, Santi, Titos, Mayo, Ángel Esteban y también Escudero, Senén, Manuel Zatarain, Cuesta, Celedonio Perellón, Tilu, Marculeta con varios seudónimos, Ángel Pardo, Carbonell, Vicente Roso, Ibarra, Luis Vigil, Huete, J osé y Carlos Laffond, Gordillo, etc. Con colaboraciones puntuales y breves de los dibujantes Manuel Gago, Antonio Hernández Palacios, Víctor de la Fuente y Manuel Vázquez.

Caso aparte fue el de Chicos, que fue una gran revista de historietas gracias a los excelentes colaboradores y a la capacidad de su directora para seleccionarlos y saber equilibrar los contenidos. Consuelo Gil Roësset, de familia acomodada radicada en Madrid, tuvo una educación selecta, en su infancia y juventud escribía, tomó lecciones de dibujo del pintor López Mezquita, de ella se conservan varios libros de cuentos infantiles, en la universidad fue alumna y después discípula de Pedro Sainz Rodríguez. En los años treinta formaba parte de la buena sociedad madrileña, y en la guerra civil y la posguerra se mostró como una gran dama de la derecha más civilizada de aquellos años. En 1941 Consuelo Gil disminuyó el tamaño de la revista Chicos y con el "recorte" obtenido, una simple franja apaisada de papel, creó la revista para niñas Mis Chicas, que tenía un tamaño fuera de lo habitual y que después aumentó considerablemente. Fue esta la primera revista infantil femenina de contenido variado publicada en la posguerra y su ejemplo despertó el interés de otros editores que seguirían el camino abierto con una gran cantidad de cuadernos de historietas, en formato apaisado, de tema sentimental.

El gran acierto de Consuelo Gil fue buscar a los mejores dibujantes españoles, como Jesús Blasco y Emilio Freixas, y abrir las puertas de sus revistas a nuevos autores que comenzaban por entonces, Ángel Puigmiquel, Alfonso Figueras, Pilar Blasco, Carlos Roca, Gabi (Gabriel Arnao), Iranzo, etc., así como la captación de algunos de los más importantes artistas portugueses como fue E. T. Coelho. Todo ello ejerciendo con mano firme y conocimiento exacto de lo que quería lograr como directora.

Jesús Blasco, tras varias historietas de continuará, realizadas con una alta calidad, se centró en su personaje Cuto, del que dejó en Chicos (imagen 18) historietas de gran nivel como "Tragedia en Oriente, Cuto en el país de los sioux" hasta la magistral, contradictoria y definitiva "Hombres muertos en la isla". También hay que destacar algunas de sus historietas cortas en los almanaques de la revista como "Cuto en Nápoles", "Cuto en el Lago de la Muerte", "Cuto en el Castillo del Terror". Asimismo, la saga de Anita Diminuta, publicada en Mis Chicas a lo largo de casi diez años, que Jesús Blasco realizó en un punto intermedio entre el folclore del cuento popular y las historias de miedo para niños. Por su parte, Emilio Freixas, más ilustrador que historietista, dejó en Chicos obras magníficas como "Desfalco en Wall Street", "El misterio del murciélago humano", "Shadu", "Los dragones del Tibet" y las aventuras del Capitán Misterio. Freixas había comenzado a dibujar para Consuelo Gil poco después de finalizar la guerra civil, movido por el miedo a haberse significado durante la guerra por algunas ilustraciones. El guionista Huertas Ventosa, que tras la guerra trabajaba para Consuelo Gil, le ofreció un guión protagonizado por militares y falangistas uniformados, de manera que la historieta, "La ciudad de las tres murallas", blanquease su imagen. A partir de aquí, Freixas se convirtió en el "otro" dibujante insustituible en Chicos. 
Consuelo Gil Roësset se distinguió por su vocación, su claridad de planteamientos editoriales y su prioridad por lograr publicaciones de calidad. Supo aunar la calidad tradicional madrileña con la popularidad de la historieta más comercial. En su trabajo como editora fue totalmente pragmática, demostrando su habilidad para obtener las mejores condiciones para sus revistas, consiguiendo papel protegido más barato, regateando hasta el último céntimo y llegando a seguir prácticas comerciales no muy ortodoxas para el logro de sus fines. El ejemplo más importante se produjo en 1944, cuando el dibujante Emilio Freixas, de acuerdo con su hijo Carlos, también dibujante, y con Ángel Puigmiquel, decidieron crear la Editorial Mosquito y la colección del mismo nombre de cuadernos de historietas. Su intención era independizarse de Chicos, controlar sus propias creaciones y así recoger el total de los beneficios. Por primera vez en España los dibujantes gestionarían su propia revista y sus propios personajes. El problema surgió cuando los autores-editores

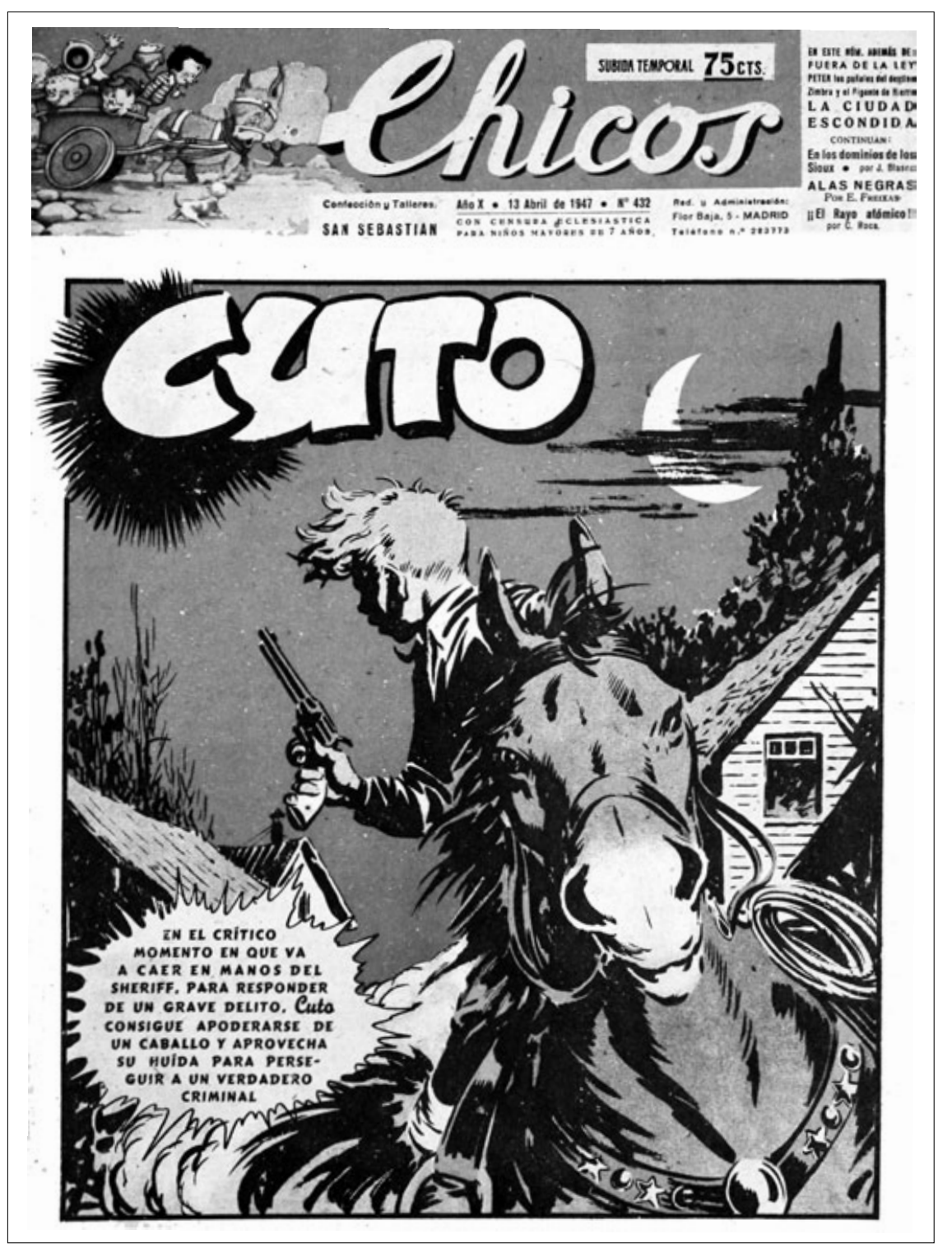

Imagen 18. 
entregaron al distribuidor los cuatro números que llegaron a publicar -protagonizados por El Capitán Misterio de Emilio Freixas, Pepe Carter de Puigmiquel y dos números de Pistol J im de Carlos Freixas-. Consuelo Gil hizo todo lo posible para que la colección no funcionase con la complicidad del distribuidor que era el mismo de sus tebeos. Tras fracasar como editores, los autores volvieron a las páginas de Chicos, con el añadido de que su directora les hizo continuar en su revista los nuevos personajes que habían creado para independizarse.

Quede aquí y ahora el simple apunte de la importancia, menor pero real, que tuvieron en el panorama editorial de los primeros cuarenta las otras revistas publicadas por los editores del régimen: Pepe y Mari, Bazar, iZás!, Trampolín, Leyendas Infantiles, etc.

\section{LOS PRIMEROS EDITORES COMERCIALES DEL MADRID DE POSGUERRA}

Algunos empresarios madrileños se interesaron por el negocio de la edición de tebeos desde fechas muy tempranas. No hay que olvidar que, según las estadísticas, la ciudad de Madrid tenía en 1930 una población de 1.137.943 habitantes, en 1945 había subido a 1.326.674 y para 1950 llegaba a 1.926.311, sin contar la población de su provincia que equivalía a otros tantos habitantes ${ }^{15}$. En este importante aumento de población cuenta tanto la inmigración del campo a la ciudad, que la guerra civil había precipitado, como el aumento de la natalidad que llegó a un 24 por ciento en 1940 y a un 20 por ciento en 1945. Estas cifras significaban muchos niños en edad escolar y aptos para la lectura recreativa, si había quien se la ofreciese. Ante la comprensión de que se encontraban ante un mercado creciente, los nuevos editores, sin formación en ese negocio, no conocían las imprentas, ni contaban con dibujantes, pero estaban dispuestos a ganar dinero, y a seguir el camino de los editores de Barcelona y Valencia. Así, entre 1941, fecha del primer tebeo comercial localizado en Madrid, hasta 1944, surgieron empresas, casi siempre unipersonales, que improvisaron publicaciones, escritores y dibujantes y se lanzaron a la edición de cuadernos de historietas, ante la imposibilidad de publicar revistas regulares.

En 1941, la SGEL, que además de distribuir editaba, lanzó el que creemos primer tebeo comercial publicado en Madrid,
La Corona de Hierro, de la colección Tres Pajaritas, en el clásico formato apaisado, versión de Sabatés de la película del mismo título. En 1942, el mercadol madrileño comenzó a animarse y ofreció una alternativa a los tebeos de Barcelona con editoriales como Marisal, Proa, Editorial Tesoro, Ediciones Tritón y Atlántida. Cuando Ediciones Marisal comenzó a publicar tebeos, 1942, tenía ya arraigo en la sociedad surgida de la guerra civil, pues durante la misma había estado publicando en Sevilla una novela por entregas con el título La Guerra, 1938, escrita por Fernando Cisneros. Por supuesto la guerra a la que el título se refería era la guerra civil española, y estos "episodios novelados" demostraban por activa y por pasiva quiénes eran los "buenos" de la historia. Tras acabar la guerra, Ediciones Marisal se instaló en Madrid. Sus primeras colecciones de tebeos fueron Las Grandes Aventuras (imagen 19), formato vertical pequeño, y Los Grandes Viajes Científicos, "maravillosa colección gráfica de aventuras extraordinarias será la más amena, más instructiva y más emocionante de las de este género", cuando lo cierto es que las viñetas llevaban densos pies de texto y el conjunto era triste y aburrido. En 1944, Marisal comenzó a publicar la colección Canguro, con ilustraciones e historietas de Vicente Roso, J ano (Fernández Zarza), Gallego, Huete, Luis Vigil (Álvarez Prieto) Villarejo, etc. Del mismo año es la colección Pelicano, con dibujos de Jano, Vicente Roso, José Laffond, etc. Y Aventuras de Abulkasen Basri, todas en cuadernos de historietas grandes.

Por el camino abierto por Marisal entraron a continuación la Editorial Proa, y acto seguido Tesoro, Tritón, Atlántida, y más tarde, mediados ya los años cuarenta, Losada, Ediciones Ángel Nieto, Ediciones Rialto y el Instituto Editorial Reus, además de Editorial Fantasía. Entre los tebeos de Proa, que la editorial llamaba "álbumes", tenemos la colección de Aventuras Sorprendentes, 1943, en cuadernos de un tamaño intermedio, la colección se subdividía en varias series: "Las Aventuras de Buffalo Hill", "Nuevas aventuras de Robinson Crusoe" y "Las Aventuras de César y Alfonso". Pero sus tebeos más importantes fueron, en tamaño grande apaisado, la colección Oro Fino. El Profesor Magnus contra el Doctor Cicuta, 1943, y la colección Tajamontes, el caballero invencible, 1944, ambas obra del autor francés que firmaba Érik (André René Jolly).

En 1944, la Editorial Tesoro lanzó una colección de cuadernos grandes, Panchito, y la colección Narraciones Cascabel, en cuadernos pequeños. En estos cuadernos publicaron 
muchos dibujantes, entre ellos Rafael Gordillo, Ibarra, J. Blanco, Manuel Vázquez, Víctor de la Fuente, Cuesta, Gabi (Gabriel Arnao). Sorprendentemente, en los tebeos de Tesoro encontramos a Manuel Gago, quien un año antes ya ha iniciado en Editorial Valenciana El Guerrero del Antifaz, pero que aún se repartía por otras editoriales. Ediciones Tritón colocó en el mercado dos colecciones tamaño grande, Gorgorito y Chorlito, al tiempo que recuperaba la vieja colección de novelas por entregas El Sheriff, de finales de los años veinte, que volvía a editar con nuevas cubiertas. Y aún quedan en los primeros años cuarenta los tebeos de la Editorial Atlántida: Aventuras extraordinarias del Capitán Antorcha y La Legión del Espacio, tan malos que solo merecen la cita fugaz, sin más detenimiento.

En general el "look" de los tebeos madrileños se diferenciaba radicalmente de los producidos en Barcelona por la presentación de las cubiertas, el menor número de viñetas por página y por las peculiaridades de unos jóvenes dibujantes que aún estaban formando su estilo. Se trataba de muchachos que apenas sabían dibujar, que lo desconocían todo acerca de la historieta, su técnica y su lenguaje y que para aprender copiaban a los grandes del cómic norteamericano. Ellos fueron el germen de la escuela madrileña.

\section{LOS PRIMEROS EDITORES DE HISTORIETAS DE VALENCIA}

Editorial Valenciana logró reiniciar sus actividades en 1940, pero muy lejos de su producción de novelas folletinescas de anteguerra, ya que Juan B. Puerto la orientó hacia la edición popular de tebeos. El primer lanzamiento fue una colección de cromos e inmediatamente después la colección de tebeos Roberto Alcázar, que alcanzaría un éxito pocas veces logrado por un tebeo español. Dueña del mercado valenciano, y por extensión muy bien situada en el mercado estatal, Editorial Valenciana se planteó la edición de tebeos

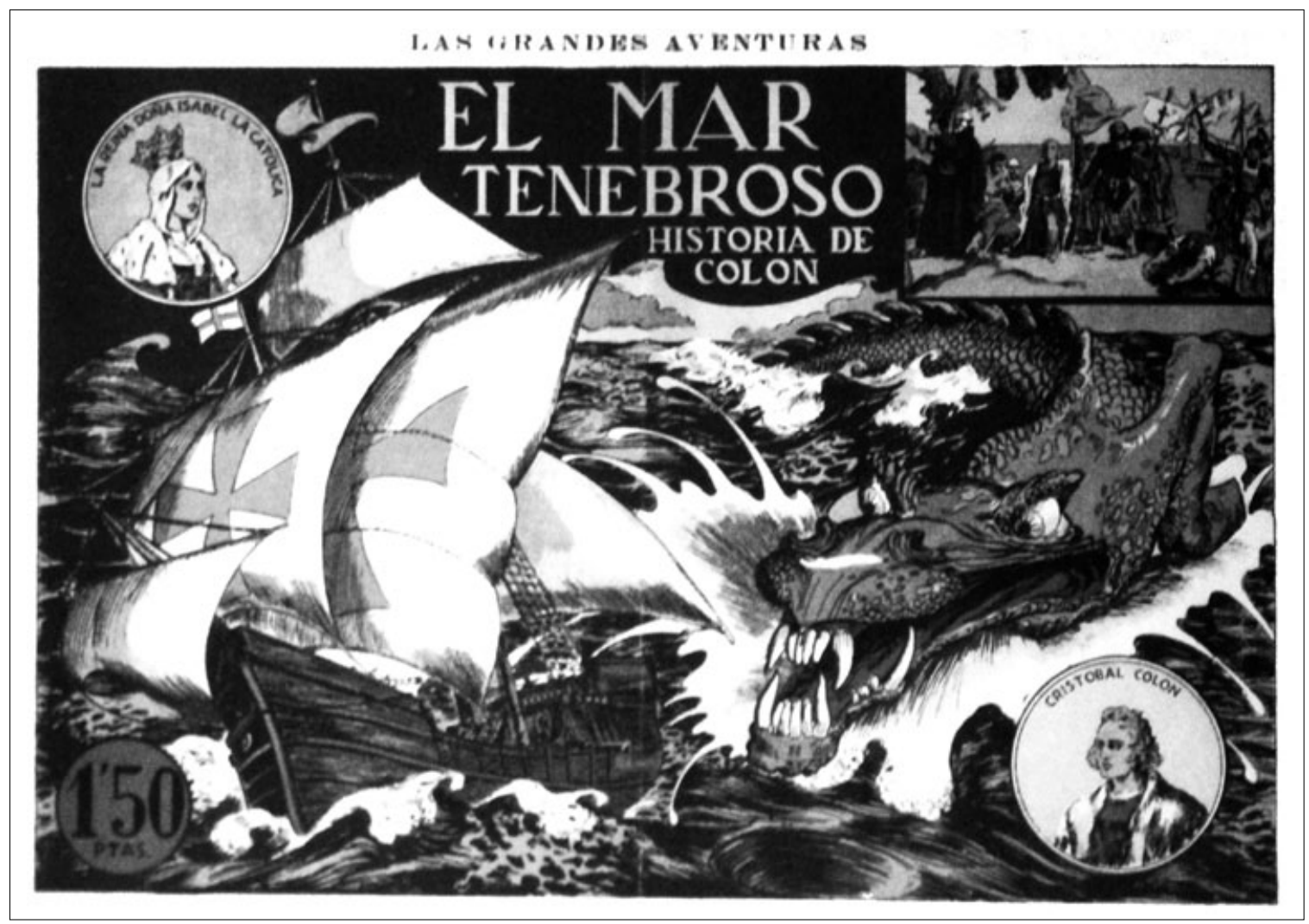

Imagen 19. 
sin urgencias e intentando asegurar cada paso que daba. Lógicamente, se acogió al modelo del cuaderno de historietas, pasando por los mismos trámites y problemas que el resto de editores de Barcelona y Madrid.

En los tres o cuatro primeros años de la posguerra, Valenciana lanzó varios tebeos para asegurarse un espacio en el mercado. Fueron las colecciones Selección Aventurera, 1940; Carlos Ray, 1941; Bob Tailer, Aventuras de Mister Bluff, Jaimito cuadernos de historietas, Grandes Aventuras y Películas, 1942; Julio y Ricardo, 1943, etc. En torno a Valenciana se agrupó una serie de colaboradores sin los que no habría podido crear una empresa sólida, hasta llegar al autor y a la colección que daría fama y fortuna a la editorial y gracias a la cual pudo emprender una eficaz competencia en el mercado de los tebeos: El Guerrero del Antifaz, de Manuel Gago (imagen 20).

Manuel Gago fue uno de esos dibujantes privilegiados que parecen haber nacido para la historieta. Trabajador incansable, tanto por vocación como por estricta necesidad, desde muy joven comenzó a publicar en cuantas editoriales le fue posible, así encontramos historietas suyas en los tebeos madrileños de Editorial Tesoro, en Flechas y Pelayos, en cuadernos de historietas de Hispano Americana de Ediciones, Marco, etc., y más tarde colaboró incluso con la Editorial Toray. En sus primeros años de profesional realizó varios cuadernos para Valenciana y en 1943 creó la que ha de ser considerada la gran obra de su vida, El Guerrero del Antifaz, sin la cual no se puede comprender en su conjunto el "fenómeno del cuaderno de historietas".

La colección se inicia en el momento en que los Reyes Católicos asediaban el Reino de Granada. El argumento es una mezcla de novela de aventuras históricas y cómic realista norteamericano, vista por un españolito de los años cuarenta. Un cóctel explosivo que, servido a los niños de la posguerra, les ofrecía mucho más que la historieta tradicional. Y es que las

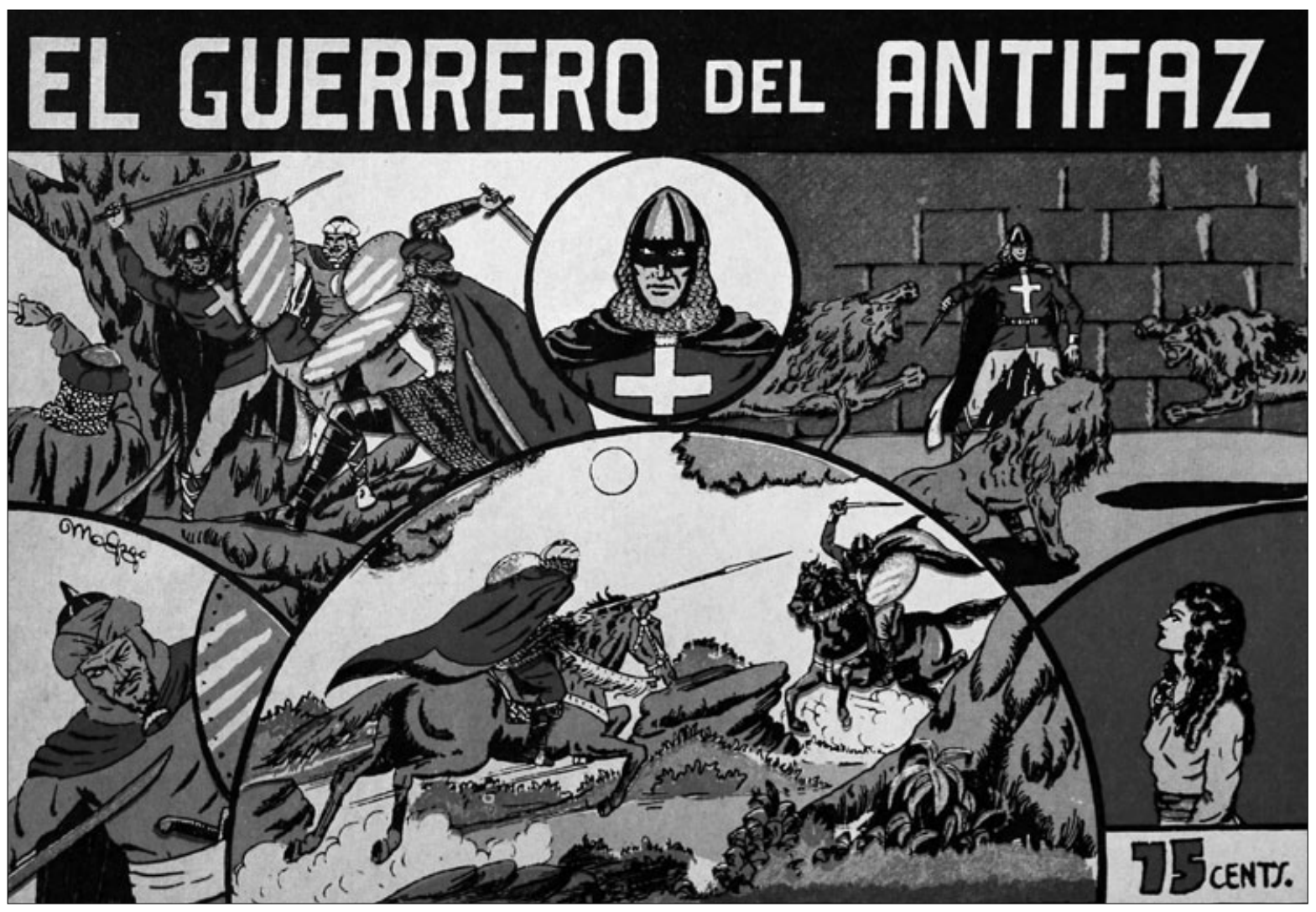

Imagen 20. 
aventuras del guerrero tenían morbo, insinuaban más que lo que decían y permitían al lector fantasear más allá de lo evidente, gracias a un dibujo enérgico en cuyo trazo rasgueado se aprecia una influencia estilística de Alex Raymond. Editorial Valenciana supo valorar lo mucho que Gago aportaba a la empresa, por lo que el autor inició en paralelo otras muchas colecciones de cuadernos, que si no alcanzaron la importancia de El Guerrero del Antifaz, sí dejaron obras importantes. De ellas vale destacar El Pequeño Luchador, 1945; Purk, el hombre de piedra, 1950; El Espadachín enmascarado, 1952, entre casi el medio centenar de títulos que realizó a lo largo de su vida. Y todo ello bajo contratos leoninos por los que el editor explotaba al dibujante y le robaba sus derechos más elementales.

J unto a Manuel Gago, los principales dibujantes de los cuadernos de historietas de Editorial Valenciana fueron, hasta 1945: Soriano Izquierdo como guionista, dibujante y pronto director artístico, y los dibujantes Eduardo Vañó, Juan P. Muro, Palmer (M iguel Martínez Verchili), Edmundo Marculeta (que trabajó con varios seudónimos), Karpa (Rafael Miguel Catalá Lucas), Enrique Pertegás, Liceras, Ayné, Miguel Quesada, José Grau, etc. Y guionistas como Puerto, Jordán Jover Amorós, Tartajada, Pedro Quesada, etc., de los que es necesario destacar especialmente a Federico Amorós.

La Editorial Valenciana fue dueña total del mercado de la historieta editada en Valencia durante muchos años. La creación de varias pequeñas editoriales a lo largo de los años cuarenta apenas le supuso problemas, Editorial José Luis Aguilar y Cía, 1943, Ediciones Lerso, 1946, Editorial Ibérica de Publicaciones, en Villena, 1946, Ediciones Saturno, 1947, etc., pues la competencia que le hicieron fue mínima. Al llegar al final de este periodo, el triángulo editorial de los tebeos españoles, Barcelona-M Madrid-VaIencia, era una realidad y Editorial Valenciana se encontraba perfectamente asentada como una de las más importantes.

\section{Primeros tebeos de género de los años cuarenta}

Los nuevos planes de educación del régimen, bajo la directa supervisión de la Iglesia así como de los pedagogos, marcaron desde la primera hora la estricta separación por sexos entre niños y niñas, anulando el régimen de coeducación que se había seguido durante la República. Ante esta situación, y en momentos en que comenzaron a publicarse numerosas revistas de información, modas, cocina, decoración y cotilleos dirigidas a las mujeres, parece sorprendente que los editores de tebeos no vieran el amplio campo que se les podía abrir con el público femenino infantil. Fue Consuelo Gil, directora de Chicos quien, como ya hemos señalado, publicó en abril de 1941 la primera revista dirigida a las niñas, a la que, siguiendo el título que había dado a la sección para niñas que publicaba desde 1938 en Chicos, tituló Mis Chicas.

La revista, con su título fijo, numeración correlativa, fecha de salida impresa en cubierta, se publicaba bajo el paraguas protector de la Delegación de Prensa de FET y de las JONS y ofrecía a los padres y educadores una revista neutra, con licencia eclesiástica y sin signos partidistas, que unía lo formativo al entretenimiento. En su primera etapa se imprimía al mismo tiempo y en el mismo papel que Chicos, y una vez impresa se guillotinaba la parte superior del papel separando ambas revistas. Consuelo Gil encargó a J esús Blasco una historieta que representase el espíritu de la revista, fue así como el dibujante creó a Anita Diminuta y sus amigos, que viven en el "País de la llusión", el oso de peluche M ateo, el Genio del bosque, el soldado cojo de Andersen, el Payaso, etc. y sus enemigos, la bruja Carraspia, el brujo Caralampio, el Diablo, etc. Las aventuras de Anita Diminuta fueron el eje sobre el que pivotó Mis Chicas durante diez años, una obra que dentro de su ingenuidad y contradicciones queda entre lo mejor de la historieta infantil española. Junto a Blasco, la revista se nutrió de las historietas de Puigmiquel, Pili Blasco, Julián Nadal, Alfonso Figueras, Alcaide, Adriano Blasco, Moreno, Gordillo, M oro e ilustraciones de Blasco, Freixas, Riera Rojas, etc.

Ante la revista de Consuelo Gil, los editores comerciales despertaron y dado que la opción de las revistas periódicas estaba cerrada para ellos, el soporte editorial tenía que ser un cuaderno $o$ una colección de cuadernos y, puesto que lo que se quería era diferenciar tajantemente a las niñas de los niños, los temas no podían ser en forma alguna los habituales de los tebeos que se estaban publicando ya. Por reducción quedaba un solo tema, el sentimental que, más que un tema, era un enfoque diferente que podía aplicarse a historias de todo tipo. Como posibles primeros cuadernos de historietas para niñas tenemos las colecciones Cuentos ilustrados, 1941, Editorial Marco, con varios 
números dirigidos a las niñas; colección Tulipán, 1941, Editorial Iberia A.G., Cuadernos Selectos, 1942, de Editorial Cisne, dedicada íntegramente a las niñas con versiones en historieta de cuentos clásicos, muchas de cuyas cubiertas las realizó Jesús Blasco, por entonces director artístico de Cisne; los cuadernos para niñas de Editorial Ameller, 1942, con gran cantidad de títulos dirigidos expresamente a las niñas: El pájaro de oro, El enanito bobalicón, La reina de la nieve, Las trenzas de seda, La princesa del cabello de oro, La hija del gigante, etc.; Historietas Gráficas "Pilarín", 1942, de Ameller; Las peripecias de Luisín y Chiquita, 1943, de Ameller; Cuentos de Hadas, 1943, de Editorial Marco; Las Hadas, 1943, Marco; Cuentos de las mil y una noches, 1943, Marco, etc. A las que pronto siguió un verdadero alud de cuadernos de historietas para niñas: colección Princesita, de Ameller, Gisela, editada por Carmen H. Bastos, Cuentos de Hadas, de Ediciones Éxito, Cuentos de Hadas, de Publicaciones Ibero-Americanas, Cuentos de Hadas Sauce, de Editorial Éxito, etc., hasta llegar a la colección Azucena, de Ediciones Toray, que con el tiempo sería la colección bestseller de los cuadernos de historietas para niñas.

Entre los muchos dibujantes que trabajaron para las colecciones para niñas hay que contar con Jesús Blasco, Pili Blasco, Jesús Blasco, F. Batet, Tomás Porto, M arsenat, Bosch Penalva, Víctor Aguado, Enriqueta Bombón, Antonio Ayné, Vilella, Longoria, Juli, Nieto, Emilio Boix, P. Casio (Pedro Alférez), Francisco Macián, A. Badía, Juez, Sabatés, Rosa Galcerán, etc. Importa destacar que entre los nombres referenciados tan solo hay cuatro mujeres.

Será así, y hasta muy entrados los años cuarenta, como el mercado del tebeo se abrió a esta nueva línea editorial, cuya especificidad no venía del tema tratado sino por ir dirigida al gueto femenino. Hasta que los editores comerciales pudieron, casi a finales de la década, lanzar tebeos de contenidos variados para las niñas, la mejor revista fue Mis Chicas -bien editada, conservadora, moralizadora y con censura eclesiástica-. Y, alternativamente, las docenas y docenas de cuadernos de historietas de hadas, pastorcillas y príncipes, enanitos, animales parlanchines, niños redichos, magos, etc., resueltos casi siempre con un tratamiento almibarado y un proyecto cultural escapista. En realidad, Mis Chicas y los muchos cuadernos para niñas que se editaron en aquellos años eran complementarios y difundían una imagen femenina discriminadora, que relegaba a la futura mujer a la cocina y la maternidad o bien le ofrecía un mundo irreal de fantasía que pretendía trascender la dura realidad de la posguerra con una falsa solución que fijaba el máximo objetivo en la obtención del amor.

\section{EDITORIALES, LA DIFíCIL ADAPTACIÓN AL PRESENTE}

Algunas editoriales de tebeos de la posguerra sufrieron una especie de síndrome de pasividad. Mientras que otras, por el contrario, no cesaron en sus constantes intentos por desarrollarse. Ejemplo perfecto del primer caso sería la empresa de Joaquín Buigas, que en estos años trabajó bajo el nombre de Ediciones TBO. Al acabar la guerra, Joaquín Buigas simplemente le lavó la cara a TBO, haciendo los cambios mínimos para intentar ponerlo al día, sin lograrlo. Partícipe del mismo desconcierto que afectó a la mayoría de editores tanto por la política de autorizaciones editoriales como por los problemas de papel y por los cambios de los intereses lectores, Buigas no supo adaptar su revista, hasta el punto de que entre 1941y 1944 solo se publicaron un almanaque y quince números de este título, a todas luces insuficientes para poder mantener la empresa a pleno rendimiento. En los mismos años Buigas recurrió a vender restos de ediciones y puso en el mercado productos tan heterogéneos como el Sobre Regalo para los Albumes $T B O$, así como juguetes en papel como El buque flotador. Buigas también intentó entrar en el negocio del cuaderno de historietas con cuatro colecciones de cuadernos apaisados: Los castillos de España, Los grandes naufragios, Las tragedias del aire y Las tragedias del mar, sin éxito. La editorial no logró recuperarse hasta que las circunstancias oficiales hicieron posible la publicación regular de TBO. Entre 1941 y 1952 solo se editaron 131 números, lo que en la práctica equivale a la salida de un número por mes. Por ello, las tiradas que se achacan a aquel TBO podrían corresponder, quizá, al número de lectores, pero nunca a los ejemplares vendidos.

Sin embargo, Joaquín Buigas hizo una aportación importante a la historieta española al crear la serie "La Familia Ulises", con él mismo como guionista y Marino Benejam como dibujante. La primera historieta apareció en el ejemplar décimoprimero de su revista, publicado en 1944 bajo el título "Risa Continua. Ediciones TBO". Es muy posible 
que el autor y editor no fuera consciente de las posibilidades que su creación ofrecía, pues tardó varios números en publicar una segunda historieta. Si examinamos la colección de TBO de los años cuarenta y cincuenta, no cabe duda de que la serie constituye una de las mejores crónicas de la sociedad española de la posguerra.

En el caso de Hispano Americana de Ediciones, el puente que enlaza los años de la posguerra con el pasado fueron los cómics norteamericanos en cuya edición se había especializado Lotario Vecchi en 1935-1936, estableciendo sólidas relaciones comerciales con King Features Syndicate, hasta el punto de convertirse prácticamente en su editor exclusivo en España. Tras jugar las cartas de sus relaciones con el régimen y de hacer valer su condición de súbdito italiano, Vecchi consiguió que todos los elementos de su empresa retornasen a su poder, incluido el importante taller de imprenta que poseía antes de la guerra, equipado con una rotativa que imprimía a todo color. Pero fracasó en lo que más deseaba, el permiso para volver a lanzar al mercado sus tebeos de anteguerra. Centró entonces su solicitud solamente en la revista Aventurero y presentó año tras año, al menos en seis ocasiones, la petición para que le autorizasen la revista sin conseguirlo. Las numerosas alegaciones y la mucha documentación que hemos revisado, presentada por Otelo Parenti -apoderado de la editorial y hombre de total confianza de Vecchi- ante las instancias que controlaban la prensa española, fueron inútiles.

Impotente para volver a publicar sus revistas, Hispano Americana de Ediciones rescató todo el material publicado en ellas: El Hombre Enmascarado (Phantom), Tarzán, Flas Gordon (Flash Gordon), Carlos el intrépido (Brick Bradford) Jorge y Fernando (Tim Tyler's Luck) y un largo etc. y, al remontarlo al nuevo formato, fue totalmente destrozado. Pese a lo cual estos tebeos, agrupados en docenas de colecciones, se editarían durante varios años. Sin embargo, no satisfecha con esto, Hispano Americana de Ediciones llegó a un acuerdo con el dibujante y editor Teodoro Delgado que le cedió la cabecera de su revista Leyendas Infantiles. Durante la guerra, Teodoro Delgado había trabajado como ilustrador, cartelista, historietista y propagandista de las glorias de Franco. Por ello, cuando solicitó en 1942 permiso para editar una revista infantil, recibió en pago a sus servicios la autorización necesaria. El primer número se puso a la venta en Madrid el 9 de mayo de 1942, con el título de Leyendas Infantiles, bajo el pie de Editorial Senda.
Delgado diagramó la nueva revista siguiendo con bastante similitud el modelo del tebeo Jeromín, 1929, del cual había sido uno de los artífices. Los dibujantes que hacían la revista formaban parte del grupo asentado en Madrid y que colaboraba con Flechas y Pelayos, Maravillas, Chicos y los tebeos de M arisal y Tesoro, más otros profesionales amigos personales de Teodoro Delgado como Pena, Soravilla, Ardel, Aróztegui, Joaquín Durán, Moro, Carmelo, Vicente Roso, Esteban, Ángel Pardo, Gabi. En 1944 y a través de una negociación sobre la que no tenemos datos y cuyo importe económico ignoramos, Teodoro Delgado cedió la explotación de Leyendas Infantiles a Hispano Americana de Ediciones, quien publicó la revista a partir de su n 084 , durante los años 1944, 1945 y posiblemente algún mes de 1946, hasta el $n=182$.

La editorial barcelonesa reconvirtió la revista en un tebeo semanal de gran tamaño, al precio de 50 céntimos, intentando revivir el éxito que años atrás había alcanzado con Aventurero, para ello publicó los cómics norteamericanos: Tarzan, de Hogarth, $X-9$, de Charles Flanders, Sergeant King, de Allen Dean, Popeye, de Segar, Flash Gordon, de Alex Raymond, Skyroads, de Russell Keaton, Radio Patrol, de Charlie Schmidt, etc. e historietas de los españoles Teodoro Delgado, Iranzo, Ripoll G., Ardel, Figueras, Castanys, etc. Hispano Americana de Ediciones mantuvo en la cabecera de la revista la dirección postal de la editorial de Teodoro Delgado en Madrid, si bien dio como dirección de la administración la suya de Barcelona en un pequeño recuadro en páginas interiores $y$, sin que en ningún momento constase su pie editorial. A efectos oficiales, la revista fue siempre publicada por Editorial Senda. Lo sorprendente es que esta operación mercantil, por la que un editor con permiso de revista periódica y cupo de papel la "alquilaba" a otro editor, no trascendió y no queda ninguna constancia de ella en los dosieres oficiales. Lo cual, teniendo en cuenta que en aquellos momentos se vivía en un estado policíaco, tiene que significar o que nadie en los estamentos oficiales daba importancia a la prensa infantil, o que era relativamente fácil saltarse las normas, o que la corrupción era tal que pequeños "negocios" como este se toleraban. En 1946, Hispano Americana de Ediciones retornó el uso de la cabecera y la publicación de la revista a su propietario, Teodoro Delgado.

Mientras editaba la citada revista, Hispano Americana de Ediciones comenzó a publicar en 1945 un nuevo tebeo 
de contenido variado y gran tamaño, con apariencia de revista aunque legalmente se publicaba como folleto. Su título era Aventurero, y se incluían series de cómics americanos, como Phantom, Tim Tyler's Lucks y el Flash Gordon de la tira diaria, realizado por Austin Briggs, Gordo, de Gus Arriola. Como complemento añadió alguna historieta española y materiales italianos y franceses, como Texas Hill, de Mario Uggeri, y el Caballero Tajamontes, de Erik. Debido a su condición de folleto, la editorial se vio obligada a dar en la cabecera la mención genérica Ediciones Aventurero y a continuación dar de forma destacada, sobre un fondo de color amarillo, una mención diferente que, de acuerdo con la legislación, sirviese para diferenciar cada número. Este tebeo fracasó, ya fuera porque su presentación y contenidos no convencieron a los lectores 0 a los poderes fácticos que controlaban la edición 0 , más simple, porque la competencia redujo su presencia en el mercado. La editorial se concentró cada vez más en la edición de cuadernos de historietas, intentando diversificarla al máximo para lo que comenzó a publicar material de historietas italianas en número creciente.

\section{LOS INTENTOS DE NUEVOS TEBEOS TOLERADOS}

Cuando se inició la Segunda Guerra M undial, Franco posicionó su régimen como neutral, una neutralidad benevolente hacia Alemania e Italia, a las que tanto debía en su victoria de 1939. Pero, a raíz del vuelco que en 1943 dio la guerra con la derrota alemana en Stalingrado, Franco inició un giro hacia una neutralidad real, que se reflejó en la "desfalangización" del régimen -más aparente que cierta-, para blanquear su imagen ante los aliados. Los ligeros ajustes en la fachada del régimen supusieron en el terreno editorial una cierta tolerancia formal, pese a que la legislación no se relajó en ningún momento. Lo cierto es que en 1944-1945 se publicaron nuevos títulos de tebeos que iban más allá del simple modelo del cuaderno de historieta y estaban muy cercanos a la revista de contenidos variados. Con ligeras variantes en el diseño, en la presentación y en los contenidos, la similitud entre estos tebeos fue muy grande y venía determinada en lo formal por los tamaños de las máquinas de imprimir disponibles en aquellos momentos y por el juego de la competencia entre editoriales. El modelo promedio de estos tebeos fue el formato vertical, tamaño aproximado de $25 \times 17 \mathrm{~cm}$, ocho páginas interiores en negro -resultantes de imprimir un pliego y plegarlo en cruz-, a veces más si el editor se atrevía a dar dos pliegos de papel, más cubierta y contracubierta en color, predominio de las historietas humorísticas de una página y precios similares en proporción al número de páginas.

Los primeros en aparecer fueron ser los tebeos de Clíper, Germán Plaza que, pese a repetir de un número a otro el modelo, cambió el título en todos: Canela fina, Una semana feliz, Historietas amenas, Selecciones cómicas, etc., todos con el precio de 30 céntimos y tan solo ocho páginas, de las cuales cuatro estaban impresas en bicolor.

Editorial Marco publicó La Risa, con el subtítulo Biblioteca especial para niños, con tan solo cuatro páginas, con un precio de 30 céntimos, El Ciclón, con ocho páginas impresas a una tinta más cuatro páginas de cubiertas en color, con un precio de 50 céntimos y Cholito y Asta, este último con el subtítulo Cuadernos infantiles Rin-Tin-Tin, ambos con solo ocho páginas impresas en negro, además de cubiertas en color. Todos los tebeos se componían de una extraña mezcla de materiales, ya que se recuperaron muchas viejas páginas de historietas de aventuras. $Y$ junto a ellas materiales nuevos dibujados por Jiménez Arnalot, Emilio Boix, Cañada, Ayné, Pedro Alférez, etc. En todos los casos, los tebeos eran simplemente, incluso por referencia a su precio, cuando otras editoriales estaban ofreciendo ya historietas más modernas y mejor dibujadas.

Por su parte, Editorial Bruguera lanzó tres tebeos que repetían las características generales de los antes citados: El As, con el subtítulo De los álbumes infantiles, AEl. y Niños, con ocho páginas, cubierta en color y con un mismo precio, 50 céntimos. Las historietas las dibujaban los nuevos colaboradores que Bruguera estaba captando en estos momentos: Ayné, Guillermo Cifré, Bataller, Ángel Nadal, Boix, etc.; pero también había un alto porcentaje de páginas de archivo vueltas a publicar. Los resultados, sin ser tan malos como los tebeos de Marco, fueron mediocres.

Es justamente en 1944-1945 cuando Editorial Bruguera volvió a lanzar su tebeo Pulgarcito. Al acabar la guerra y justo en el momento en que El Gato Negro pasaba a ser 
Editorial Bruguera, ya se habían publicado varios números únicos con el mismo título de Pulgarcito. Y ahora, aprovechando que el momento parecía propicio, hicieron un nuevo intento, esta vez con continuidad, aunque fue de corta duración ya que solo se editaron ocho números. La presentación de todos los números fue uniforme, con una cabecera fija con un logotipo idéntico de un número a otro. El tebeo tenía 12 páginas incluidas las cubiertas, que estaban impresas a todo color, el precio de venta era de 1 peseta. Pero, al no conseguir la autorización como revista periódica, el nuevo Pulgarcito se publicó con la categoría de folleto, por lo que en unos números llevaba como antetítulo la referencia Biblioteca infantily en otros Cuadernos Infantiles (imagen 21) a mayor parte de los contenidos eran historietas de humor de una página, obra de los nuevos dibujantes que Francisco Bruguera había captado en otros tebeos y lugares de trabajo como Chamartín Films: José Escobar, Jiménez Arnalot, Guillermo Cifré dibujando tanto páginas de humor como páginas de estilo realista, José Peñarroya, Eugenio Giner, Ángel Nadal, etc. Este Pulgarcito presentaba aún muchos fallos: abundaban las páginas de historietas con textos al pie de las viñetas, que se publicaban junto a otras resueltas totalmente en bocadillos, muchas páginas llevaban demasiadas historietas muy pequeñas formando un conjunto abigarrado que recordaba los peores ejemplos de TBO. Visto en perspectiva, este tebeo parece una especie de "ensayo general" de lo que poco después sería el modelo definitivo del Pulgarcito.

La competencia entre editoriales había hecho que la lucha por el mercado de los tebeos se hiciese más dura. Editorial Valenciana potenció la edición de cuadernos de historietas de todos los temas, géneros y personajes, siempre con la gran baza comercial que le suponía el trabajo de Manuel Gago, dando poco a poco entrada a otros dibujantes que entonces comenzaban y aumentando el trabajo a otros de la primera hora. Con una importante línea editorial de cuadernos de historietas, Valenciana podía competir en el mercado español en igualdad de condiciones con las editoriales más fuertes, y ello le permitió abrirse a otros proyectos, entre los que siempre contó el humor.

Pero el rendimiento económico no era suficiente. Para que una editorial de tebeos funcionase bien era necesario contar con un profesional, 0 un equipo, que la gestionase a nivel creativo, buscando ideas, dibujantes y temas de interés para los lectores. En los años cuarenta y en Editorial Valenciana la persona fundamental fue José Soriano Izquierdo, dibujante de historietas que había colaborado en los años treinta en TBO, Pocholo, KKO. Al acabar la guerra comenzó a colaborar como dibujante con Editorial Valenciana y pronto se convirtió en el creativo de la empresa, con título o sin él, director artístico de la misma.

Soriano Izquierdo impulsó los proyectos más importantes de Valenciana. Entre ellos, la recuperación de dibujantes como Juan Pérez Muro y la entrada de jóvenes a los que se solía poner por ejemplo y maestro a Manuel Gago. También dio cabida a dibujantes ya clásicos, como Pertegás o Palmer (Enrique Martínez Verchili), siendo este último el realizador de una serie de cuadernos humorísticos, Aventuras de Jaimito y Periquete, 1943, que popularizarían el personaje Jaimito, un chico simpático y atrevido que vive aventuras cotidianas, más cerca del golfillo que del niño modélico. A partir de este personaje se planteó la creación de la revista Jaimito, con historietas variadas, siendo las protagonizadas por Jaimito y su pandilla el elemento aglutinador (imagen 22). Tras un inicio confuso en el que se editaron media docena de números sin referentes suficientes, se continuó con números sin periodicidad fija hasta que se consiguió la máxima regularidad en aquellos momentos. Jaimito se convirtió en el buque insignia de la editorial junto con las colecciones Roberto Alcázar y El Guerrero del Anti$f a z^{16 .}$

Jaimito fue un tebeo vertical, con 16 páginas más cubiertas, de contenido predominantemente humorístico, la historieta principal estaba protagonizada por Jaimito, primero realizado por Liceras y Soriano Izquierdo y después y ya definitivamente por Karpa (Rafael Catalá Lucas). El tebeo se componía de historietas de Soriano Izquierdo, Jesús Liceras, Alamar, Karpa, Pertegás, Palmer, Ángel Nadal, Palop, V. Maciá, Serafín, Sanchís, Alfonso Alamar, Martínez Osete, Serna, Ayné, Iranzo, la mayoría de ellos residentes en Valencia, con el añadido de algunas páginas de series de humor norteamericanas. Además fue uno de los primeros tebeos de humor que añadieron a sus contenidos historietas dibujados en estilo realista, por dibujantes como Manuel Gago, Luis Bermejo, José Grau, Miguel Quesada, Claudio Tinoco, Frejo, etc. 


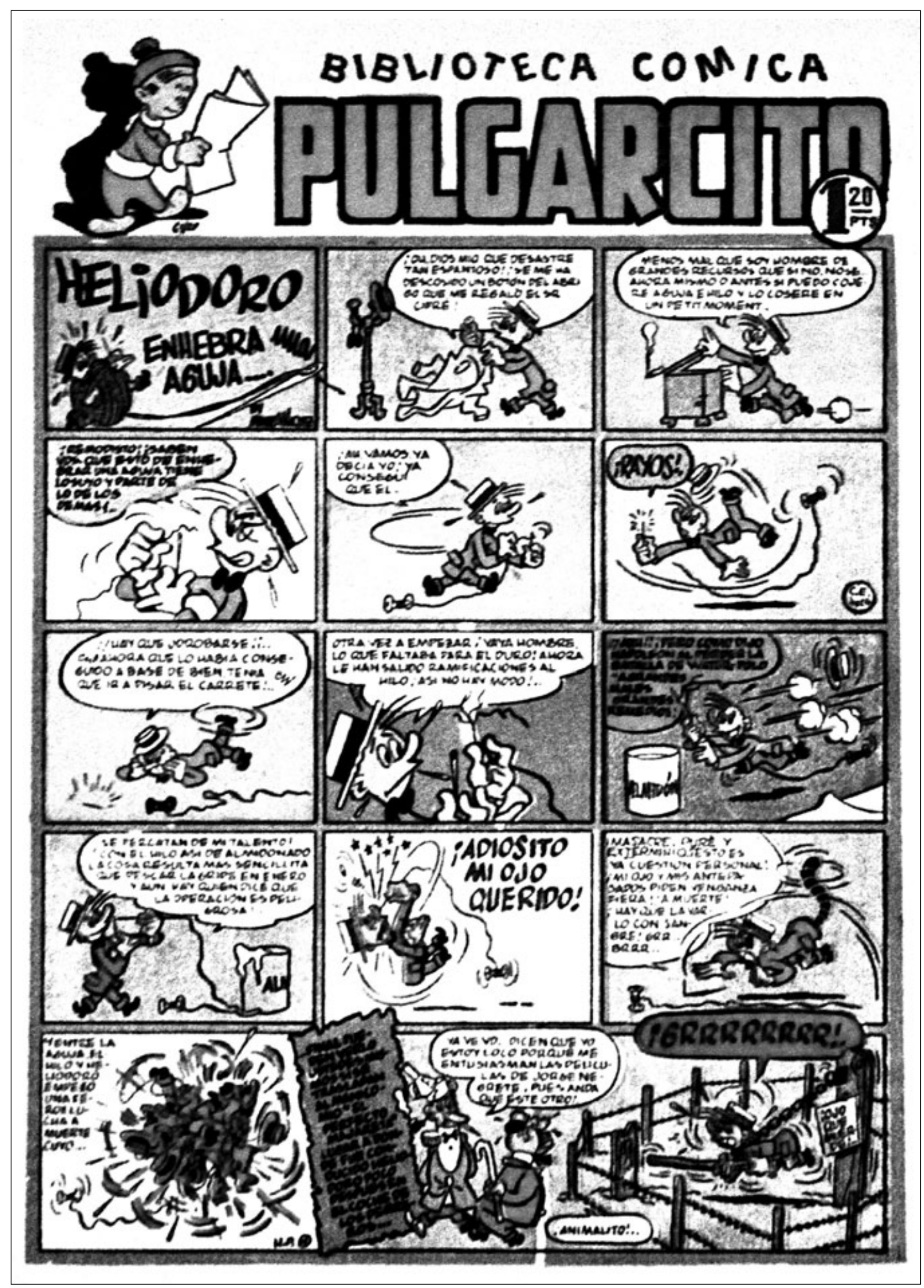

Imagen 21. 


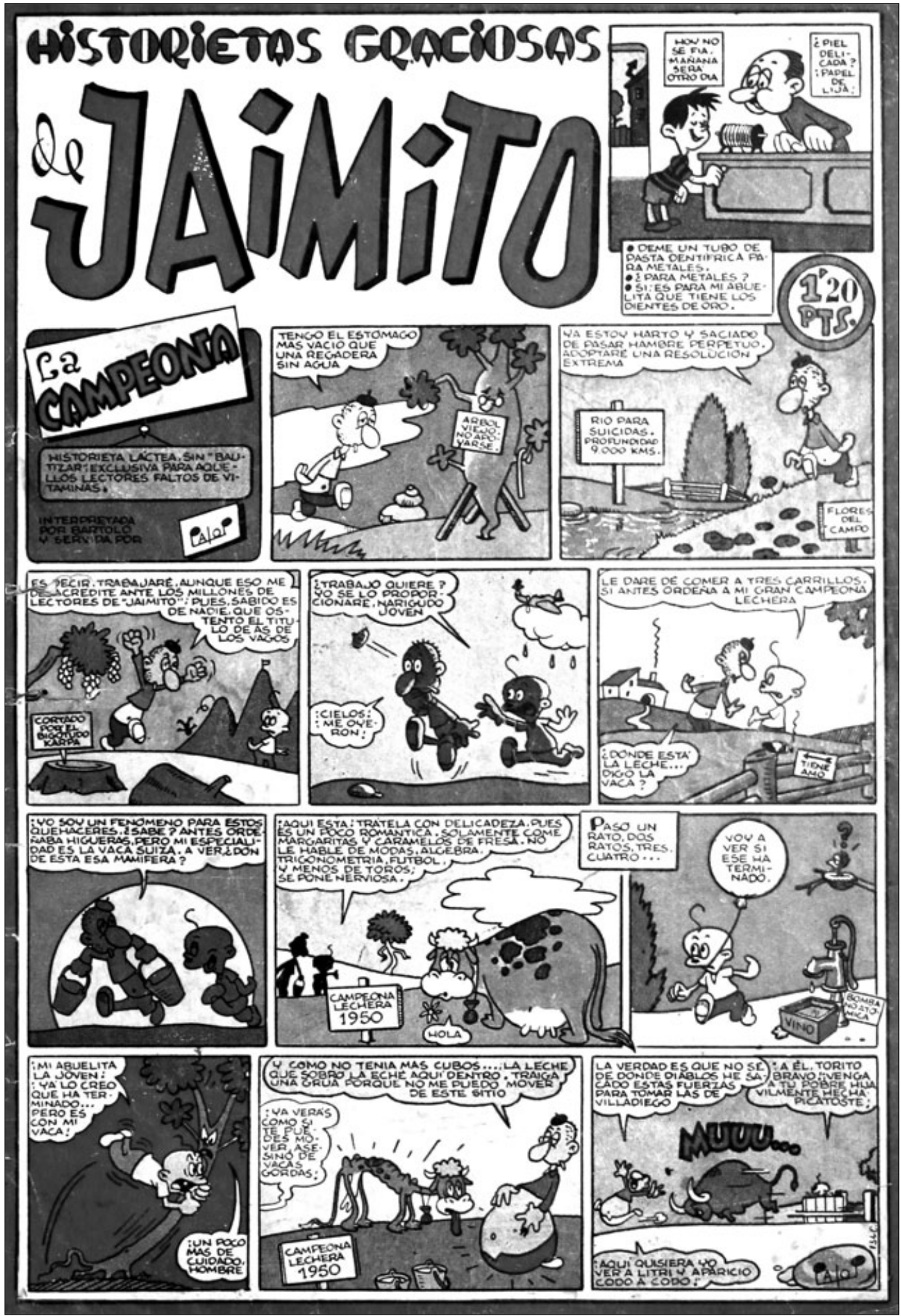

Imagen 22. 
El tebeo se publicaba con la categoría y autorización de folleto, por lo que su título era siempre cambiante -Amenidades de Jaimito, Risa fácil con Jaimito, Brotes festivos de Jaimito, Alegres inocentadas de Jaimito, etc. - y la numeración era inexistente al principio y más tarde minúscula y disimulada en la contracubierta. En cualquier caso, este tebeo funcionó como una auténtica revista. Su precio inicial era de 1 peseta, pero muy pronto subió a 1,20. Jaimito sería imitado por otros editores valencianos con títulos como Cubilete, de Editorial Gong, o KChT, de Ediciones Saturno, así como por editores de Barcelona y Madrid, pero sin ser nunca igualado.

Todos estos tebeos estaban indicando que algo se movía en el panorama editorial, calladamente y sin cambiar ni una letra la Ley de Prensa. M ediada la década de los cuarenta, los tebeos que a principios de siglo podían haberse considerado como una prolongación de la cultura popular, derivaban hacia la cultura de masas, que se desarrolló gracias al interés de quienes la consumían y, por ello, de espaldas a la cultura del régimen.

\section{LA INVASIÓN DE LOS CUADERNOS DE HISTORIETAS}

El giro estratégico que Franco había iniciado en 1943 acabó concretándose en la formación de un nuevo Gobierno en julio de 1945 que reflejaba la nueva correlación de fuerzas y grupos de presión del régimen, con el dato importante de la desaparición del cargo de ministro secretario general del M ovimiento. En el terreno de la prensa, a resultas del cambio de Gobierno, se traspasaron los servicios administrativos del control de la prensa desde la Vicesecretaría General de Educación Popular del Movimiento, dirigida por Gabriel Arias Salgado, a la Subsecretaría de Educación Popular del Ministerio de Educación Nacional, mediante un Decreto- Ley de julio 1945, que fue ratificado por la J efatura del Estado el 31 de diciembre de 1945. A partir de enero de 1946 el Ministerio de Educación se hizo cargo del control de la prensa española en todas sus formas, prensa diaria, revistas, folletos sin periodicidad fija, etc. Este simulacro de apertura del régimen se tradujo en una mayor tolerancia en la mecánica de la prensa, sobre todo en cuanto a la periodicidad, por lo que los editores de tebeos vieron cómo sus problemas se reducían.
En el panorama editorial y pese a la aparición de diversas revistas de historietas de contenido variado, el negocio de los editores españoles hasta mediados de los años cincuenta 0 algo más continuó centrado en la edición de cuadernos de historietas. El cuaderno de historietas, en todas sus formas, modelos y tamaños y en todos los géneros existentes, se convirtió en el mejor vehículo de evasión para los niños de la segunda mitad de los años cuarenta. Era relativamente barato de crear, técnicamente fácil de producir y editar y por ello la edición de tebeos se multiplicó, podemos rastrear colecciones aisladas e incluso grupos de dos, tres o más colecciones de un mismo editor en Bilbao, La Coruña, Vigo, Zaragoza, Alicante, Málaga, Córdoba, Sevilla, Logroño, Murcia, etc. Pero el grueso de la edición de cuadernos de historietas se concentró durante los últimos años cuarenta en Barcelona, Valencia y Madrid.

Por este camino lo que había comenzado siendo un simple recurso para poder editar en las difíciles circunstancias legales de aquellos años se convirtió en un gran negocio que exigía inversiones comparativamente bajas. Las capacidades innovadoras y la experiencia de muchos editores quedó desviada y muchos dibujantes, que se acostumbraron a un trabajo continuado, pero generalmente tópico, se quedaron en ello en lugar de evolucionar y hacer evolucionar la historieta. Como siempre, hay excepciones, con algún editor que transformó el soporte para convertirlo en el modelo mejor para contar una historia concreta, y con dibujantes que no se conformaron y que con los años dieron el gran salto adelante desde el cuaderno de historietas.

Barcelona fue el motor que arrastró en los años cuarenta y en las décadas siguientes la producción de cuadernos de historietas. Junto a las editoriales que podemos llamar "históricas", que venían de los años de anteguerra, surgieron muchas editoriales, de las que con solo citar las más importantes podemos adquirir una vista panorámica abrumadora. Recordemos una vez más la existencia de Editorial Bruguera, Editorial Grafidea, Hispano Americana de Ediciones, Editorial Marco, Cisne y Clíper, Editorial Ameller, Iberia A.G., Editorial 3 Pingüinos, Ediciones Éxito, Publicaciones Ibero-Americanas, Paidos, Baguñá. Y añadamos, a partir de 1945-1946, Editorial Símbolo, Pellicer, Ediciones Toray, Fabregat, Editorial Bergis Mundial, Ediciones De Haro, Ediciones Fantasio, Cuqui, Ediciones Harpo, Ediciones Gráficas Ricart, Ediciones Hércules, A. Geniés, Jovi, 
Favencia, etc. Si a las anteriores añadimos las valencianas, tendremos que las ya existentes en la etapa anterior, Editorial Valenciana, Ediciones Guerri, Editorial J osé Luis Aguilar y Cia., más las que aparecen a partir de 1945-1946, Ediciones Lerso, Editorial Ibérica de Publicaciones, Ediciones Saturno, Ediciones de Dibujos Cort, Editorial Realce, Editorial Edeta, Editorial Garga, Editorial Editorial Gong, Ediciones Jovi, etc., nos dan un número total que vuelve a multiplicar la producción de cuadernos de historietas hasta límites notables. Y aún habremos de sumar las editoriales de Madrid, las ya existentes antes de 1945, Ediciones M arisal, Ediciones Proa, Editorial Tesoro, Ediciones Tritón, Editorial Atlántida, más las que comienzan a editar a partir de 1945-1946, Ediciones Rialto, Editorial Losada, Ediciones Josán, Editorial Augusta, Instituto Editorial Reus, Editorial Fantasía, Ediciones Recreativas, etc.

Tan elevado número de editoriales obliga a preguntarse por los beneficios objetivos que ello reportó a la historieta española. Pongamos en la cuenta del haber: muchos particulares metidos a editores, sin vocación de tales, ganaron sus buenos dineros. Muchos dibujantes españoles, que quizá habrían malvivido, lograron vivir unos escalones por encima de la miseria gracias a la abundancia de trabajo mal pagado que pudieron conseguir. Muchos lectores, cuya economía era mínima, pudieron tener acceso a la lectura a través de estos tebeos. Muchos dibujantes sacaron de su etapa como autores de cuadernos de historietas un interesante repertorio de conocimientos prácticos y trucos profesionales, que después trasladaron a historietas de más importancia.

Y ahora pongamos en la cuenta del debe: los cuadernos de historietas, por ser una producción barata y con muy escaso riesgo, no colaboraron a dar solidez al tejido industrial de la edición de tebeos; al contrario, lo debilitaron por su intrínseca inconsistencia editorial. Los lectores, al darse a la lectura de los cuadernos de historietas, perdieron la perspectiva sobre lo que era la historieta de calidad. Los cuadernos de historietas profundizaron la distinción de género, en la que las lectoras quedaron atrapadas debido a los mensajes y la ideología más idealista. Los cuadernos de historietas potenciaron la pasividad del grupo social en manos de héroes sustitutivos. Los muchos dibujantes que vivieron de dibujar cuadernos de historietas a la larga quedaron en simples trabajadores de la viñeta, sin mayores perspectivas de futuro y sin mayores ambiciones de crear una obra propia.
En resumen, la industria del cuaderno de historietas acabó convirtiéndose en una fábrica de papel impreso que arrojó miles de páginas absolutamente innecesarias al mercado de las lecturas recreativas, tanto que, pese a la importancia de algunas obras, que destacan como geniales entre la gigantesca masa de papel, el balance final es que la edición masiva durante dos décadas de los cuadernos de historietas perjudicó más que benefició al medio17.

\section{Editorial BRUGUera, 1946-1951}

Al promediar los años cuarenta Editorial Bruguera logró superar la crisis generada por la guerra. Los hermanos Bruguera habían reflotado económicamente la empresa siguiendo una política de estricta austeridad, acompañada por un continuo ensayar publicaciones, combinando los viejos materiales de archivo con las novedades. Pantaleón Bruguera demostró ser un gestor eficaz, a la altura de su padre, y quizá aún más pragmático. Durante varios años tuvo que asumir la representación oficial de la empresa para proteger tanto a esta como a su hermano. Por su parte, Francisco Bruguera asumió las tareas creativas y lo intentó todo en la búsqueda de los soportes editoriales que mejor pudiesen conectar con el nuevo público.

El primer gran éxito comercial se produjo con el lanzamiento de la colección Cromos Cultura. Es fama que el renacer de Bruguera vino impulsado por el extraordinario éxito que alcanzaron las muchas series de estos cromos culturales: Los Reyes de España, Zoología Mamíferos, Banderas del Mundo, Historia de la locomoción terrestre, etc. Sea cierto o exageración empresarial, a partir de los primeros años cuarenta y durante toda su historia, Bruguera dedicó especial atención a la edición de cromos: "Cromos Cultura Deportes", "Ases del Fútbol", "Campeones, Las grandes figuras del futbol español", "Álbum Foto Deporte", "Cromos Cinefoto", "Caperucita Roja" realizado por Sabatés, "Los siete enanitos" y el conejito "Thumper" de Walt Disney, "Los tres cerditos" y "Caperucita Roja contra el Lobo feroz", etc.

En los primeros años de posguerra el negocio se concentró en las colecciones de novela popular y en las de cromos, 
con un constante insistir en el lanzamiento de tebeos. Primero como prueba y después ya como negocio seguro, lanzó continuas colecciones de cuadernos de historietas: Aventuras y Viajes de varios autores, Aventuras del Capitán Microbio de Sabatés, El Fantasma de Luis Poch, colección Gente Menuda de varios autores, colección Cine Aventura de varios autores, etc. El gran logro de Bruguera fue conseguir, 1944-1945, los derechos sobre los cómics de los Estudios Disney. Ello permitió a la editorial lanzar cinco o más colecciones de cuadernos de historietas, subdivididos en varias series, unas protagonizados por Mickey Mouse, otras por el Pato Donald, con el resto de personajes Disney, unas en formato gigante como los antiguos tebeos de los años treinta, otras en formato muy pequeño. Y ello en momentos en los que Hispano Americana de Ediciones era la única editorial que publicaba de forma regular cómics americanos. Este lanzamiento, que Bruguera hizo a lo grande, desbordando todos los puntos de venta, en momentos en que los cortometrajes de Disney se daban como complemento de los programas de cine en toda España, contribuyó a consolidar la marcha de la editorial.

En aquellos momentos se incorporó a Editorial Bruguera un antiguo periodista, represaliado tras la guerra civil, Rafael González, como colaborador para todo, especialmente en los trabajos de redacción, además de escribir novelas, traducir libros y preparar guiones de historietas ${ }^{18}$. A partir de entonces, González trabajó mano a mano con Francisco Bruguera en la creación de nuevos títulos de tebeos. Durante el verano y el otoño de 1946 prepararon la maqueta y los contenidos de un nuevo Pulgarcito y a finales del año apareció el primer número. Se trataba de la versión definitiva de este tebeo, aunque posiblemente ni Bruguera ni González lo sabían. Pulgarcito se editaba bajo la categoría legal de folleto, prevista por la Ley de Prensa. Tenía formato vertical y un tamaño de $24 \times 17 \mathrm{~cm}$, con 16 páginas interiores en mal papel, impresas en negro, más cuatro páginas de cubiertas en papel alisado, con la cubierta y la contracubierta a todo color. Su precio inicial fue de 1 peseta, aunque pronto subió a 1,20. La periodicidad inicial era quincenal19. Del total de 20 páginas, 15 eran historietas, dos de ellas de aventuras. Los dibujantes tenían que realizar historietas con seis calles, con un total de 17 a 24 viñetas diminutas, por página. La sensación de producto compacto venía dada por las diminutas viñetas y aumentaba por el peso de los textos de los bocadillos, en general muy extensos.

Pulgarcito estaba dibujado por Guillermo Cifré, Ángel Nadal, José Escobar, Jorge (Miguel Bernet), José Peñarroya, Manuel Vázquez, Ramón Sabatés, Iranzo, a los que algo más tarde su uniría Conti. Y ocasionalmente Manuel Urda, Gabi (Gabriel Arnao), Martz Schmidt, Ayné y García Lorente. $Y$ en las historietas dramáticas Eugenio Giner para el Inspector Dan e inicialmente Ripoll y después Ángel Pardo para la otra historieta de aventuras. Colaboraban además, realizando las curiosidades o chistes Pedro Alférez, Óscar Daniel, Jiménez Arnalot, Rizo, Jaime Juez, Blanco, Jorge Macabich, etc. Sus personajes más importantes en los primeros tiempos de Pulgarcito fueron Don Furcio Buscabollos y El reporter Tribulete, de Cifré; Carpanta y Zipi y Zape, de Escobar; Leovigildo Viruta y Doña Urraca, de Jorge; Calixto, Don Pío y Gordito Relleno, de Peñarroya; la Familia Pepe, de Iranzo; Casildo Calasparra, de Ángel Nadal; Heliodo Hipotenuso de Manuel Vázquez y el inspector Dan, de Eugenio Giner, a los que se irían añadiendo las hermanas Gilda, Cucufato Pí, el loco Cario$\mathrm{co}$, etc.

Tras el lanzamiento de Pulgarcito, Bruguera puso en manos de González la sección -hoy diríamos la división- de revistas infantiles, con el cargo de supervisor o redactor jefe. Sus ganas de trabajar y su inventiva hicieron que Rafael González se dedicase con total entrega a buscar nuevos modelos de tebeos que formaron familia con Pulgarcito. Así aparecieron sucesivamente El Campeón, 1948; Super Pulgarcito, 1949; Magos del Lápiz, 1949; Magos de la Risa, 1950, y El DDT, 1951. Además de renovar los cuadernos de historietas con el lanzamiento de Brick Bradford, El caballero de las tres cruces, El hombre de la estrella, todos en 1947, y Aguila Negra, Juan el intrépido y El rey de la Jungla en 1948.

En definitiva, el origen de todo estaba en Pulgarcito, un tebeo muy diferente. Los dibujantes eran mejores, las historietas más divertidas, con una carga crítica que aportaba Rafael González, los personajes tenían personalidad y el conjunto estaba bien equilibrado. Comparado con los tebeos aparecidos hasta entonces, Pulgarcito resultaba innovador, brillante y un punto explosivo debido a sus contenidos, en los que, "sotto voce", se ajustaban las cuentas con el sistema. 


\section{LoS tebeOS DESPuÉs de 'Pulgarcito'}

La creación del Pulgarcito definitivo marcó un momento importante en el desarrollo del tebeo español. La obra de Francisco Bruguera y Rafael González demostraba que era posible hacer un tebeo diferente, más completo, con historietas bien dibujadas, con personajes sólidos, que al ser fijos retenían el interés de los lectores de un número al otro, en suma: una auténtica revista de historietas, fuese cual fuese su categoría legal. Hasta los años cuarenta el tebeo de contenidos variados había quedado fijado en el modelo de TBO. Pero, con el paso de los años, el tebeo creado por Arturo Suárez y mejorado por Buigas había quedado desfasado. Pulgarcito demostraba que se podía ir más lejos. En 1946, TBO se mantenía por tradición y también porque su raigambre popular había hecho que en Cataluña sustituyese de alguna forma a En Patufet, que tras la guerra había sido depurado por su pasado catalanista.

Durante esa década, Buigas probó diversos productos, solo 0 en sociedad con otros editores. M ovido posiblemente por el desafío que significaba la aparición del nuevo Pulgarcito, lanzó en 1947 dos nuevas publicaciones. Una de ellas fue la colección de números extraordinarios titulada genéricamente Cuaderno Extraordinario de Ediciones TBO, monográficos dedicados a antologizar historietas publicadas anteriormente de Urda, Moreno, Opisso, Forton, CuviIlier, Perré, y Benejam. En 1947 comenzó a publicar la colección $S$, un tebeo en formato vertical y con historietas de aventuras y humor, que al publicarse con la categoría de folleto obligó a añadir la mención Episodios y aventuras de $S$ - Narraciones extraordinarias de S. El personaje que daba título al tebeo era $\mathrm{S}$, el "superhombre universal inventor de la pistola atómica", según guión de Canellas Casals, que repetía sin cesar sus elucubraciones seudocientíficas y filosóficas.

Contemplado desde la perspectiva actual, el interés de este tebeo radica en que fue idea del dibujante Serra Massana, que formó sociedad con Joaquín Buigas para editarlo. Fuera de ello, sus contenidos, dibujados por Athos Cozzi, Tínez, Mestre, Castellote, J osé Aroca, Urda, García Lorente, BatIlori Jofré, y el mismo Serra Massana, resultan aburridos. Por ello, su vida fue corta. Buigas cerró el tebeo cuando le convino y Serra Massana quedó frustrado en su propósito de convertirse en partícipe de los beneficios que debería haber generado su trabajo e inversión. En el mercado de los últimos años cuarenta ya no eran factibles los tebeos que nacían de planteamientos más propios de los años veinte. El desconcierto con que se habían vivido los primeros años de la posguerra se estaba disipando y, prueba tras prueba, los editores comenzaban a encontrar nuevos caminos para convivir con el régimen y para llegar hasta los nuevos lectores que, pese a la pobreza de la sociedad española, aumentaban lenta pero constantemente.

La aparición de Pulgarcito supuso una sacudida, sobre todo entre los editores. Inicialmente, su importancia se reflejó en cómo algunos se afanaron en imitar el nuevo modelo editorial. Pero pocos editores tenían la suficiente solidez empresarial, fuera de Toray y Plaza, para competir con Pulgarcito. Y no bastaba con copiar el esquema editorial. En realidad nadie lo logró y, si es cierto que algunos tebeos que aparecieron en los últimos años cuarenta fueron igualmente importantes, también fueron muy diferentes.

Los lanzamientos de nuevos títulos entre 1947 y 1951 demuestra que las novedades más numerosas fueron nuevas colecciones de cuadernos de historietas más algunos, pocos, tebeos-revista: Azucena, 1947; El Coyote, 1951; El Capitán Marvel, 1947; El Jinete Fantasma, 1947; Dumbo, 1947; Rip Kirby, 1947; Dumbo, 1947; Hazañas Bélicas, 1948; Nicolás, 1948; Spirit, 1948; Episodios de guerra, 1948; El pequeño sheriff, 1948; Aguila Negra, 1948; El Campeón, 1948; Suchai, 1948; KKO, 1948; Super Pulgarcito, 1949; Florita, 1949; Trampolín, 1949; Historietas, 1949; Rayo Kit, 1950; Purk, "El hombre de piedra", 1950; Humor de bolsillo, 1950; Chicos, 1950; Topolino, 1950; Magos de la risa, 1950; El libertador, 1950; Pacho Dinamita, 1951; El DDT, 1951; Chispita, 1951; Detector, 1951; Inspector Dan; 1951; S.O.S., 1951; Aventuras del FBI, 1951; Lupita, 1951; El Cachorro, 1951; etc.

Estos tebeos fueron verdaderamente importantes, al margen de su comercialidad y de su permanencia en el mercado, debido al fuerte impacto que causaron en los lectores títulos como Azucena, El Jinete Fantasma, Purk "El Hombre de Piedra", Inspector Dan, El Cachorro, etc. También porque algunos de ellos significaron la entrada de nuevos cómics estadounidenses e italianos que aportaban conceptos nuevos para el desarrollo de la historieta española, como por ejemplo Rip Kirby, Spirit, El pequeño sheriff, Suchai, etc. 0 porque fueron modelos de revista-tebeo con lo que se ensanchaba el repertorio editorial, El Coyote, Nicolás, 
Florita, Super Pulgarcito, S.O.S., etc. 0 porque significaron la madurez de un dibujante que se confirmaba en una colección concreta, como por ejemplo Hazañas Bélicas, Aguila Negra, Rayo Kit, Inspector Dan, etc. 0 porque supusieron la puesta de largo de editoriales que a partir de entonces contarían de forma decisiva en el panorama de la historieta, como Toray, Maga y Plaza.

Es decir, el mercado no cambió de repente. Sin embargo, basta recordar que en 1947 Germán Plaza lanzó bajo el pie editorial Clíper su revista El Coyote, a las que siguieron Nicolás y Florita. Que Ediciones Toray dio su paso más sólido, con el lanzamiento de Hazañas Bélicas de Boixcar, para convertirse a partir de 1948 en una de las editoriales de referencia. Y que la aparición en 1951 de Editorial Maga, propiedad de Manuel Gago y familia, rompió el monopolio de Editorial Valenciana, de la que a partir de entonces sería directa competidora.

\section{Las reVistas de historietas de Germán Plaza}

Falto de una tradición editorial similar a la de los editores que venían de los años veinte, Germán Plaza no se encontraba hipotecado sentimental y comercialmente por una obra pasada, por lo que tenía mayor libertad de planteamientos para entrar en el negocio de los tebeos. Su actividad de anteguerra había sido mínima, pasó de vendedor de libros a editor prácticamente de un día para el otro e hizo dinero con pequeñas ediciones lejanas al mundo de la historieta. Por ello, cuando acabó la guerra civil y ante los problemas legales de los permisos, eligió editar colecciones de cuentos infantiles de bajo precio, colecciones de cromos, colecciones de cuadernos de dibujos coloreables y sobre todo novelas tipo "pulp", en la línea abierta por Editorial M olino. En estos primeros años de posguerra publicó con dos pies editoriales diferentes pero complementarios, Clíper y Cisne, comercializados a través de una tercera empresa, Comercial Gerpla.

En el campo de la novela popular, Plaza editó con el pie de Clíper varias colecciones, colección Novelas del Norte, colección Fred Custer, colección Mac Larry, siendo la más famosa la colección Novelas del Oeste, por haberse derivado de ella la colección El Coyote. Situado firmemente como editor popular, Germán Plaza hizo una prueba en la edición de tebeos en 1942, siempre bajo la condición de folletos, razón por la que, además de publicar algunas colecciones genéricas, no le importó lanzar números sueltos sin continuidad, repitiendo los lanzamientos con diversos títulos. Bajo el pie editorial Clíper publicó la colección Huracán, cuadernos de aventuras de formato vertical, colección el intrépido Arizona en películas del Oeste, en formato apaisado con algunos números dibujados por Jesús Blasco, Almanaque Aviación 1943 y Almanaque Deporte 1943. Y con el pie editorial Cisne publicó en 1942: colección Aventuras Célebres, cuadernos de formato apaisado con adaptaciones de Verne, Stevenson, Dickens, etc., realizadas por Tomás Porto, Longoria, Jesús Blasco, José María Torrent, etc., colección Cuadernos Selectos formada por cuadernos de historietas de formato apaisado que adaptaban relatos de Andersen, Perrault, cuya obra quedaba aquí convertida en cuadernos sentimentales dirigidos particularmente a las niñas. Además, con este pie, se editaron colección Películas Famosas y las Morrocotudas aventuras de Tontaina y Filetito, en formato vertical.

Germán Plaza no se precipitó y, tras la prueba realizada con estos tebeos, fue consciente de que la presencia de Bruguera, Hispano Americana de Ediciones, Grafidea, Valenciana y otras editoriales asentadas en el mercado, requería planteamientos innovadores y una buena financiación. Aún hizo alguna prueba aislada en 1944-1945, con tebeos sueltos, pero en general permaneció a la expectativa. Hasta que en 1947, cuando había cambiado la situación y Bruguera había demostrado que era posible un tipo de tebeo menos simplistas que los cuadernos de historietas y era más fácil conseguir las autorizaciones, decidió entrar de nuevo en el mercado de la historieta. La estrategia de Plaza consistió en aprovechar su implantación en el campo de la novela popular para llegar hasta el tebeo. Su baza más sólida era la colección de El Coyote, escrita por José Mallorquí, que en poco tiempo se convirtió en el mayor bestseller de la novela popular española.

Fue así como Plaza lanzó en 1947 el tebeo El Coyote, en el formato de la revista de contenidos variados, aunque la autorización oficial fuese como folleto. Varios protagonistas de sus historietas provenían de novelas editadas por Plaza, como Máscara Negra, El Encapuchado, Billy el Niño, Mac Larry y el propio Coyote, con lo que se generaba una sinergia que favorecía igualmente al tebeo y a las novelas. El resto de páginas lo ocupaban personajes de nueva creación, 
tanto de aventuras como de humor, y los principales dibujantes eran Francisco Batet, que llevaba a la historieta los guiones de El Coyote, teóricamente escritos por Mallorquí, J esús Blasco y sus hermanos Pili, Alejandro y Adriano, Vicente Roso, que creó aquí un singular personaje femenino, Florita, una mujer de 18 a 20 años con un interesante "sex apeal", Francisco Darnís, que llegaba a la madurez y era capaz de dibujarlo todo, Manuel Urda, García Lorente, Alfonso Figueras, etc.

El éxito de El Coyote demostró la capacidad de Germán Plaza como empresario, su habilidad para moverse en un mercado que comenzaba a saturarse y su acierto al rodearse de colaboradores eficaces. Animado por el éxito, comenzó a publicar en 1948 el tebeo Nicolás, formato vertical, básicamente de historietas de humor, en línea con la fórmula que Pulgarcito había potenciado. El siguiente gran lanzamiento de Plaza fue el tebeo Florita en 1949, dirigido al público infantil femenino. La protagonista era la misma Florita que Vicente Roso había creado en $E I$ Coyote dos años antes pero, ahora y posiblemente por imposición de la censura, el personaje pasó de ser una mujer joven, con formas de mujer, ropa de mujer y personalidad adulta, a niña de edad indefinida - ¿13, 14 años?que, como tal, vivía aventuras más o menos infantiles. Florita se convirtió en la revista de historietas femeninas mejor en aquellos años, un modelo de publicación que le comió el terreno a Mis Chicas, que por comparación resultaba muy infantil. También elevó el nivel en que se movían los tebeos de hadas, tipo Azucena, y demostró que había una realidad que iba más allá de los edulcorados cuadernos de historietas para niñas.

Sobre la base de estos tres tebeos, publicados como Clíper, la empresa logró una sólida implantación que reforzó publicando de nuevo colecciones de cuadernos de historietas: Billy el Niño, 1948; colección Cuentos de Hadas, 1948; Hazañas de Mac Larry el temerario, 1949; El Encapuchado, 1950, y los tebeos de contenido variado Lupita 1950, que se dirigía a las niñas como prolongación del éxito de Florita, y en el mismo año Topolino. Entre los principales logros de Germán Plaza está su comprensión de la industria editorial del tebeo, su alejamiento de la empresa familia, sin sentido ya a finales de los cuarenta, para sacarla de su crónica situación de subdesarrollo y llevarla más allá del barato y esquemático cuaderno de historietas.

\section{LAS HISTORIETAS DE MADRID, 1946-1951}

En años anteriores Madrid se había constituido en feudo editorial de las publicaciones de la Delegación de Prensa y Propaganda de FET y de las J ONS: Flechas y Pelayos, Maravillas, Chicos, Mis Chicas y Chiquitito. Y por añadidura de los suplementos de historietas del Grupo de la Prensa del Movimiento, más los pocos tebeos que los clientes políticos del franquismo habían conseguido que les autorizasen como revistas periódicas: Pepe y Mari y Leyendas Infantiles, hasta donde llega nuestro conocimiento actual. Sin olvidar la acción de la Iglesia en la formación de la infancia, que en los tebeos se concretó en la revista iZás!. En el margen de mercado que quedaba lograron asomar algunos pequeños editores comerciales, Marisal, Proa, Tesoro, Tritón, Atlántida, que concentraron sus esfuerzos en la publicación de cuadernos de historietas en competencia con Barcelona y Valencia. Por este camino seguirían, mediados los años cuarenta, las editoriales Rialto, Losada, Ediciones Ángel Nieto, Rialto y el Instituto Editorial Reus, además de Editorial Fantasía que después se transformaría en Ediciones Recreativas. De todas ellas, la más importante fue Ediciones Rialto, que inició su actividad en 1942 publicando novelas, novelizaciones de películas, novelas policíacas, etc. Ediciones que mantuvo hasta 1946, alternándolas a partir de 1944 con la edición de cuadernos de historietas y convirtiéndose así en eje sobre el que podemos promediar la década.

Rialto publicó varias colecciones de cuadernos de historietas en diferentes formatos, utilizando siempre al numeroso grupo de dibujantes residentes en Madrid. Las colecciones fueron: Diamante Negro, que se inició en 1944 en formato grande apaisado, con 16 páginas en negro más cuatro de cubiertas, al precio de 1,75 pesetas. La colección Diamante Amarillo, también de 1944 en formato pequeño apaisado, protagonizada por el joven actor del cine español Ginés Gallego, de sobrenombre artístico "Satanás", al precio de 1 peseta. La colección Jauja Chuda, Taquito y Churrete, 1944, en formato pequeño apaisado, protagonizada por un niño, una niña y su perro, que se habían popularizado en las emisiones infantiles de Radio Madrid y que el dibujante Gros adaptó. En la que consideramos que fue su etapa de decadencia editorial, Rialto publicó otras colecciones menores, como la colección Películas Policíacas y la colección Películas de Dibujos. Más la colección Serie Azul. 
Del total de tebeos de Ediciones Rialto, más de 200 números, destacan dos colecciones más por las circunstancias sociológicas que concurren en ellas que por la calidad de sus historietas. Es el caso de la colección Diamante AmariIlo, protagonizada por el actor Ginés Gallego. La publicidad afirmaba en la contracubierta de los primeros números: "El más original y famoso protagonista infantil relatará semanalmente sus aventuras, interpretadas por el lápiz del genial dibujante López Rubio" y añadían "Un alarde de presentación ¡Emoción! ¡Intriga! ¡Humor!”. Adolfo López Rubio, que había trabajado en la escenografía de algunas películas, conoció a Ginés Gallego -quien intervino en películas como El destino se disculpa de Rafael Gil y Domingo de Carnaval de Edgar Neville-y le convirtió en personaje de sus tebeos. La colección se inició con el número "Presentación de Satanás" y se mantuvo hasta al menos su no 22 con el nombre de Satanás en el título. El personaje mereció la atención de la censura debido al apodo del protagonista, por lo que al menos en los tebeos debió pasar a llamarse Ginesito a partir del no 23, desapareciendo para siempre la mención a Satanás ${ }^{20}$. La colección se prolongó hasta su $\mathrm{n}-58$ y se hicieron reediciones de algunos números. El dibujo, que Rialto atribuía al genial López Rubio, estuvo realizado por Ibarra, Jano, Laffond, Cardona, Perellón, Gordillo, Blanco y otros historietistas del grupo madrileño, a los que coordinaba Adolfo López Rubio, que generalmente ilustraba las cubiertas.

La colección Diamante Negro, la más importante de Ediciones Rialto, estaba formada por cuadernos grandes de historietas con una historieta completa y autoconclusiva en cada número. Comenzó con el cuaderno "La vuelta de Fu-Manchú", en cuya contracubierta la publicidad afirmaba "iAtención! Fu-Manchú, Dick Turpin, El Hombre invisible, vuelven presentados por Ediciones Rialto [...] Personajes conocidos del mundo infantil irán saliendo del tintero mágico del dibujante A. López Rubio, quien regalará un estupendo dibujo original a todo color del personaje que deseéis, presentando los diez primeros cupones de esta colección". Afirmación que se desmentía en la primera viñeta de la primera página donde ponía: "Original de A. López Rubio con ilustraciones del mismo en colaboración con M. Huete".

Interesa destacar cómo Adolfo López Rubio estaba adelantando lo que años más tarde sería la agencia productora de cómics. López Rubio era un dibujante de poca monta, escenógrafo en algún momento, que llegó a estar muy bien relacionado con las editoriales Rialto, Marisal y Tesoro, a las que ofreció proveerlas de historietas originales, garantizando la entrega de cuadernos de historietas completos dibujados, rotulados y con su cubierta en color por un precio fijo alzado. Es posible que en algún momento López Rubio pensara en realizar él mismo este trabajo pero pronto conoció a una serie de jóvenes dibujantes, chicos de 14 a 17 o 18 años, que solían pulular por Flechas y Pelayos y Chicos a la busca de pequeños trabajos, les habló de sus contactos con nuevos editores madrileños y pronto tuvo a un numeroso y variopinto grupo de dibujantes haciendo cola en su estudio.

Lo siguiente fue fácil, López Rubio conseguía los encargos de Marisal, Tesoro y Rialto, formaba equipos y ponía a trabajar a los jovencísimos dibujantes junto con aprendices de guionista, a los que echaba una mano de vez en cuando, aparte de reservarse el retocar los dibujos, corregir errores y, casi siempre, la realización de los originales en color de las cubiertas. Fue así como en dos o tres años pudo suministrar más de 300 tebeos completos. En lo económico era fácil, López Rubio cobraba por cada cuaderno entregado, se quedaba la parte principal y a los dibujantes les pagaba una pequeña cantidad más la satisfacción de ver su nombre impreso en los cuadernos publicados. Los dibujantes que más se prodigaron en los tebeos de Rialto fueron José Laffond, Víctor de la Fuente, Ibarra Montilla, Manuel Cuesta y Blanco, si bien el total de dibujantes que formaban los equipos de López Rubio llegó al menos hasta 25. Figuraron como guionistas Adolfo de Lara, L. Hernández, Bum, A. López Rubio, J. J. Gómez Soler, "Pipo"...

J unto a Rialto hay que destacar la Editorial Fantasía que en 1947 comenzó a publicar la colección Dumbo, que se nutría de los cómics de los Estudios Walt Disney, que tras haber estado en poder de Editorial Bruguera, pasaron a esta empresa que los editó durante los años 1947 y 1948. Fantasía fue comprada o simplemente cambió de nombre en 1948 y a partir de entonces y durante varias décadas continuó la colección Dumbo Ediciones Recreativas, participada por la familia Luca de Tena, propietarios de Prensa Española.

Hay que señalar aquí, puesto que Madrid era el centro del universo franquista, la escasísima presencia de la historieta para adultos. Cosa fácilmente explicable por la condición 
infantil que se había atribuido al medio por parte de los pedagogos, eclesiásticos y laicos, y por las élites políticas del régimen. Todos ellos, autoridades, entidades y personas asimilaban niños con historieta, que así acabó efectivamente infantilizada. Por otro lado, era realmente difícil que un dibujante de los años cuarenta pretendiese realizar una historieta expresamente dirigida a los adultos y más difícil aún que el director de un periódico o revista la publicase. Si un diario publicaba historietas, lo hacía en un suplemento dedicado a las mismas que se dirigía a los hijos de los compradores del periódico.

No obstante, sí hubo historieta adulta, más como rareza que como norma. Algún diario publicó tiras de prensa, habitualmente mudas y procedentes de agencias de prensa extranjeras. También algún estudio y algún dibujante español lo intentaron, pero fue de manera excepcional. Así, nos queda como ejemplo la tira "Don Celes Carovius", más conocida simplemente como "Don Celes", dibujada por Luis del Olmo Alonso, que se comenzó a publicar en 1945 en el diario La Gaceta del Norte. Hay más tiras aisladas, pero rastrearlas ahora supondría pura arqueología.

El soporte idóneo para la historieta de humor para adultos debería haber sido las revistas de humor para adultos, pero La Codorniz, que casi monopolizó el ejercicio del humor gráfico, raramente publicó historietas y cuando lo hizo solían ser extranjeras. Fue en la revista de humor Cu Cú, dirigida a lectores adultos, editada y dirigida por Cristino Soravilla en Madrid y cuyo primer número apareció en abril de 1944, donde sí se publicaron historietas absolutamente intrascendentes y de un humor muy aguado. Pero eso es lo que daba el franquismo de sí.

\section{Los 'Otros' tebeos de MadRID}

Los tebeos proselitistas del final de la década se editaron en Madrid, como ha ocurrido casi siempre. Nos referimos por igual a los de carácter político, como Flechas y Pelayos y Maravillas, 0 a los doctrinales editados por la Iglesia católica, como ¡Zás!, Trampolín y Valentín. Los tebeos del Movimiento se habían convertido en publicaciones menores cuya vida transcurría lánguidamente y sin lograr interesar al público lo suficiente como para que los comprase. Ello se debía a la dinámica por la que los editores comerciales se habían apoderado del mercado, que generaba una competencia que expulsaba a los tebeos menos atractivos, sobre todo si además representaban al régimen. Pero se debía también al escaso interés que Fray Justo Pérez de Urbel ponía en los tebeos que editaba y dirigía. De ahí que, pese a la filiación falangista, sus contenidos, que habían dejado de ser rabiosamente militantes, fuesen tan aburridos. Las secciones de texto repetían los viejos conceptos ideológicos pero sin convicción, y las historietas, pese a la calidad de algunos dibujantes, estaban construidas sobre guiones sin interés, solo para que la revista pudiese mantener su salida periódica.

Convertido en un personaje del régimen, Fray Justo Pérez de Urbel acumuló con el tiempo los cargos de asesor religioso y capellán de la Sección Femenina de FET y de las JONS, miembro del Consejo Nacional del Movimiento, procurador en Cortes, prior de la Iglesia de Montserrat de Madrid, consejero de honor del CSIC, director del Colegio Mayor Marqués de la Ensenada de Madrid y catedrático de Historia de la Edad Media de la Universidad de Madrid a partir de 1948. Además escribía libros de historia y religiosos, para lo que contaba con varios "negros". Cabe pensar que no dispondría de mucho tiempo para las revistas infantiles. En estos años, 1945-1948, realizaban Flechas y Pelayos M aría Claret, Teodoro Delgado, Gila, Cristino Soravilla, Vicente Roso, Ardel, Carboneras, Gabi, Moro, Ángel Pardo, Estebita, Mayo, Avelino Aróztegui, J osé Laffond, F. Barrio, Titos, Pérez Vigo, Carbonell, Celedonio Perellón, Luis Vigil, T. Dominique, Raskolnicoff (Edmundo Marculeta), Santi, Víctor de la Fuente, Palacios (Antonio Hernández Palacios), Escudero, Manuel Zataraín, etc. Y escribían Gloria Fuertes, Duquesa de Medina Sidonia, Justo Pérez de Urbel, García Lago, García Verdugo, Julio M ontañés, V. Franco, Francisco Fernández-Vegue, etc.

Vale preguntarse si estos dibujantes tenían algo que ver con la simbología del Frente de Juventudes, águilas imperiales, yugos y flechas, que la revista ostentaba en cubierta. Puede ser que alguno de ellos se sintiese como una especie de dibujante-funcionario al servicio del sistema, pero, si se dieron dichos casos, fueron la excepción. La mayor parte eran profesionales que tenían que ganarse la vida. $Y$ en los años cuarenta ganarse la vida sin caer en contradicciones era difícil.

Fray Justo Pérez de Urbel era consciente de la decadencia de Flechas y Pelayos y Maravillas y, siendo un hombre 
pragmático, intentó poner estos tebeos al amparo de otros órganos de prensa. En 1948 transformó la revista Flechas y Pelayos en un suplemento de la revista Juventud, órgano de las Falanges J uveniles de Franco. Fue así como en enero de 1949 apareció el tebeo Clarín, como "suplemento de J uventud para la legión de flechas". La nueva publicación retrocedió a los planteamientos de la guerra civil y sus páginas se llenaron de referencias a la misma, con historietas de una virulencia política panfletaria ${ }^{21}$. En paralelo, Pérez de Urbel transformó la revista Maravillas en Suplemento infantil de Arriba, el diario más emblemático del régimen.

Por parte de la Iglesia Católica se dio siempre una sorda rivalidad con FET y de las J ONS motivada por el conflicto de intereses sobre la educación de la infancia y la juventud. Ello y los planteamientos que desde principios de siglo había tenido la Iglesia en favor de una prensa propia habían motivado las publicaciones confesionales de todo tipo y modelo dirigidas a los niños que habían editado diversas órdenes religiosas así como Acción Católica. En el recuerdo están títulos como Titirimundi y Jeromín o el hecho de que Pelayos fuese obra de dos sacerdotes catalanes. En los años cuarenta se planteó de nuevo la utilidad de publicar, además de las tópicas hojas parroquiales, revistas infantiles desde las que catequizar a los niños. Fue así como se editaron Atalaya, 1941; iZás!, 1945; Volad, 1948; Trampolín, 1949 y 1950, Tin Tan, 1950; Jóvenes, 1951, y una larga lista de títulos que llega prácticamente hasta el siglo XXI.

De estos títulos, los más importantes fueron los promovidos por Acción Católica. En 1945, el Consejo Superior de los Jóvenes de Acción Católica comenzó a publicar la revistatebeo iZás!. Tenía por misión el apostolado entre los niños y Io intentaba con textos edificantes e historietas. El resultado fue poco atractivo y la revista pasó sin lograr lo que pretendía y dejando como máxima realización historietas dibujadas por Ángel Pardo, Fernando Fernández, Vicente Roso, Gabi, Víctor de la Fuente, Zaragüeta, Madorell, etc. Varios años después, Acción Católica se planteó editar una nueva revista para los niños y jóvenes, que tituló Trampolín, cuyo primer número apareció en febrero de 1949, editado por El Consejo Superior de los Jóvenes de Acción Católica, con el subtítulo Semanario popular para los muchachos editado por la Sección de los Aspirantes de Acción Católica.

Trampolín se presentó con el aspecto de un periódico y en papel de periódico, con ocho páginas de gran tamaño y al precio de 1 peseta. Su contenido lo formaban secciones de deportes, chistes, curiosidades científicas, crucigrama, ajedrez, cine y una sección religiosa dirigida a los aspirantes de Acción Católica. La revista se completaba con chistes gráficos e historietas de Manuel Huete, Escudero, Gabi, José Laffond, Luis Vigil, Armando, Rafael Gordillo, Fernando, Francisco de la Fuente, Masán Algora, Eugenio, Vizcaino, Fernando Fernández, Mané y Ramón Sabatés e Iranzo. Pese a que las historietas se apretujaban entre los textos sin apenas espacio para respirar, Trampolín era espectacular y su calidad bastante buena. Pero la revista no funcionó y el último número fue el 53, que apareció en octubre de 1950. En el mismo se anunciaba la inmediata aparición de un Nuevo Trampolín, que tendría las siguientes características: en color, con 20 páginas, tamaño normalizado, precio de 1,25 pesetas, con salida el 19 de noviembre de 1950.

Efectivamente, el nuevo Trampolín, que iniciaba numeración, apareció en 1950 con periodicidad quincenal y con el mismo pie editorial, el color solo estaba en la cubierta y contracubierta. Por fin, los editores de Acción Católica se habían planteado un tebeo que podía competir con los que publicaban los editores comerciales y en el que las intenciones confesionales no eran visibles en texto alguno, salvo en una historieta de corte realista que se publicaba en cada número con guión de Eduardo Valdés. Los principales dibujantes fueron Escudero, Sabatés, Vizcaíno, Karpa, Gabi, Iranzo, que aquí desarrollaba "Perico y Frescales, los dos iguales", una de sus mejores series de humor y peor conocidas, José Laffond, Enric, Iranzo, Serafín, Armando, Gordillo, Escobedo, Martín Mena, Rubio Cordón, Jordom, Marculeta, Palop, etc.

Queda por revisar la evolución de los tebeos de Consuelo Gil Roësset. En 1945 Consuelo Gil lanzó una nueva revista mensual, esta sí revista y no tebeo, El Gran Chicos, con muchas secciones de texto y pocas historietas. También en 1945 creó una nueva empresa, Editorial Augusta, que publicó varios libros, entre ellos los de historietas en gran formato apaisado y con tapas duras: La princesa de las manos de oro, de Pili Blasco, Aventuras de Pikis en Burrilandia, de Adriano Blasco, Aventuras de Morronguito en el Río de Perlas, de Alejandro Blasco y Chispita en yo quiero la Luna, de Adriano Blasco. Los años más brillantes de la actividad editorial de Consuelo Gil y por extensión de mayor calidad de Chicos y Mis Chicas, fueron los comprendidos entre 1945 y 1948. Cuando la competencia se hizo más intensa, los negocios de Gil comenzaron a tener problemas. En 1948 intentó luchar con los editores 
más comerciales en su propio terreno y decidió publicar también cuadernos de historietas. Llegó a un acuerdo con el representante de Blasco, por el que el dibujante se asociaba con ella para publicar con el pie de Editorial Augusta una colección de cuadernos de historietas que se llamaría Episodios de Guerra. La idea era buena y a priori todo parecía garantizar el éxito. Jesús Blasco dibujó en equipo con sus hermanos Alejandro y Adriano media docena de cuadernos ambientados en la Segunda Guerra Mundial. Se pusieron a la venta los tres primeros, Dunkerque, Abatió al "samurái" y La última defensa, y el resultado fue un total fracaso, que pudo deberse en parte al alto precio de venta, 2,50 pesetas, y en parte a la inexperiencia de Consuelo Gil en el peculiar mercado de los cuadernos de historietas. La editora canceló la colección y los Blasco quedaron frustrados económicamente al fracasar el proyecto en el que eran socios.

A partir de 1949 se precipitó la decadencia comercial de los tebeos de Consuelo Gil. El mercado estaba cambiando aceleradamente, cada vez había más colecciones de cuadernos de historietas, los gustos de los lectores evolucionaban y, aunque muy despacio, se comenzaba a salir de los años de plomo del franquismo. En este cuadro Consuelo Gil realizó cambios radicales en sus tebeos. En 1950 llevó a cabo una transformación total de Chicos, redujo el formato a casi de bolsillo, eliminó las secciones de texto y aumentó el número de historietas, con el error de no ser tan selectiva en la elección de dibujantes para reducir costes, algunos de sus autores de siempre comenzaron a recibir mejores ofertas y abandonaron sus revistas. A estos errores se sumó el definitivo en 1951: llenar las páginas de Chicos con cómics norteamericanos de King Features Syndicate, Flash Gordon dibujado por Mac Raboy, Big Ben Bolt de Cullen Murphy, Brick Bradford de Clarence Gray y William Ritt, Rip Kirby de Alex Raymond, materiales que además se editaron a tamaño pequeño y mal reproducidos. El resultado fue totalmente negativo y en 1952 Chicos fue sustituido por Chicos Deportivo, una revista deportiva para niños. Era el final.

\section{LOS TEBEOS FEMENINOS DESPUÉS DE 1946 Y HACIA EL FUTURO}

La revista Mis Chicas supuso una auténtica aportación al mercado de la prensa recreativa por su calidad y por las buenas historietas que publicó. Ahora bien, la simple existencia de la revista apoyaba la distinción niño-niña y ahondaba en la separación entre sexos. De esta manera, Mis Chicas se convirtió en una pieza más en el muro que se levantó alrededor de la niña lectora, con la doble función de evitar que llegasen hasta ella las influencias del mundo masculino y que la niña escapase del gueto hacia el mundo externo y real. Por el camino abierto por Mis Chicas se precipitaron los editores populares, que no se planteaban problemas morales sino que aumentar sus cuotas de mercado. Ello generó una superabundancia de tebeos baratos, con argumentos estúpidos, habitualmente mal dibujados, que se ofrecían bajo una etiqueta sentimentaloide. De esta manera los cuadernos de historietas para niñas de los años cuarenta acabaron proponiendo un proyecto cultural escapista, basado en una imagen discriminadora de la condición femenina.

En 1947, la Sección Femenina de FET y de las JONS pretendió salir al paso de este tipo de lecturas con una revista propia, Bazar, que erróneamente proponía como alternativa la otra cara de la misma moneda: una revista basada en consignas, gimnasia, mucho deporte, ropa sencilla, más propia de las marchas de campamento, con la propuesta de una feminidad basada en la camaradería de las niñas con las niñas. Para lograr esta niña patriótica y cristiana que Bazar propugnaba, la Sección Femenina proponía campañas con las que lograr la "formación de las mujeres en el ámbito nacional, que abarca todas las manifestaciones de la actividad femenina, desde las enseñanzas del hogar, de puericultura y maternología, hasta los bailes y cantos regionales, pasando por toda una gama de preocupaciones religiosas, patrióticas y culturales". Para hacer tragar todo esto, la revista llevaba historietas de Serny, Goñi, J esús Bernal, Tauler, Picó, Tilu, etc., que volvían al viejo modelo de historieta con los textos al pie de las viñetas.

Por supuesto, tanto por sus planteamientos ideológicos como por el escaso interés de sus contenidos, Bazar quedó desbordada por los tebeos para niñas de los últimos años cuarenta, Cuentos de Hadas, 1947; Ediciones Ibero-Americanas, colección Princesita, 1947; Editorial Ameller, colección Azucena, 1948; Ediciones Toray, Cuentos Azucena, 1948; Ediciones Toray, colección Celeste, 1948; Editorial Grafidea, Aventura de Estrellita, 1948; Ediciones Toray, Cuentos de Hadas, 1948; Editorial Grafidea, colección Cuentos 
de Hadas, 1948; Ediciones Clíper, Betsy, 1949; Editorial Geniés, Cuentos de Hadas, colección Carmencita, 1949; Editorial Geniés, Cuentos de la abuelita, 1949; Ediciones Toray, colección Susy, 1949; Editorial Geniés, colección Ardillita, 1949; Ediciones Gráficas Ricart, Historietas cómicas de Merche, 1950; Editorial Marco, colección Margari, 1950; Ediciones Toray, Ardillitas, 1950; Ediciones Gráficas Ricart, colección Mari Lu, 1950; Editorial Marco, Mary-Luz Historia de un corazón, 1951, Ediciones Toray, etc. Así, hasta que Florita dio la vuelta a la situación. Los cuadernos de historietas sentimentales continuaron los pasos dados en años anteriores y se impusieron hasta constituir una prensa peculiar, que en todos los casos se basaba en la distinción de género.

Florita, 1949, rompió muchos de los planteamientos anteriores al ofrecer a las niñas nuevos modelos sociológicos y una estética acorde con la España que había surgido de la posguerra. Un país dominado por una nueva aristocracia del dinero, en el que el poder se vinculaba a las relaciones de interdependencia con el régimen y lo sentimental se encuadraba en la moral burguesa. La propuesta que destilaba este tebeo no era precisamente modélica pero sí era real. Hasta 1951 se mantuvo la política de prensa del régimen que separaba los tebeos con categoría de revistas periódicas de los tebeos que eran solo folletos. Pero primero Bruguera con Pulgarcito y después Plaza lograron que de facto se tolerase la existencia de tebeos que, pese a estar autorizados como folletos, eran auténticas revistas. Como último resultado positivo, a Florita le siguieron otros títulos que intentaban medrar a su sombra: Lupita, 1950; Ediciones Clíper, Estrellita, 1950; Editorial De Haro, Mariló, 1950, Editorial Valenciana.

El balance final de los tebeos para niñas de los años cuarenta es negativo. Evolucionaron y ofrecieron nuevas temáticas, los dibujantes intentaron seguir en sus historietas los gustos de las lectoras, a veces solo reflejándolos y en ocasiones haciendo nuevas propuestas. Pero las pautas más profundas desde las que se movía el grupo social no cambiaron y, si bien es cierto que las niñas de los años cincuenta gozarían de unas lecturas menos moralistas, por el momento las estructuras permanecieron y los componentes ideológicos de las mismas se estratificaron en la arcaica división entre sexos y en la sumisión obligada y legislada de la mujer al hombre.

\section{LOS TEBEOS TRAS LA CREACIÓN DEL MINISTERIO DE INFORMACIÓN Y TURISMO}

En julio de 1951, Franco realizó un nuevo cambio de Gobierno en el que se creó el Ministerio de Información y Turismo, siendo nombrado ministro del mismo Gabriel Arias Salgado. Esto formaba parte de la estrategia de blanqueamiento del régimen que se había iniciado en 1945 y del proceso de acercamiento a Estados Unidos, que se aceleró a partir del inicio de la guerra fría en marzo de 1946, cuando Churchill certificó la existencia del Telón de Acero, y se confirmó por el inicio de la guerra de Corea en 1950. Dos años después, la amistad hispano-norteamericana se concretaría en los Convenios de Ayuda Mutua. El nuevo Ministerio llevaría todos los temas concernientes a la prensa, sin que por ello se derogase o cambiara la Ley de Prensa de 1938, vigente hasta 1966. La Dirección General de Prensa del mismo inició una política de apertura por la que todas las publicaciones de historietas podrían reconvertirse en revistas, con título fijo, salida periódica y numeración correlativa, siempre que cumplieran la normativa oficial.

Gabriel Arias Salgado, falangista, fue nombrado al acabar la guerra vicesecretario de Educación Popular y, simultáneamente, delegado nacional de Prensa y Propaganda de FET y de las JONS. Su nombramiento como ministro de Información no cambió en nada los planteamientos del régimen respecto a la prensa, ya que la normalización administrativa fue solo eso, administrativa, medida necesaria para mejorar la imagen del régimen ante la opinión pública internacional. Fue así como en agosto de 1951 TBO recibió la autorización como revista infantil periódica, en noviembre del mismo año la consiguió Pulgarcito y en 1952 El Coyote, Nicolás y Florita. De manera que a partir de 1951 comenzaron a aparecer numerosos tebeos nuevos: Pacho Dinamita, EI DDT, La vuelta al mundo de dos muchachos, S.O.S., Humor de bolsillo, Aventuras del FBI, Valentín, El Cachorro, Los exploradores del Universo, Chispita, etc. Aparentemente lo más duro del franquismo había pasado.

Arias Salgado se había mostrado durante los años de plomo del franquismo como el máximo guardián de las esencias patrióticas. Como ministro de Información sería, incluso, más duro, ya que como Antonio Izquierdo y Juan Blanco han recordado en su libro Elegía por la generación perdida "estaba convencido de que la implacable censura 
que se aplicaba a la información en general y a las disciplinas artísticas en particular había elevado el número de españoles que iban directamente al cielo". En junio de 1952 una Orden M inisterial creaba la Junta Asesora de la Prensa
Infantil, a partir de la cual el Estado asumía una responsabilidad directa en la existencia, contenidos, y futuro de los tebeos. Arias Salgado estaba dispuesto a velar por la salud espiritual de los niños españoles.

\section{NOTAS}

1 Para ampliar la información sobre la transición de la historieta española del siglo XIX al XX, véase Antonio Martín, Historia del cómic español: 1875-1939, capítulos 1 y 2. Gustavo Gili, 1978, Barcelona. Lo mismo para el resto de este artículo hasta 1939.

2 El desarrollo de la prensa popular estuvo siempre determinado por las altas tasas de analfabetismo que España padecía aún a inicios del siglo XX. En 1910 era de un 64 por ciento. Véanse las cifras establecidas por Narciso de Gabriel, de la Universidad de La Coruña, en su artículo "Alfabetización, semialfabetización y analfabetismo en España, 1869-1990", en Revista Complutense de Educación, vol. 8, no 1 . Servicio de Publicaciones Universidad Complutense, 1977.

3 El desarrollo hacia la modernidad de la historieta española para adultos se deberá en parte a la influencia de los más modernos cómics americanos, pero también a la experimentación que los autores llevaron a cabo constantemente. Es materia de estudio averiguar cómo en unas mismas fechas de los años veinte un dibujante desarrollaba historietas modernas, con perfectas elipsis narrativas y cuya expresión verbal se vehiculaba mediante bocadillos, y al mismo tiempo dibujaba para los tebeos infantiles historietas primitivas, de reducida agilidad gráfica.

Recibido: 27 de septiembre de 2010 Aceptado: 13 de diciembre de 2010
4 Para el mejor conocimiento de las relaciones entre la historieta española y el cine en las décadas de 1920 y 1930 véase Paco Baena, Tebeos de cine. La influencia cinematográfica en el cine clásico español, 1900-1970, aún pendiente de edición. Debo a la cortesía de Paco Baena y a su amistad el que me haya permitido consultar su obra cuando aún está en pruebas.

5 Para conocer más de los tebeos publicados en Madrid hasta 1936, véase Antonio Martín, "Los tebeos de Madrid", en CLIJ Cuadernos de Literatura Infantil y Juvenil, № 174. Barcelona, septiembre de 2004.

6 Sobre la presión que ejercía la Iglesia sobre la prensa, especialmente sobre la prensa recreativa, es instructiva la cita: "Te lo figuras tú, joven cristianamente educado y discreto; pero precisamente entre tus compañeros, y hasta entre los niños de las escuelas, es donde escoge sus víctimas esa prensa inmunda. Pasando por delante de un kiosco y viéndole empapado de monigotes indecentes, cierto médico reputado y yo lamentábamos que se tolerasen estas exhibiciones de letrina en naciones cultas por el daño que causan a la juventud inocente [...]". Tomado del folleto Las Malas Lecturas. Madrid: Editorial Apostolado de la Prensa, S.A.

7 Cita reproducida de una carta personal de Magdalena Rosell Matlléu al autor. El teniente coronel Jorge Villamide, ascendido a coronel en 1939 sería el primer presidente del Tribunal Regional de Responsabilidades Políticas que incoó el expediente contra el president de la 
Generalitat de Catalunya Lluis Companys.

8 Cierta bibliografía reciente ha establecido una construcción teórica según la cual el año 2010 sería el centenario de la fundación de El Gato Negro. Esto es falso. Uno de los problemas de la investigación radica en la correcta utilización de la historia oral cuando no existe una verificación documental de la misma. Siendo El Gato Negro la editorial de anteguerra sobre la que existe más información, los datos que se manejan son en su mayor parte dispersos y contradictorios y proceden de personas relacionadas con la empresa, sin que nunca se hayan contrastado documentalmente.

9 Respecto a Juan Bruguera Teixidor, es significativo que Juan Palau, gran autoridad en la bibliografía española, señalase el bajo rango editorial que se le concedía en el panorama de la edición "[...] Bruguera, alias El Gato Negro, editor de menudencias populares [...] el libro viejo le atrajo, y abandonando sus deberes editoriales, se lanzó a la caza de piezas bibliográficas. Durante tres años solo se le vio por los encantes y puestos de libros, afanoso, con más ilusión que práctica [...] El tiempo disipó la bravura de Bruguera, y se reintegró a las tareas editoriales. Publicaba folletos y obras de aventuras por cuadernos [...]". Véase Antonio Palau. Libro Memorias de un librero catalán, 1867-1935. Barcelona: Librería Catalonia, 1935.

10 Público de masas o lo que por tal podemos considerar en los años veinte, lectores de tebeos populares, estratos bajos de la sociedad y por ello Ios más amplios; y entre estos lectores no solo niños sino también público recién alfabetizado. Estamos faltos de estadísticas que relacionen la población española, los niveles de alfabetización, los sueldos, los movimientos de población, la estratificación por clases, etc. Mientras carezcamos de estas herramientas, todo estudio sobre la historieta será cuestionable.

11 En 1930, el número de analfabetos en España había bajado a un 42 por ciento de la población total. Véanse las cifras establecidas por Narciso de Gabriel en el artículo citado más arriba.

12 Enrique Guerri, italiano, había sido empleado de Lotario Vecchi, con quien había aprendido el oficio. Representante de la Casa Editorial Vecchi en Valencia y después en Buenos Aires, a su retorno a España después de la gran guerra se estableció en Valencia como editor. Véase Lotario Vecchi, Las novelas por entregas y los tebeos. Primera crónica de Hispano Americana de Ediciones. Barcelona: Editores Asociados, en prensa.

13 Palabras textuales de José Canellas Casals recogidas por Antonio M artín en entrevista realizada en agosto de 1968.

14 Para situar los tebeos de la guerra civil remito a Antonio Martín, "Història de la premsa espanyola, 19361939. Notes per a un catàleg dels tebeos de la Guerra Civil", en Revista El contemporani, no 27. Barcelona: Editorial Afers, enero-junio de 2003.

15 Datos estadísticos del Informe sociológico sobre la situación social de Madrid, de Cáritas. Madrid: Suramérica, 1967.

16 La fecha exacta de publicación de Jaimito es ejemplo de la confusión existente para documentar los tebeos aparecidos en los primeros años cuarenta. Al redactar este trabajo hemos encontrado que diferentes fuentes dan como fecha de aparición los años 1943, 1944, 1945 y hasta 1946. El estudio comparativo nos permite creer que debió comenzar en 1944.

17 En la actualidad, 2011, aún carecemos de las herramientas necesarias para documentar con exactitud la historia de los tebeos españoles, incluso en algo tan básico como son las fechas de creación de las empresas editoriales y de publicación de cada colección. Los catálogos existentes han fijado fechas por un sistema de tanteo, sin recurrir a la documentación escrita oficial, números publicados, composición de las empresas, tiradas declaradas, etc. Nuestra mejor opción radica en un gran equipo, compuesto por más de un centenar de documentalistas, que ahora mismo trabaja en la realización de la que con tiempo podría ser la herramienta que reclamamos. Se trata del Gran Catálogo de la Historieta, http://www.tebeosfera. com/catalogos, que produce la Asociación Cultural Tebeosfera. Este catálogo se encuentra en proceso de construcción, con un largo trabajo por delante. Por el momento, el estudio del tebeo español de los años cuarenta solo será posible a través de seminarios 0 de cursos de doctorado. $Y$ el buen conocimiento de aquellos tebeos proporcionaría claves para comprender la sociedad española de la posguerra.

18 En los últimos años se ha hablado e inventado mucho sobre Rafael González antes de trabajar para Bruguera. Los datos comprobados son: Rafael González Martínez era periodista, militante socialista y tenía 29 años al acabar la guerra. Durante la República había sido colaborador en los diarios La Noche y La Vanguardia. Al acabar la guerra se exilió a 
Francia y durante unos meses vivió en Montauban, en Toulouse y otros lugares cercanos a la frontera española. Al fin, consciente de lo que podía esperarle, volvió a Barcelona. Como periodista republicano que había hecho la guerra en Cataluña fue depurado por los tribunales franquistas e inhabilitado para ejercer. Sin oficio ni dinero, González se encontró en una Barcelona ocupada militarmente y donde sus viejos conocidos de la prensa le volvían la espalda por miedo. Durante un tiempo vivió con la familia de su hermano en el barrio de Poble Sec, tal y como su sobrino Francisco González Ledesma ha dejado escrito en Historia de mis calles. Lo único que sabemos con certeza, por cartas de su puño y letra que hemos podido consultar, es que pasó hambre, que por falta de recursos tuvo que estar separado de su familia, que en ese tiempo desempeñó diversos trabajos, entre ellos el de vendedor a comisión de una empresa de carbones. Que escribió por encargo. Y que finalmente logró un trabajo en Bruguera como escritor y redactor, a la sombra de Francisco Bruguera. Tenemos constancia documental de que al menos escribió dos novelas de su personaje el Doctor Niebla, bajo el seudónimo de Douglas $L$.
Templewood, para la colección Superhombres, e igualmente que utilizó el seudónimo Caddo Cameron para escribir varias novelas del Oeste en la colección Mi Novela y en la colección Superaventura, de Bruguera.

19 La fecha exacta de aparición de este Pulgarcito en el año 1946 -durante años se había datado en 1947- ha sido establecida por Manuel Barrero y Antonio Moreno en diciembre de 2010. También la inicial periodicidad quincenal de este tebeo. Véanse los datos en Tebeosblog, http://tebeosfera.blogspot.com/2010/12/tebeosfera-un-hito-en-el-estudio- de-la.html

20 El caso de Ginés Gallego "Satanás" es un ejemplo perfecto de las formas que revistió el control de prensa. El 12 de mayo de 1944, el delegado nacional de Propaganda, David J ato, envió al delegado nacional de Prensa la siguiente nota: "Repetidas veces han aparecido en la Prensa y revistas cinematográficas trabajos periodísticos referentes al niño Ginés Gallego, alias Satanás. Estimando a todas luces improcedente este seudónimo, te ruego curses las órdenes oportunas a todas las revistas cinematográficas y Prensa española, prohibiendo el empleo de dicho seudónimo". (Documento en la caja 1139 del Archivo General de la Administración, AGA.)
Lo cual, al ejecutarse la prohibición, repercutió también sobre la colección de tebeos.

211948 fue el año del "rearme ideológico" por parte de los grupos más radicales de Falange que reivindicaban la "revolución pendiente". Actualmente, elementos residuales, herederos de aquel pensamiento escriben: "[...] Fue en la segunda etapa azul (1948-1957) cuando la Falange más juvenil y revolucionaria, personificada en organizaciones como el Frente de Juventudes, el Sindicato Español Universitario, SEU, y la Guardia de Franco, acabarían chocando y enfrentándose a un Estado cada vez más aburguesado y burocratizado, que lo único que buscaba era el reconocimiento internacional por parte de los vencedores de la II Gran Guerra [...]". Véase el blog Septentrionix Lux, www.nuevorden.net/k 25.html La publicación de Clarín como suplemento de la revista Juventud, órgano de las Falanges Juveniles de Franco, que formaban parte de este reducto revolucionario, explica sus contenidos panfletarios. Es más difícil comprender cómo Justo Pérez de Urbel, consejero nacional del Movimiento y procurador nato en Cortes, a quien interesaba permanecer a la sombra de Franco, puso su tebeo al servicio de estos grupos fraccionales. 